UNIVERSIDADE DE SÃO PAULO

ESCOLA DE ENFERMAGEM

NARIANI SOUZA GALVÃO

PREVALÊNCIA DE FERIDAS AGUDAS E CRÔNICAS E FATORES ASSOCIADOS EM PACIENTES DE HOSPITAIS PÚBLICOS EM MANAUS-AM

SÃO PAULO

2016 
NARIANI SOUZA GALVÃO

\section{PREVALÊNCIA DE FERIDAS AGUDAS E CRÔNICAS E FATORES ASSOCIADOS EM PACIENTES DE HOSPITAIS PÚBLICOS EM MANAUS-AM}

Versão corrigida da Tese apresentada ao Programa de Pós-Graduação em Enfermagem na Saúde do Adulto -PROESA, da Universidade de São Paulo - USP, para obtenção do Título de Doutor em Ciências

Área de concentração: Enfermagem na Saúde do Adulto.

Orientadora: Profa. Dra. Vera Lúcia Conceição de Gouveia Santos

Co-Orientadora: Profa. Dra. Paula Cristina Nogueira

\section{VERSÃO CORRIGIDA}

A versão original encontra-se disponível na Biblioteca da Escola de Enfermagem "Wanda de Aguiar Horta" da Universidade de São Paulo e na Biblioteca Digital de Teses e Dissertações da Universidade de São Paulo.

\section{SÃO PAULO}


AUTORIZO A REPRODUÇÃO E DIVULGAÇÃO TOTAL OU PARCIAL DESTE TRABALHO, POR QUALQUER MEIO CONVENCIONAL OU ELETRÔNICO, PARA FINS DE ESTUDO E PESQUISA, DESDE QUE CITADA A FONTE.

Assinatura:

Data:

\section{Catalogação na Publicação (CIP)}

Biblioteca "Wanda de Aguiar Horta"

\section{Escola de Enfermagem da Universidade de São Paulo}

Galvão, Nariani Souza

Prevalência de feridas agudas e crônicas e fatores associados em pacientes de hospitais públicos em Manaus-AM / Nariani Souza Galvão. São Paulo, 2016.

$162 \mathrm{p}$.

Tese (Doutorado) - Escola de Enfermagem da Universidade de São Paulo.

Orientadora: Prof. ${ }^{a}$ Dr. ${ }^{a}$ Vera Lúcia Conceição de Gouveia Santos

Co-orientadora: Prof. ${ }^{a}$ Dr. ${ }^{\text {a }}$ Paula Cristina Nogueira Área de concentração: Enfermagem na Saúde do Adulto

1. Prevalência. 2. Ferimentos e lesões. 3. Hospitais. 4. Enfermagem. I. Título. 
Nome: Nariani Souza Galvão

Título: Prevalência de Feridas Agudas e Crônicas e Fatores Associados em Pacientes de Hospitais Públicos em Manaus-AM.

Tese apresentada ao Programa de Pós-Graduação em Enfermagem na Saúde do Adulto da Escola de Enfermagem da Universidade de São Paulo para obtenção do título do título de Doutora em Ciências.

Aprovado em:

\section{Banca Examinadora}

Prof. Dr. Instituição:

Julgamento: Assinatura:

Prof. Dr. Instituição:

Julgamento: Assinatura:

Prof. Dr. Instituição: Julgamento: Assinatura:

Prof. Dr. Instituição: Julgamento: Assinatura:

Prof. Dr. Instituição:

Julgamento: Assinatura: 


\section{DEDICATÓRIA}

A minha mãe querida: Aurea Monteiro Galvão (in memoriam), que sempre torceu por mim em todos os momentos da minha vida.

Ao meu pai Wilson Souza Galvão pela força e incentivo para conclusão deste estudo.

Ao meu marido Raimundo Anastácio Carvalho Dutra Filho que sempre me apoiou e incentivou desde o começo desse trabalho.

Ao meu filho querido, João Gabriel, razão da minha luta, e crescimento profissional.

Ao meu irmão Wilson Junior, cunhadas (Adriana e Carla) e aos meus sogros (Raimundo e $\mathcal{N i z a n ) ~ q u e ~ s e m p r e ~ m e ~ i n c e n t i v a r a m , ~}$ rezaram e torceram por mim. 


\section{AGRADECIMENTOS}

Primeiramente a Deus e a Maria Santíssima pela fonte inesgotável de força, sem Eles essa conquista não seria possível.

À Reitora da Universidade Federal do Amazonas professora Dra Márcia Perales Mendes da Silva pelo apoio e incentivo a pesquisa.

Ao Programa de Pós-graduação em Enfermagem na Saúde do Adulto PROESA/USP, pela contribuição na minha formação, bem como aos queridos docentes.

À diretora da Escola de Enfermagem de Manaus (EEM/UFAM), Professora Dr $^{a}$ $\mathcal{N}$ air Chase da Silva que sempre proporciona oportunidades para a aprendizagem e crescimento profissional.

Às Coordenadoras de Curso e Acadêmico, Profa ${ }^{a}$. Dra. Noeli Toledo Neves e Profa. Dra. Gilsirene Scantelbury de Almeida da EEM/UFAM, pelo apoio e incentivo ao meu sucesso pessoal e profissional.

À minha querida orientadora, Profa. Dra. Vera Lúcia Conceição de Gouveia Santos, pela orientação preciosa, paciência e incentivo, sem sua ajuda esse trabalho nunca teria sido possível.

À minha co-orientadora, Profa. Dra. Paula Cristina Nogueira, pelo estímulo constante e disponibilidade, para a conclusão desse projeto.

A todos que de alguma forma contribuíram para a realização deste trabalho. 
GALVÃO, N.S. Prevalência de feridas agudas e crônicas e fatores associados em pacientes de hospitais públicos em Manaus-AM [tese]. São Paulo: Escola de Enfermagem, Universidade de São Paulo; 2016.

\section{RESUMO}

Introdução: As feridas agudas e crônicas provocam alterações físicas, psíquicas, sociais e econômicas para o indivíduo e família. Embora bem estabelecidos os dados epidemiológicos sobre essas lesões no contexto internacional, ainda são incipientes no Brasil, principalmente na Região Amazônica. Objetivo: Identificar e analisar a prevalência e fatores demográficos e clínicos associados à ocorrência de algumas feridas agudas e crônicas (Lesão por Friç̧ão - LF, Dermatite Associada à Incontinência DAI, Ferida Operatória Complicada - FOC, Lesão por Pressão - LP e Úlcera Diabética - UD) em pacientes hospitalizados. Métodos: Trata-se de estudo epidemiológico, observacional, transversal, analítico e descritivo, realizado em sete hospitais da cidade de Manaus. Os dados foram coletados por meio de consulta aos prontuários, entrevistas com os pacientes ou responsáveis legais e exame físico de todos os pacientes internados, durante o período de março a junho de 2015. As lesões encontradas foram avaliadas utilizando-se os seguintes instrumentos: Sistema de Classificação STAR - Lesão por Fricção para as LF; Incontinence Associated Dermatitis Intervention Tool (IAD-IT) para DAl; Pressure Ulcer Scale for Healing - PUSH pernas, para FOC, Pressure Ulcer Scale for Healing - PUSH UP para LP e Classificação de Wagner para as UD. Ademais, instrumento para levantamento dos dados sociodemográficos e clínicos e a Escala de Braden também foram empregados. Os dados foram analisados por meio de: teste Qui-quadrado ou exato de Fisher para as variáveis categóricas e teste t para as numéricas. Modelo de árvore de decisão com o algoritmo Classification and Regression Tree (CART) foi utilizado para identificação dos fatores associados à presença das feridas, de maneira simultânea e isolada. Resultados: A amostra $(n=775)$ foi predominantemente do sexo masculino (457/ 58,9\%), com média de idade de 60,4 anos ( $\mathrm{DP}=18,7)$ raça parda $(240 / 30,9 \%)$; situação conjugal com companheiro $(413 / 53,2 \%)$ e ensino fundamental $(403 / 52,0 \%)$. Cento e setenta e oito pacientes apresentaram lesões durante a coleta de dados, acarretando prevalência pontual global de $23 \%$. Com média de 1,1 ferida $(D P=0,4)$ por paciente, predominaram as $L P(n=80 /$ $10,3 \%)$, seguidas de UD $(n=66 / 8,5 \%)$. Os demais tipos de feridas mostraram prevalências de $2,7 \%(n=21)$ para FOC; $0,9 \%(n=7)$ para LF e $0,5 \%(n=4)$ para DAl. A maior ocorrência das lesões quanto às regiões corporais foram o dorso da mão $E$ para a LF; região dos grandes lábios para $\mathrm{DAl}$; perna $\mathrm{E}$ para FOC; região sacra para LP e: planta do pé E para UD. O CART mostrou Diabetes Mellitus, uso de anticoagulante, presença de 
rigidez, escore de Braden sem risco (>18), presença de curativo e de hematoma como os fatores associados à presença de todas as feridas, de forma simultânea, repetindo-se algumas dessas condições para LP e UD. Conclusão: $O$ estudo, inédito na região amazônica, possibilitou um diagnóstico mais acurado da epidemiologia de algumas das mais importantes e prevalentes feridas agudas e crônicas, em pacientes hospitalizados, como a LF $(0,9 \%)$, DAI $(0,5 \%)$, FOC $(2,7 \%)$, LP $(10,3 \%)$ e UD $(8,5 \%)$. Com prevalências pontuais inferiores à maioria dos resultados de estudos nacionais e internacionais, o estudo suscita a necessidade de mais investigações na região, particularmente estudos de incidência, mesmo que a maioria dos fatores associados constatados nos pacientes hospitalizados amazonenses esteja também presente na literatura.

PALAVRAS-CHAVE: Prevalência; Ferimentos e lesões; Hospital; Enfermagem. 
GALVÃO, N.S. The prevalence of acute and chronic wounds and associated factors in public hospitals in Manaus-AM [thesis]. São Paulo: Escola de Enfermagem, Universidade de São Paulo; 2016.

\section{ABSTRACT}

Introduction: Acute and chronic wounds provoke physical, psychological, social and economic changes for individuals and their families. While, in an international context, epidemiological data regarding these wounds and lesions is well established, it is still in an incipient stage in Brazil, particularly in the Amazon Basin Region. Objective: To identify and analyze the prevalence and demographic and clinical factors associated with the occurence of several acute and chronic wounds (frictional lesions - frictional keratosis, incontinence-associated dermatitis - IAD, post-operative wound complications, pressure sores and diabetic ulcers) in hospitalized patients. Methods: This is an observational, transverse, analytical and descriptive epidemiological study conducted in seven hospitals in the city of Manaus. The data was collected by consulting hospital records, interviews with patients or legal guardians and physical examinations of all hospitalized patients, during the period from March through June 2015. The lesions found were evaluated using the following instruments: Classification System STAR -- Frictional Lesion for frictional lesions; Incontinence Associated Dermititis Intervention Tool (IAD-IT) for IAD; Pressure Ulcer Scale for Healing - PUSH UP for pressure sores and Wagner Classification for diabetic ulcers. Moreover, an instrument for socio-demographic and clinical data collection and the Braden Scale were also employed. The data was analyzed by way of the Chi-squared distribution test or T-Test for numerical ones. The decisionmaking tree model using the Classification and Regression Tree (CART) algorithm was utilized in the identification of factors associated with the presence of lesions, simultaneously and in isolation. Results: The study sample $(n=775)$ was predominantly of the male sex $(457 / 58,9 \%)$ with an average age of 60.4 years $(\mathrm{DP}=18.7)$ mulatto $(240 / 30.9 \%)$; marital situation with spouse (413/53.2 \%) and elementary school complete (403/52.0\%). One hundred and seventy-eight patients presented lesions during the datacollection period, leading to an overall point prevalence of $23 \%$. With an average of 1.1 lesions $(\mathrm{DP}=0.4)$ per patient, pressure sores predominated $(n=80 / 10.3 \%)$, followed by diabetic ulcers $(n=66 / 8.5 \%)$. The remaining types of lesions showed a prevalence of $2.7 \%(\mathrm{n}=21)$ for post-operative wound complications; $0.9 \% \quad(n=7)$ for frictional lesions and $0.5 \% \quad(n=4)$ for incontinence associated dermititis (IAD). The primary occurence of lesions to particular parts of the body were frictional lesions to the back of the left hand; incontinence associated dermititis lesions to the region of the outer labia; post-operative wound complications to the left leg; pressure sores to the sacrum; and diabetic ulcers to the sole of the left foot. CART showed Diabetes Mellitus, the use of anticoagulants, the presence of rigidness, the 
Braden score without risk (>18), the presence of bandages and bruises as factors simultaneously associated with the presence of lesions, repeating some of these conditions for pressure sores and diabetic ulcers. Conclusion: The study, unprecedented in the Amazon Basin region, made a more accurate epidemiological diagnosis possible of some of the most important and prevalent acute and chronic lesions in hospitalized patients, such as frictional lesions $(0.9 \%)$, IAD $(0.5 \%)$, post-operative wound complications $(2.7 \%)$, pressore sores $(10.3 \%)$ and diabetic ulcers $(8.5 \%)$. With point prevalences inferior to the majority of national and international studies, despite the fact that the majority of the associated factors found in hospitalized Amazonian patients are the same as those present in a review of the literature, this study evokes the need for more investigation throughout the region,.particularly incidence studies.

KEYWORDS: Prevalence; Wounds and Lesions; Hospital; Nursing. 


\section{LISTA DE QUADROS}

Quadro 1 - Fatores associados ao desenvolvimento de LF...................23

Quadro 2 - Fatores associados ao desenvolvimento de DAl..................28

Quadro 3 - Fatores associados ao desenvolvimento de FOC. ..................31

Quadro 4 - Fatores associados para o desenvolvimento de LP. ...............34

Quadro 5 - Fatores associados ao desenvolvimento de UD.....................37

Quadro 6 - Variáveis dependentes e independentes do estudo. ..............48

Quadro 7 - Classificação do edema............................................59

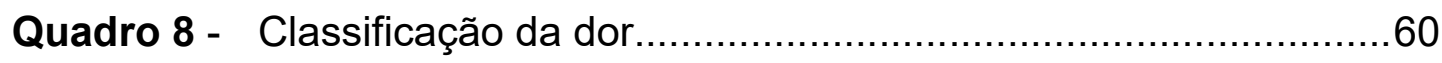

Quadro 9 - Fórmula de predição do peso corporal. ..............................61

Quadro 10 - Prevalência das Feridas Agudas e Crônicas segundo Instituição Hospitalar..... 


\section{LISTA DE FIGURAS}

Figura 1 - Esquema conceitual de fatores de risco para desenvolvimento de LP......................................................33

Figura 2 - Fluxograma da co.leta de dados...................................54

Figura 3 - Classificação do IMC adulto, segundo a Organização Mundial de Saúde.

Figura 4 - Distribuição das LF, segundo a região corporal e sua classificação. Manaus, 2015.

Figura 5 - Distribuição das lesões do tipo DAl, segundo a região corporal e a classificação da lesão. Manaus, 2015.

Figura 6 - Distribuição das lesões do tipo FOC, segundo a região corporal e a classificação da lesão. Manaus, 2015.

Figura 7 - Distribuição do número de LP, segundo a região corporal e o estágio da lesão. Manaus, 2015.

Figura 8 - Distribuição das UD, segundo a região corporal e a classificação da lesão. Manaus, 2015

Figura 9 - Prevalência de acordo com o tipo de lesão em pacientes hospitalizados. Manaus, 2015.

Figura 10 - Fatores associados à presença de LF, segundo a análise CART. Manaus, 2015.

Figura 11 - Fatores associados à presença de DAI, segundo a análise CART. Manaus, 2015.

Figura 12 - Fatores associados à presença de FOC, segundo a análise CART. Manaus, 2015.

Figura 13 - Fatores associados à presença de LP, segundo a análise CART. Manaus, 2015.

Figura 14 - Fatores associados à presença de UD, segundo a análise CART. Manaus, 2015.

Figura 15 - Fatores associados à presença de feridas agudas e crônicas, segundo a análise CART. Manaus, 2015. 


\section{LISTA DE TABELAS}

Tabela 1 - Variáveis sociodemográficas dos pacientes da amostra. Manaus, 2015.

Tabela 2 - Variáveis clínicas dos pacientes da amostra. Manaus, 2015

Tabela 3 - Intensidade de dor nos pacientes hospitalizados, total e de acordo com o tipo de lesão. Manaus, 2015.

Tabela 4 - Variáveis sociodemográficas e clínicas dos pacientes hospitalizados com e sem LF. Manaus, 2015

Tabela 5 - Variáveis sociodemográficas e clínicas dos pacientes hospitalizados com e sem DAI. Manaus, 2015.

Tabela 6 - Variáveis sociodemográficas e clínicas dos pacientes hospitalizados com e sem FOC. Manaus, 2015.

Tabela 7 - Variáveis sociodemográficas e clínicas dos pacientes hospitalizados com e sem LP. Manaus, 2015

Tabela 8 - Variáveis sociodemográficas e clínicas dos pacientes hospitalizados com e sem UD. Manaus, 2015. 


\section{LISTA DE SIGLAS}

$\begin{array}{ll}\text { CART } & \text { Classification and Regression Tree } \\ \text { CDC } & \text { Centro para Controle e Prevenção de Doenças } \\ \text { CNS } & \text { Conselho Nacional de Saúde } \\ \text { DAI } & \text { Dermatite associada a incontinência } \\ \text { DIP } & \text { Incisional Profunda Primária } \\ \text { DIS } & \text { Incisional Profunda Secundária } \\ \text { DM } & \text { Diabetes Mellitus } \\ \text { EB } & \text { Escala de Braden } \\ \text { FOC } & \text { Ferida operatória complicada } \\ \text { IAD-IT } & \text { Incontinence Associated Dermatitis Intervention Tool } \\ \text { IRAS } & \text { Infecções relacionadas a Assistência à Saúde } \\ \text { ISC } & \text { Infecção de sitio cirúrgico } \\ \text { ISTAP } & \text { International Skin Tear Advisory Panel } \\ \text { LF } & \text { Lesão por fricção } \\ \text { LP } & \text { Lesão por pressão } \\ \text { NPUAP } & \text { National Pressure Ulcer Advisory Panel } \\ \text { SIP } & \text { Superficial Incisional Primária } \\ \text { SIS } & \text { Superficial Incisional Secundária } \\ \text { STAR } & \text { Skin Tear Classification System } \\ \text { UTI } & \text { Secretaria de Estado de Saúde do Amazonas } \\ \text { Unidade de Terapia Intensiva }\end{array}$




\section{SUMÁRIO}

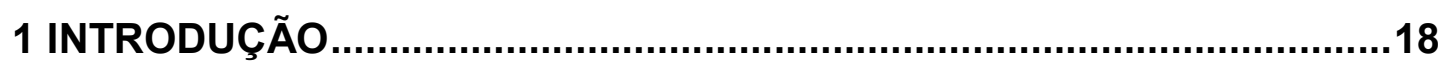

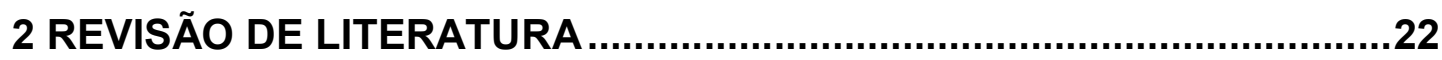

2.1 FERIDAS AGUDAS E CRÔNICAS: CONCEITO, PREVALÊNCIA

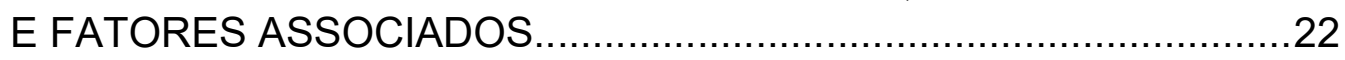

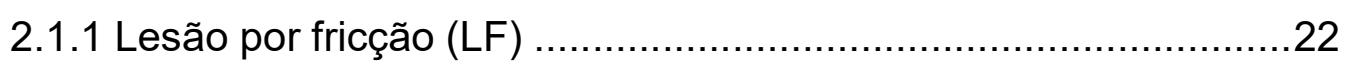

2.1.2 Dermatite associada à incontinência (DAI) ................................24

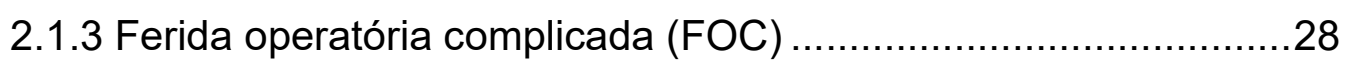

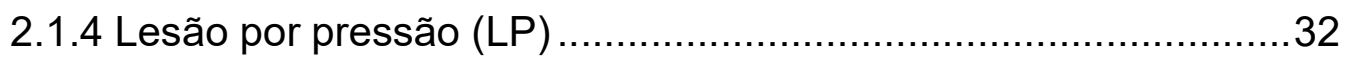

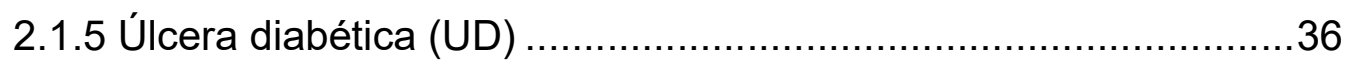

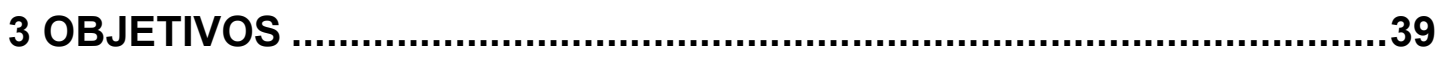

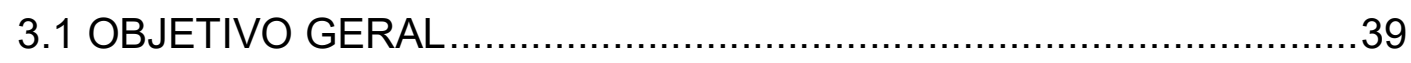

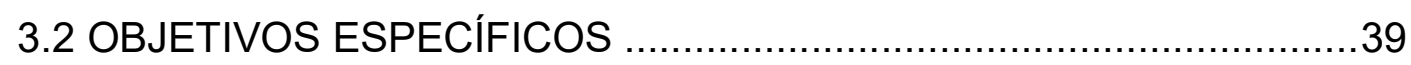

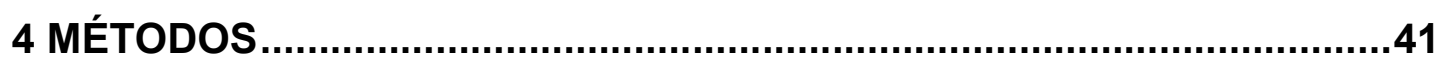

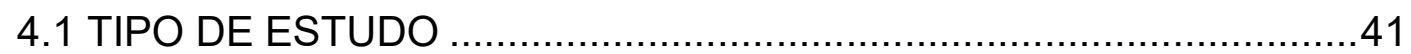

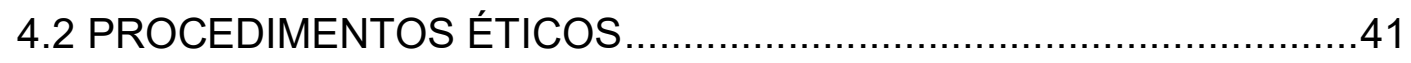

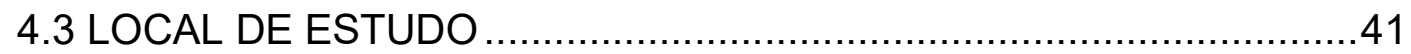

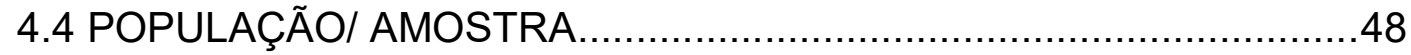

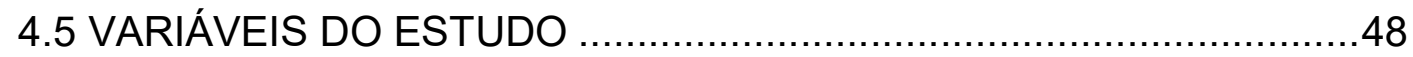

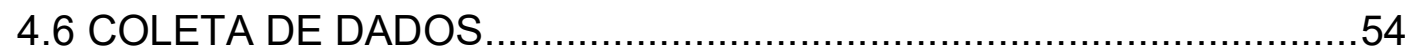

4.6.1 Procedimentos para a coleta de dados ....................................54

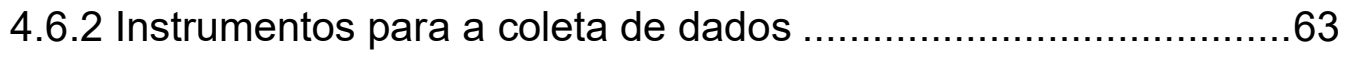

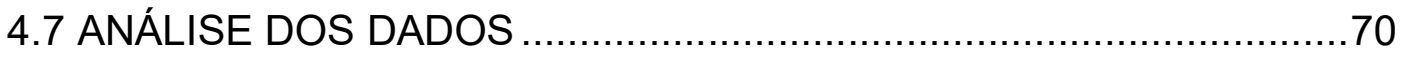

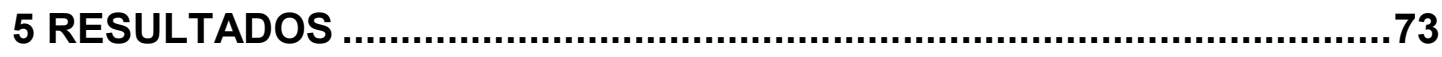

5.1 CARACTERIZAÇÃO DEMOGRÁFICA E CLÍNICA DA AMOSTRA .....73

5.2 CARACTERÍSTICAS CLÍNICAS DAS FERIDAS AGUDAS E

CRÔNICAS DOS PACIENTES HOSPITALIZADOS ............................77

5.3 PREVALÊNCIA DAS FERIDAS AGUDAS E CRÔNICAS E

FATORES ASSOCIADOS

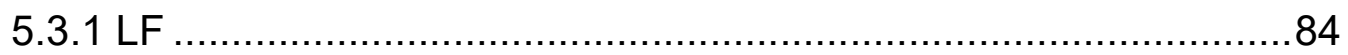

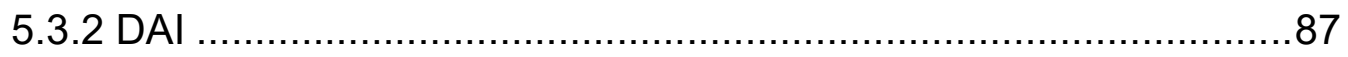

5.3.3 FOC 
5.3.4 LP .93

5.3.5 UD 96

6 DISCUSSÃO. 101

6.1 PREVALÊNCIA DE LF E FATORES ASSOCIADOS 101

6.2 PREVALÊNCIA DE DAI E FATORES ASSOCIADOS 103

6.3 PREVALÊNCIA DE FOC E FATORES ASSOCIADOS 105

6.4 PREVALÊNCIA DE LP E FATORES ASSOCIADOS 107

6.5 PREVALÊNCIA DE UD E FATORES ASSOCIADOS. 111

6.6 FATORES ASSOCIADOS DAS FERIDAS AGUDAS E CRÔNICAS

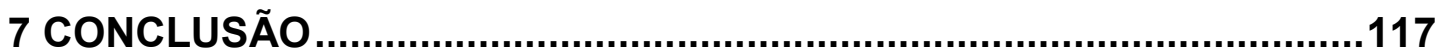

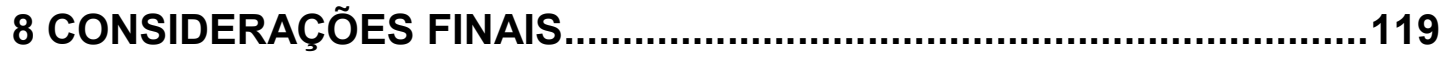

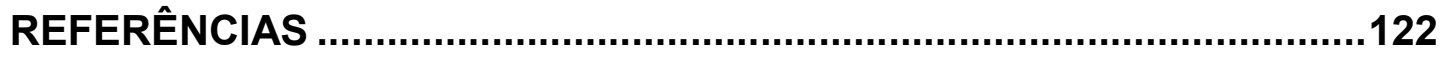

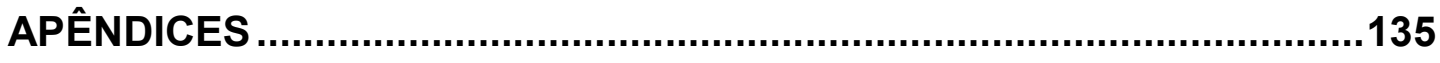

ANEXOS 


\section{INTRODUÇÃO}

Uma ferida ocorre devido à interrupção da solução de continuidade da pele, podendo ser em maior ou menor extensão, por causas traumáticas, intencionais, por isquemia ou por pressão (BRITO et al., 2013).

As feridas agudas e crônicas acometem a população de maneira geral e constituem um grave problema de saúde pública. Os dados estatísticos desses agravos na população brasileira ainda são muito escassos, devido à precariedade dos registros nos prontuários hospitalares ou ambulatoriais (ALBUQUERQUE; ALVES, 2011).

No Brasil, as pesquisas sobre a prevalência das feridas agudas, ainda são muito incipientes, sendo necessário mais pesquisas para definir a real porcentagem de pessoas acometidas por essas lesões (ALBUQUERQUE; ALVES, 2011).

Apesar das poucas pesquisas sobre as feridas agudas, estudos nacionais e internacionais, apontam uma prevalência de lesões por fricção (LF), que varia de $3,3 \%$ a $22 \%$, em cenário hospitalar. Resultados foram identificados nos estudos desenvolvidos respectivamente, no Brasil, com pacientes adultos hospitalizados com câncer, onde a prevalência de LF foi 3,3\% (AMARAL et al., 2012); no Japão em um hospital de retaguarda geriátrico, com prevalência de LF de $3,9 \%$ (KOYANO et al., 2014) e no Canadá, com idosos residentes em Instituições de Longa Permanência, com prevalência de LF de 22\% (LEBLANC et al., 2013).

Outra lesão aguda, a Dermatite Associada à Incontinência (DAI) obteve prevalência de $15,3 \%$, entre os 11 pacientes hospitalizados em Unidade de Terapia Intensiva (UTI), no Paraná (BAESSA et al., 2014). Estudo em Minneapolis, sobre a prevalência de DAl em pacientes hospitalizados, mostrou que dos 189 pacientes da amostra, (99/52,5\%) apresentaram a lesão (ROHWE et al., 2013).

Com relação as feridas operatórias complicadas (FOC), estudo nacional, aponta uma prevalência de 17,2\% em ambiente hospitalar, 
(RIBEIRO et al., 2013). Enquanto nos EUA, a prevalência foi de $4 \%$, no mesmo cenário (CLAESSEN et al., 2016).

O envelhecimento populacional e o consequente aumento das doenças crônicas, especialmente as cardiovasculares e o Diabetes Mellitus, são os principais fatores de risco para o desenvolvimento das lesões crônicas na população (FREITAS et al., 2011).

No Brasil, dentre as feridas crônicas com maior prevalência, destacam-se as Lesão por pressão (LP), afetando aproximadamente $9 \%$ de todos os pacientes hospitalizados, principalmente os idosos, e de $19,1 \%$ (CHAYAMITI; CALIRI, 2010) a 23\% (FREITAS et al., 2011) entre os pacientes acamados em cuidados domiciliares. Em pacientes críticos, identificaram-se prevalências de LP de 32,7\% (CARDOSO et al., 2010); em estudos internacionais mais recentes, identificaram-se prevalência de $22 \%$ na Irlanda (SKERRITT; MOORE, 2014); 23\% na Suécia (LEIJON et al., 2013) e 24\% na Jordânia (ALJA' AFREH; MOSLEH, 2013).

Entre as úlceras diabéticas (UD), o estudo de Oliveira et al. (2016) constatou prevalência de $62,5 \%$ em 42 indivíduos que participaram da pesquisa. $\mathrm{O}$ estudo ocorreu em um hospital geral, de ensino e pesquisa de média e alta complexidade no estado de Goiás. A prevalência de UD na Itália foi em torno de $8,3 \%$, segundo estudo observacional, realizado com pacientes em ambulatório (APOLLONIO et al., 2016).

Devido à grande variedade de lesões agudas e crônicas, o uso de uma classificação precisa pelo enfermeiro, durante a assistência hospitalar, auxilia no registro de informações relacionadas aos fatores de risco ou associados ao seu desenvolvimento e das suas características. Tais sistemas de classificação de risco e das lesões permitem o seguimento do paciente e da evolução da ferida segundo o tratamento proposto pelas equipes de enfermagem e de saúde em geral, com maior precisão e eficiência, predizendo resultados e facilitando a comunicação entre todos (WAIDMAN et al., 2011).

Embora se constate um aumento na produção científica sobre as feridas agudas e crônicas no Brasil, ela é ainda localizada, oriunda 
principalmente dos estados do Sudeste e Sul do país e, ainda assim, para alguns tipos de feridas, como as LP. Constata-se, portanto, a escassez de estudos epidemiológicos sobre essas feridas desenvolvidos com a população da região norte (GALVÃO et al., 2015).

Nesse sentido, a proposta desta pesquisa é identificar e analisar a prevalência e os fatores demográficos e clínicos associados à ocorrência de algumas feridas agudas e crônicas, consideradas mais prevalentes dentro das unidades hospitalares da região, como a Lesão por Friç̧ão (LF), a Dermatite Associada à Incontinência (DAl) a Ferida Operatória Complicada (FOC), Lesão por Pressão (LP) e a Úlcera Diabética (UD), em pacientes internados em hospitais públicos da cidade de Manaus, no Estado do Amazonas.

Considera-se que o conhecimento adquirido trará novas alternativas no cuidado das feridas e contribuirá para o enriquecimento da literatura nacional. Ademais, colaborará para o crescimento do profissional enfermeiro da região amazônica, uma vez que esse tipo de estudo é inédito nessa região. 
2 REVISÃO DA LITERATURA 


\section{REVISÃO DE LITERATURA}

\subsection{FERIDAS AGUDAS E CRÔNICAS: CONCEITO, PREVALÊNCIA E FATORES ASSOCIADOS}

As feridas agudas podem ser definidas como aquelas que apresentam início e cura rápida, sem complicações quanto à cicatrização (DEALEY, 2008). Podem ser intencionais (ocorridas no pós-operatório) ou ocasionadas por acidentes (como queimaduras, lacerações, mordeduras e etc.) (BLANES; FERREIRA, 2014). LF, DAI e FOC constituem exemplos de feridas agudas.

As feridas crônicas podem originar-se a partir de um longo processo agudo, com perda de tecido, ou evoluir devagar com quadros diferentes de inflamação aguda. Não seguem o processo cicatricial normal, ou seja, este prolonga-se por período superior a quatro semanas (BLANES; FERREIRA, 2014), devido à presença de complicações, principalmente a infecção. Entre as feridas crônicas, destacam-se as LP e UD.

\subsubsection{Lesão por fricção (LF)}

O International Skin Tear Advisory Panel (ISTAP) define a LF como uma ferida provocada por cisalhamento, atrito ou trauma, que resulta em separação de camadas da pele (LEBLANC et al., 2013).

A separação de camadas da pele pode ser resultante de fricção ou de uma combinação de fricção e cisalhamento, levando à separação da epiderme da derme (ferida de espessura parcial) ou separando totalmente a epiderme e a derme das estruturas subjacentes (ferida de espessura total) (STRAZZIERI-PULIDO; SANTOS, 2011).

Tem como principal característica apresentar retalho de pele, de aspecto viável a necrosado, leito raso, podendo variar o tamanho e formato de acordo com a intensidade do trauma. As regiões mais propensas para o surgimento de LF são as extremidades superiores como dorso das mãos 
(12\%) e braços $(48 \%)$ e cotovelos $(22 \%)$, bem como, as extremidades inferiores (pernas 40\%) (PAYNE; MARTIN, 1993; STRAZZIERI-PULIDO, SANTOS, 2010; LEBLANC; BARANOSKI, 2011; LEBLANC et al., 2013).

As LFs são feridas agudas comuns na população idosa. Segundo pesquisas internacionais, estima-se que 1,5 milhão de pacientes idosos hospitalizados apresentam LF, com prevalências que variam de $14 \%$ a $24 \%$ (HOLMES, 2013; LEBLANC; BARANOSKI, 2014). Em estudo desenvolvido com 113 idosos residentes em Instituições de Longa Permanência no Canadá, as autoras apontam prevalência de LF de 22\% (LEBLANC et al., 2013); já no Japão, a prevalência de LF variou de 3 a $9 \%$ em um total de 410 idosos com idade de 73 a 87 anos (KOYANO et al., 2014). No Brasil, até o presente, foi desenvolvido somente um estudo com pacientes hospitalizados com câncer, obtendo-se prevalência de LF de 3,3\% (AMARAL; STRAZZIERI-PULIDO; SANTOS, 2012).

Dentre os principais fatores associados ao surgimento de LF, destacam-se os pacientes debilitados e dependentes, com mobilidade e nutrição comprometidas, pele frágil, em uso de corticoides, anti-inflamatórios e anti-hipertensivos, como os idosos e as pessoas em fase final de vida. Além desses, outros fatores presentes no cotidiano de adultos jovens e crianças podem ser mencionados (STRAZZIERI-PULIDO; SANTOS, 2011; LEBLANC; BARANOSKI, 2011; HOLMES et al., 2013; LEBLANC et al., 2013; LEBLANC; BARANOSKI et al., 2014; KOYANO et al., 2014) e encontram-se no Quadro 1.

Quanto à classificação das LF, ainda não há um instrumento universalmente aceito. $O$ primeiro e mais referenciado instrumento de classificação foi proposto por Payne e Martin, em 1990, com revisão em 1993. O Payne-Martin Classification System for Skin Tears é baseado no grau de perda do retalho de pele e conta com três categorias de lesões por fricção. É considerado pelos estudiosos um modelo simples, por não conter informações acerca da viabilidade do retalho da pele e, por isso, é bastante criticado. Ainda não foram feitos os testes de validade e confiabilidade desse instrumento (STRAZZIERI-PULIDO, 2010). 
Quadro 1 - Fatores associados ao desenvolvimento de LF

\begin{tabular}{|c|c|}
\hline Idade avançada > 85 anos & História de LF \\
\hline Sexo feminino & Câncer de pele \\
\hline Raça branca & Obesidade \\
\hline Desnutrição & Alterações do sistema vascular \\
\hline Desidratação & Edema nos MMII \\
\hline Demência & Subnutrição \\
\hline Rigidez/ espasticidade & Acidente vascular cerebral \\
\hline Perda sensorial & Infarto do miocárdio \\
\hline Imobilidade & Diabetes \\
\hline Falta de apetite & Distúrbio da tireóidea \\
\hline $\begin{array}{c}\text { Uso de medicamentos (corticoides; anti- } \\
\text { hipertensivos; analgésicos; antidepressivos; } \\
\text { esteroides; anti-histamínicos; } \\
\text { imunossupressores; anti-inflamatórios; } \\
\text { anticoagulantes; contraceptivos orais) }\end{array}$ & $\begin{array}{c}\text { Disfunção cognitiva } \\
\text { Doença Pulmonar crônica } \\
\text { Uso de dispositivos de apoio }\end{array}$ \\
\hline Presença de equimose & Neurit visual e auditivo \\
\hline
\end{tabular}

Em 2007, Carville et al. sugeriram um sistema de classificação das LF - Skin Tear Classification System (STAR) - a partir da revisão de Payne e Martin, em 1993. Essa classificação inclui cinco categorias de LF (1a, 1b, 2a, $2 b$ e 3) e já se encontra adaptada e validada para o português (STRAZZIERI-PULIDO; SANTOS, 2011).

O STAR - Skin Tear Classification System baseia-se na avaliação da presença ou ausência do retalho de pele e sua viabilidade. A identificação do retalho fornece condições para escolher a melhor forma de tratamento para a lesão. O instrumento conta ainda com um glossário, o Star Skin Tear Classification System Glossary, que traz as definições de LF e de termos técnicos relacionados ao assunto.

\subsubsection{Dermatite associada à incontinência (DAl)}

Em 2005, nos Estados Unidos, especialistas clínicos e investigadores reuniram-se em um consenso para discussão sobre os danos na pele 
associados com a exposição a fezes ou urina. As dermatites associadas à umidade foram caracterizadas como eritema e edema da superfície da pele, acompanhados de bolhas com presença de exsudato seroso e erosão. Estão relacionadas a uma variedade de distúrbios clínicos consequentes à exposição excessiva aos efluentes, tais como urina, fezes, perspiração e exsudato de feridas. Nessa classificação, os especialistas incluíram quatro tipos de dermatites: dermatite periestoma, dermatite intertriginosa, dermatite periferida e dermatite associada à incontinência (GRAY et al., 2002; GRAY, 2004; GRAY et al., 2007; GRAY et al., 2012).

A DAI engloba diversas dermatoses inflamatórias que podem afetar a região perineal, vulva, grandes lábios, virilha, região glútea e o escroto. As alterações são iniciadas por uma combinação de fatores sendo o contato prolongado e a irritação pela urina e fezes os mais significativos (GRAY et al., 2002; GRAY, 2004; BLISS et al., 2006; GRAY et al., 2007).

Segundo o Incontinence Associated Dermatitis Intervention Tool (IADIT) - Consenso Internacional sobre DAI (2012), as manifestações clínicas na pele são eritema brilhante, com variações de intensidade, pápulas eritematosas associadas ao edema e discreta descamação. Em pessoas de pele escura, as lesões são mais difíceis de visualizar, apresentam-se com cores diferentes (branco, amarelo, vermelho escuro e roxo), sendo também recomendada a palpação da pele para detectar a lesão (DOUGHTY et al., 2012).

Estudo nacional, com pacientes críticos $(n=72)$ em hospital privado no Paraná, mostrou que $15,27 \%$ deles apresentavam DAI (BAESSA et al., 2014). Na cidade de Minnesota (EUA), a prevalência de DAl foi $52,5 \%$ entre 189 pacientes internados. A maioria dos participantes era do sexo feminino (77\%), com média etária de 65 anos; $66 \%$ da amostra apresentavam incontinência anal, seguida de 34\% com dupla incontinência (ROHWE et al., 2013). Em estudo australiano com 376 pacientes hospitalizados, a prevalência de DAl foi $24 \%$, sendo maior nos pacientes do sexo masculino (52\%), com média de 62 anos de idade (CAMPBELL et al., 2014). 
A DAl ainda é um desafio para os profissionais da equipe de enfermagem quanto à sua diferenciação com as LPs nos estágios 1 e 2 . Segundo o IAD-IT (2012), a DAl é uma resposta inflamatória, ocasionada pela exposição prolongada da pele às fezes e urina. Diferentemente, as LP consistem em lesões isquêmicas, com progressiva morte tecidual e que, geralmente, se localizam sobre proeminências ósseas ou sob dispositivos médicos. A DAI apresenta-se inicialmente como eritema com pele intacta, evoluindo para formação de vesículas com perda de tecido.

Com relação aos fatores associados ao desenvolvimento de DAI, é necessária a identificação de grupos de pessoas com especial risco de integridade cutânea prejudicada relacionada com a incontinência e/ou com o excesso de umidade. Assim, podem-se distinguir diferentes grupos em função da idade, sexo e outros fatores, expostos a seguir:

Idosos: constituem um grupo de alto risco de sofrer danos na pele, uma vez que a sua pele é qualitativamente diferente da pele de um adulto mais novo. Caracteriza-se pela redução de elasticidade, textura, sensibilidade e circulação periférica, acarretando maiores dificuldades no processo cicatricial (GRAY, 2007). É mais permeável, o que permite que a umidade exterior penetre nas capas da epiderme aumentando o nível de fricção na superfície e aumentando o risco de lesão. Essa maior permeabilidade na pele dos idosos torna-a mais ressecada devido à perda de água, o que se calcula afetar entre $59 \%$ a $80 \%$ dessa população (FERNADEZ et al., 2006).

Obesidade: é considerada como um fator de risco para a ocorrência da incontinência urinária e do aumento da vulnerabilidade da pele às lesões, principalmente associadas à umidade (como a formação de pregas) (FERNADEZ et al., 2006). O tecido adiposo é considerado outro fator de risco, por ser pouco vascularizado e menos resistente à pressão, sendo mais susceptível à ruptura e consequente formação de lesões (BLISS et al., 2006). 
Enurese: embora seja um fator predominante na idade infantil e juvenil, um número importante de pessoas (cerca de $1 \%$ da população) a mantém ou a desenvolve na idade adulta (FERNADEZ et al., 2006).

Comprometimento neurológico: urinar é um ato voluntário e consciente que se consegue graças ao controle que exercem os centros superiores sobre o reflexo da micção. Qualquer doença que intervém sobre esse processo pode induzir à incontinência, tais como traumatismos cranioencefálicos, acidente vascular encefálico, tumores cerebrais, esclerose múltipla em fases iniciais, demências, doença de Parkinson, etc. ou como sequela de complicações secundárias de outras doenças ou procedimentos como DM, intervenções cirúrgicas nas zonas pélvica ou abdominal ou à utilização de algum tipo de fármaco (FERNADEZ et al., 2006).

Outros problemas de saúde: problemas cardiopulmonares que comprometem diretamente a oxigenação e nutrição dos tecidos; e problemas de mobilidade ou restrições físicas ou sensoriais também podem comprometer a continência. Baixos níveis de albumina podem provocar um edema intersticial que compromete a cura de feridas e o aporte de nutrientes à pele, tornando-a mais vulnerável à umidade (FERNADEZ et al., 2006).

Tratamentos farmacológicos: determinados fármacos podem favorecer a incontinência tanto urinária como fecal. Para a incontinência urinária, encontram-se os diuréticos, antihipertensivos (antagonistas do cálcio), AINE e outros. Para a incontinência anal, têm-se os antibióticos, lítio, digoxina, cloreto potássico, anti-H2, antigripais e outros (FERNADEZ et al., 2006).

O Quadro 2 mostra a síntese dos fatores associados à ocorrência da DAI (GRAY et al., 2012; AQUINO et al., 2012; DOUGHTY et al., 2012; ROHWER et al., 2013; CAMPBELL et al., 2014; KOTTNER et al., 2014). 
Quadro 2 - Fatores associados ao desenvolvimento de DAI

\begin{tabular}{|c|c|}
\hline $\begin{array}{c}\text { Infecção por Candida Albicans/ } \\
\text { staphylococcus aureos }\end{array}$ & IMC elevado \\
\hline Uso de fralda & Umidade \\
\hline Sexo masculino & Calor \\
\hline Idade $>60$ anos & Enurese \\
\hline Incontinência fecal e urinária & Obesidade \\
\hline Diabetes Mellitus & Pacientes neurológicos \\
\hline Restrições físicas/ sensoriais & Mobilidade \\
\hline Diminuição do nivel de albumina & Edema intersticial \\
\hline $\begin{array}{c}\text { Medicamentos como: diuréticos; anti- } \\
\text { hipertensivo; AlNE; antibióticos; lítio; cloreto } \\
\text { de potássio }\end{array}$ & $\begin{array}{c}\text { Fricção mecânica durante as trocas de } \\
\text { fraldas e limpeza do períneo }\end{array}$ \\
\hline
\end{tabular}

\subsubsection{Ferida operatória complicada (FOC)}

A FOC é considerada como uma lesão primariamente intencional que teve seu processo cicatricial alterado devido a fatores adversos. Dentre esses tipos podem-se relacionar a deiscência, fístula, hemorragia e infecção, consideradas como as principais complicações associadas à ferida operatória (DEALEY, 2008).

A deiscência da ferida operatória ocorre após a ruptura parcial ou total da sutura cirúrgica, ocasionada geralmente por processo infeccioso como o seroma e infecção (CARVALHO; BORGES, 2011). Os fatores de risco como a distensão abdominal, obesidade, ascite, tosse, vômito e espirro, ocasionam um aumento na pressão intra-abdominal que, em casos de inadequado fechamento das camadas intersticiais por suturas, também causam a deiscência cirúrgica. Nesses casos, uma das formas de prevenir a abertura das bordas intersticiais é a realização de uma incisão precisa, evitando a desvitalização das bordas faciais (TILLOU et al., 2003).

Com relação à fístula, acontece devido a um trajeto anormal adquirido ou congênito entre duas vísceras ocas ou espaços potenciais internos ou entre esses e a pele, sendo denominados respectivamente de internas e 
externas. Dentre os fatores congênitos ou adquiridos mais frequentes, podem-se mencionar como causas os traumas, doenças inflamatórias, neoplasias, radioterapia ou cirurgia, dentre outros. Entre os fatores predisponentes encontram-se ainda a idade, o estado nutricional e as doenças associadas (como doenças cardiovasculares, inflamatórias intestinais, hipóxias, cirrose e outras) (WERCKA et al., 2016).

A hemorragia pós-operatória pode ocorrer devido a uma sutura insuficiente ou pelo abuso de movimentos feitos por parte do paciente. Uma das causas das hemorragias de ferida operatória são as rupturas de ligadura ou hemostasia inadequada, que tem como consequência a hipovolemia, colocando a vida do paciente em risco (STRACIERI, 2008).

Baseada nos critérios do Centro para Controle e Prevenção de Doenças (CDC), publicados em 1992, a terminologia utilizada para as infecções associadas a procedimentos cirúrgicos foi alterada de infecção da ferida operatória para infecção de sítio cirúrgico (ISC) (HORAN et al., 1992). Segundo o CDC (2016), as infecções de sítio cirúrgico (ISC) podem ser classificadas em:

- Superficial Incisional: ocorre 30 dias após o procedimento cirúrgico, envolvendo apenas a pele e tecidos subcutâneos da incisão. Os pacientes podem apresentar sinais e sintomas como dor, edema, eritema, calor e secreção purulenta na incisão, com ou sem a confirmação do exame de cultura laboratorial. Existem dois tipos específicos de ISC superficial incisional:

1. Superficial Incisional Primária (SIP) - é identificada na incisão primária em paciente que tenha feito uma cirurgia, apresentando uma ou mais incisões;

2. Superficial Incisional Secundária (SIS) - é identificada na incisão secundária em paciente que tenha feito a cirurgia, apresentando mais de uma incisão.

- Profunda Incisional: ocorre dentro de 30 a 90 dias após o procedimento cirúrgico. Atinge tecido moles mais profundos como fáscias e camadas musculares. $\mathrm{O}$ paciente apresenta febre $\left(>38^{\circ} \mathrm{C}\right)$, dor localizada e 
abscesso no local da incisão, incisão profunda com deiscência espontânea ou aberta por um cirurgião, médico, assistente ou outro. Existem dois tipos específicos de ISC profunda incisional:

1. Incisional Profunda Primária (DIP) - é identificada na incisão primária em paciente que tenha feito uma cirurgia, apresentando uma ou mais incisões;

2. Incisional Profunda Secundária (DIS) - é identificada na incisão secundária em paciente que tenha feito a cirurgia, apresentando mais de uma incisão.

- Órgão / ISC Espaço: ocorre dentro de 30 a 90 dias após o procedimento cirúrgico. Pode acometer qualquer órgão do corpo humano. No caso de uso de drenos, pode apresentar exsudato purulento e presença de abscesso envolvendo o órgão infeccionado.

As infecções pós-operatórias e hospitalares têm sido consideradas como um grave problema de saúde pública desde que surgiram os hospitais. Muitos são os esforços para prevenir sua ocorrência e expansão. O início desses esforços começou há muitos anos, quando foram construídos hospitais de isolamento para pacientes com doenças transmissíveis, na tentativa de separar doentes infectados dos demais indivíduos da comunidade (AGUIAR et al., 2012). As infecções relacionadas à assistência à saúde (IRAS) são classificadas em infecção do Sistema Urinário, Sistema Respiratório, Sistema Vascular e de Sítio Cirúrgico (AGUIAR et al., 2012).

Por ser considerada como uma das maiores e mais importantes complicações pós-operatórias, devido principalmente aos seus altos índices de morbidade e mortalidade, altos custos referentes ao tratamento, além da questão litigiosa, a ocorrência de ISC está diretamente ligada à qualidade da assistência (BELLUSE et al., 2015).

Segundo o CDC (2016), 157.500 casos foram associados a infecções hospitalares notificados no ano de 2013, com taxa de mortalidade de 3 a $75 \%$. Estudo desenvolvido no México com 312 pacientes hospitalizados aponta prevalência de 5,5\% de ISC (PORTILLO et al., 2014). Na República Eslovaca, entre 298 pacientes hospitalizados, a prevalência de ISC foi 
$15,7 \%$. Os patógenos mais frequentemente encontrados foram Escherichia coli (15\%), Klebsiella spp. (12,5\%) e Pseudomonas aeruginosa (10,8\%) (LITVOVÁ et al., 2014). Em outro estudo, desenvolvido na Itália, avaliaramse pacientes internados nas clínicas cirúrgicas dos hospitais da região, observando-se que $2,6 \%$ de 1628 casos foram de ISC, sendo $60 \%$ dos casos diagnosticados com infecção após 30 dias de vigilância pós-alta (MARCHI et al., 2014).

A ISC ocupa a terceira posição entre todas as infecções em serviços de saúde no Brasil e compreende 14 a 16\% daquelas encontradas em pacientes hospitalizados (BATISTA; RODRIGUES, 2012).

Diversos fatores predispõem o indivíduo ao desenvolvimento de ISC e podem estar relacionados ao paciente (como idade, presença de doenças crônicas), ao procedimento cirúrgico (como duração da cirurgia) e à equipe de saúde (AGUIAR et al., 2012; BATISTA; RODRIGUES, 2012; BRASIL, 2014). A síntese desses fatores é apresentada no Quadro 3.

Quadro 3 - Fatores associados ao desenvolvimento de FOC

\begin{tabular}{|c|c|}
\hline $\begin{array}{c}\text { FATORES RELACIONADOS AO } \\
\text { PACIENTE }\end{array}$ & $\begin{array}{c}\text { FATORES RELACIONADOS AO } \\
\text { PROCEDIMENTO CIRÚRGICO }\end{array}$ \\
\hline Doenças pré-existentes & Natureza e local da cirurgia \\
\hline Desnutrição & Técnica cirúrgica adotada \\
\hline Idade avançada & Uso de sondas e drenos \\
\hline Obesidade & Grau de contaminação da cirurgia \\
\hline Imunossupressão & Duração da operação \\
\hline Defesas orgânicas alteradas & Habilidade técnica da equipe cirúrgica \\
\hline Doenças crônicas & Tempo de internação pré e pós-operatório \\
\hline Tabagismo & Classificação da ferida operatória. \\
\hline Infecções coexistentes & Preparo pós-operatório ineficiente \\
\hline
\end{tabular}




\subsubsection{Lesão por pressão (LP)}

As úlceras por pressão acabam de receber nova denominação: lesões por pressão (LP) (NPUAP 2016; CALIRI; SANTOS; MANDELBAUM; COSTA, 2016), terminologia a ser empregada neste relatório de tese. Em 13 de abril de 2016, o National Pressure Ulcer Advisory Panel - NPUAP, através de um complexo processo para o estabelecimento de consenso, emitiu um release contendo a nova terminologia para as úlceras por pressão, além do conceito e classificação atualizados (NPUAP, 2016).

A LP pode ser definida como dano localizado na pele e/ou tecido subjacente, geralmente sobre uma proeminência óssea, ou relacionada ao uso de um dispositivo médico ou a outro artefato. Como resultado da pressão, ou pressão em combinação com cisalhamento, também pode ser afetada pelo microclima, nutrição, perfusão, comorbidades (NPUAP, 2016).

Quanto à sua classificação, a mesma organização internacional NPUAP - adota o seguinte sistema a partir do novo consenso (NPUAP, 2016):

- Lesão por Pressão Estágio 1: Pele íntegra com eritema que não embranquece;

- Lesão por Pressão Estágio 2: Perda da pele em sua espessura parcial com exposição da derme;

- Lesão por Pressão Estágio 3: Perda da pele em sua espessura total;

- Lesão por pressão Estágio 4: Perda da pele em sua espessura total e perda tissular;

- Lesão por Pressão Não Classificável: Perda da pele em sua espessura total e perda tissular não visível

- Lesão por Pressão Tissular Profunda: descoloração vermelho escura, marrom ou púrpura, persistente e que não embranquece.

Definições adicionais:

- Lesão por Pressão Relacionada a Dispositivo Médico;

- Lesão por Pressão em Membranas Mucosas. 
A etiologia das LP foi proposta por Bergstrom et al., (1987), ao desenvolverem um esquema conceitual com os determinantes intensidade e duração da pressão sobre regiões do corpo bem como a tolerância da pele e tecidos adjacentes à pressão (Figura 1). Outros fatores hipotéticos: edema; estresse emocional; fumo e temperatura da pele também são acrescentados.

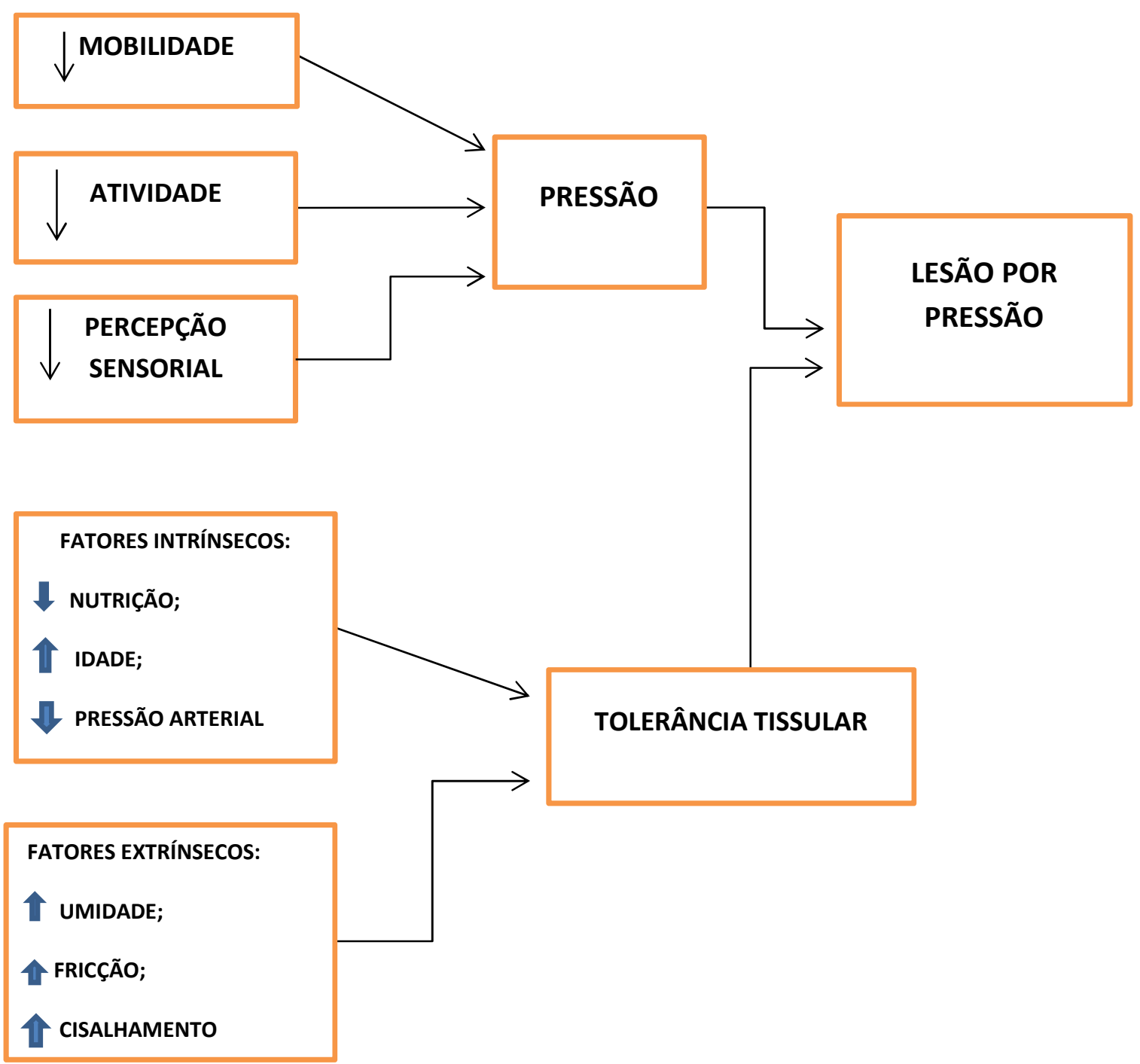

Figura 1 - Esquema conceitual de fatores de risco para desenvolvimento de LP

Fonte: BERGSTROM, N.; BRADEN, B.J.; LAGUZZA, A.; HOLMAN, V. The Braden Scale for Predicting Pressure Sore Risk. Nurs Res. v. 36, n.4, p:205-10. Jul-Aug, 1987. 
Por meio desse esquema, compreende-se que a intensidade e a duração da pressão estão relacionadas com os fatores de risco, percepção sensorial, mobilidade e atividade. Em relação à tolerância da pele e suas estruturas em suportar a pressão, relaciona-se aos fatores intrínsecos como a nutrição, a idade e pressão arterial. Já a umidade, fricção e cisalhamento são considerados como fatores extrínsecos que interferem na capacidade dos tecidos (pele e músculos) em redistribuir a carga mecânica, ou seja, em suportar a pressão.

Esse modelo conceitual fundamentou a construção da Escala de Braden (EB), desenvolvida pelas mesmas autoras (BERGSTROM et al., 1987) para avaliação do risco de desenvolvimento de LP, o que permitiria a implementação de medidas preventivas, diminuindo assim sua ocorrência em pacientes hospitalizados.

Os fatores associados ao desenvolvimento de LP encontram-se listados no Quadro 4 (FREITAS et al., 2013; GONSKA et al., 2013; ALVES et al., 2014).

Quadro 4 - Fatores associados para o desenvolvimento de LP

\begin{tabular}{|c|c|}
\hline FATORES INTRÍNSECOS & FATORES EXTRÍNSECOS \\
\hline Estado nutricional alterado & Friç̧ão \\
\hline Incontinência urinária e fecal & Força de cisalhamento \\
\hline Hipertermia & Umidade por contato \\
\hline Tabagismo & Uso de catéter vesical de demora \\
\hline Idade avançada & \\
\hline Insuficiência arterial ou venosa & \\
\hline Diabetes Mellitus & \\
\hline Hipertensão & \\
\hline Paresia/plegia & \\
\hline Mobilidade & \\
\hline Alterações de sensibilidade dolorosa e tátil & \\
\hline Fraturas & \\
\hline Perfusão tissular alterada & \\
\hline Alteração do sono e repouso & \\
\hline Anemia & \\
\hline Temperatura da pele & \\
\hline Edema & \\
\hline Estresse emocional & \\
\hline
\end{tabular}


Do ponto de vista epidemiológico, apesar dos avanços tecnológicos nos cuidados com a saúde, a prevalência das LP, principalmente em Unidades de Terapia Intensiva (UTI), continua elevada no Brasil, atingindo de $10,6 \%$ a $62,5 \%$ (ALVES et al., 2014).

Em estudo brasileiro sobre a prevalência de LP em pacientes internados em instituições públicas e privadas, com idade média acima de 58,4 anos (38,9\%), 80 pacientes apresentaram LP, com prevalência de $16,3 \%$. As LP localizaram-se principalmente na região sacra $(82,5 \%)$, seguindo-se a trocantérica $(37,5 \%)$ e calcânea $(27,5 \%)$ (BRITO et al., 2013).

Outro estudo brasileiro, desenvolvido por Costa et al. (2015), em um Hospital de cuidados paliativos, mostrou prevalência de $12,5 \%$, predominando entre os homens (60\%), na região sacra (55\%) e em estágio 4 (77,5\%). Em outro estudo desenvolvido com pacientes em estágio avançado de câncer e recebendo cuidados paliativos no domicilio, os autores (QUEIROZ et al., 2014) detectaram que a prevalência de LP dos 64 pacientes da amostra foi $18,8 \%$, com predomínio do estágio $3(47,4 \%)$.

Na Suécia, Leijon et al. (2013) obtiveram prevalência de $23 \%$ de LP em 258 pacientes hospitalizados, predominando a LP estágio 1 (19\%) e as localizações anatômicas sacra $(7,5 \%)$ e calcânea $(5 \%)$. Na Jordânia, estudo de prevalência mostrou que $24 \%$ dos 190 pacientes hospitalizados apresentaram LP, $23 \%$ nos estágios 3 e 4, localizadas principalmente na região sacra (43\%) e calcâneo (24\%). A média de idade foi superior a 60 anos $(75 \%)$ e houve predomínio do sexo masculino (53\%) (ALJA' AFREH; MOSLEH, 2013). Outro estudo de prevalência, também na Jordânia (ALJEZAWI et al., 2014), com 118 pacientes idosos (faixa etária de 65 anos) residentes em casas de repouso, mostrou que 16,9\% apresentaram LP, sendo a região glútea a mais acometida (42,9\%). Os estágios 1 e 2 apareceram em $40 \%$ dos casos. Na Irlanda (SKERRITT; MOORE, 2014), o estudo constatou prevalência de LP de $22 \%$ em pacientes hospitalizados. E, na China (JIANG et al., 2014), os autores encontraram prevalência de apenas $1,5 \%$ de LP em 631 pacientes hospitalizados, sendo as regiões sacra e crista ilíaca os locais mais acometidos. 


\subsection{5 Úlcera diabética (UD)}

O Diabetes Mellitus (DM) é um dos problemas mais importantes de saúde na atualidade, por ser uma doença com elevada morbidade e mortalidade. É responsável pela maioria das amputações de membros inferiores, precedida, muitas vezes, por uma úlcera, gerando incapacidade, invalidez, aposentadoria precoce e mortes evitáveis. Além disso, a doença é considerada como um dos fatores de aumento das internações que se tornam prolongadas e causam grandes prejuízos ao sistema público de saúde (ALMEIDA et al., 2013).

Uma de suas complicações mais frequentes é o "pé diabético", caracterizado pela presença de lesões em decorrência das alterações vasculares e/ou neurológicas peculiares do DM. A úlcera diabética - pé diabético é uma complicação crônica que ocorre, em média, após 10 anos de evolução da doença e é a causa mais comum de amputações não traumáticas. Por isso, sugere-se que haja uma intervenção intensiva para prevenir o seu aparecimento ou atenuar a sua evolução (ALMEIDA et al., 2013).

No Brasil, um estudo recente de prevalência de UD nos pés de 42 pacientes diabéticos hospitalizados foi 61,9\% (OLIVEIRA et al., 2016).

Segundo estudo na Polônia (NEHRING et al., 2014), a prevalência de UD na população geral com DM foi $15 \%$, estimando variação de $2 \%$ a $12,1 \%$ para os pacientes com DM tipo 2. Ferguson et al. (2013) constataram prevalência de $4,3 \%$ de pacientes com UD em um estudo desenvolvido na Jamaica (143 mulheres e 45 homens, com média de idade de 56 anos).

Os fatores associados ao desenvolvimento da UD estão relacionados aos antecedentes de úlceras e amputações não traumáticas nos pés; ao descontrole metabólico; à obesidade; à idade; ao sexo; ao tempo de evolução do DM; à neuropatia com diminuição de sensibilidade e deformidades; às calosidades; ao uso de calçados inadequados; ao tabagismo; à educação terapêutica deficiente e à dificuldade de acesso ao sistema de saúde, dentre outros (PEREIRA et al., 2010; LADEIRA et al., 
2011; DUARTE; GONÇALVES, 2011; FERGUSON et al., 2013; BABA et al., 2014; KAVITHA et al., 2014; NEHRING et al., 2014). Esses fatores são apresentados no Quadro 5.

Quadro 5 - Fatores associados ao desenvolvimento de UD

\begin{tabular}{|c|c|}
\hline Retinopatia & Nefropatia \\
\hline Doença cerebrovascular & Acidente vascular cerebral \\
\hline Alcoolismo & Deformidade dos pés/ calos/Trauma \\
\hline Insuficiência renal & Hiperglicemia não controlada \\
\hline Doença arterial periférica & Imunocomprometimento \\
\hline Neuropatia periférica & Uso de calçado inadequado \\
\hline Hipertensão arterial & História de UD anteriores/ amputações \\
\hline Diabetes & Idade avançada \\
\hline Deficiência visual & Controle metabólico \\
\hline Doença renal crônica & Obagismo \\
\hline Desnutrição & Falta de bons hábitos higiênicos com os pés \\
\hline Sexo masculino & Estresse oxidativo \\
\hline Alta concentração de metaloproteinases &
\end{tabular}


3 OBJETIVOS 


\section{OBJETIVOS}

\subsection{OBJETIVO GERAL}

- Identificar e analisar as prevalências de Lesão por Fricção - LF, Dermatite Associada à Incontinência - DAI, Ferida Operatória Complicada - FOC, Lesão por Pressão - LP e Úlcera Diabética - UD, bem como os fatores demográficos e clínicos associados à sua ocorrência, em pacientes hospitalizados.

\subsection{OBJETIVOS ESPECÍFICOS}

- Descrever o perfil demográfico e clínico dos pacientes hospitalizados.

- Descrever as características das feridas agudas e crônicas encontradas quanto a: localização, classificação, tipo de tecido, quantidade de exsudato e medida. 
4 MÉTODOS 


\section{MÉTODOS}

\subsection{TIPO DE ESTUDO}

Trata-se de estudo epidemiológico, observacional, transversal, analítico e descritivo.

\subsection{PROCEDIMENTOS ÉTICOS}

Inicialmente, o projeto de pesquisa foi encaminhado à SUSAM (Secretaria de Estado de Saúde do Amazonas), para conhecimento e autorização da realização da coleta de dados nas instituições da saúde da capital (ANEXOS 1 a 7). Após obtenção dessa anuência, o projeto foi submetido ao Comitê de Ética em Pesquisa da Escola de Enfermagem da Universidade de São Paulo, sendo aprovado sob o número CAAE: 38329114.6.0000.5392 (ANEXO 8).

Os sujeitos da pesquisa foram esclarecidos sobre os objetivos do estudo e, ao aceitarem participar, receberam e assinaram o Termo de Consentimento Livre e Esclarecido (TCLE) (APÊNDICE 1) em duas vias, conforme a Resolução $n^{\circ}$ 466, de 12 de dezembro de 2012, do Conselho Nacional de Saúde (CNS), assegurando-se o anonimato, o sigilo dos dados coletados e o direito de declinar do estudo em qualquer momento sem penalização (BRASIL, 2012).

Após a assinatura, uma das vias ficou com o participante e a outra com a pesquisadora. Vale ressaltar que o referido termo foi em linguagem simples e de fácil compreensão e acessibilidade aos sujeitos do estudo.

\subsection{LOCAL DE ESTUDO}

O estudo foi realizado em sete instituições hospitalares públicas, na cidade de Manaus, descritas a seguir: 


\section{$\checkmark$ Hospital e Pronto Socorro 28 de Agosto}

O Hospital e Pronto Socorro 28 de Agosto (Manaus-AM) é unidade de referência na Amazônia Ocidental, principalmente no tratamento de pacientes vítimas de queimaduras. O Hospital e Pronto Socorro 28 de Agosto foi fundado em 1986 para tentar desafogar os atendimentos do Pronto-Socorro Universitário Getúlio Vargas. Na época, a unidade hospitalar ocupava uma área de 3.543 metros quadrados e mantinha um atendimento de 1,3 mil pacientes por ano. Ao longo dos anos, a demanda de atendimentos cresceu e o hospital precisou passar por uma reforma interna e externa totalizando dez mil metros de área construída. São aproximadamente 15 mil pacientes que procuram os serviços do hospital durante o mês.

Trata-se de Hospital de média complexidade que conta com 259 leitos ativos, distribuídos em sete pavimentos. Possui 902 profissionais, lotados em clínicas de especialidades: neurocirurgia, cirurgia geral, ortopedia e traumatologia, cardiologia, clínica geral, nefro-urologia, unidade de isolamento, UTI adulto tipo II e UTI de queimados. O Hospital oferece também atendimento ambulatorial e de urgência. O hospital não dispõe de serviço de estomaterapia, sendo os curativos complexos e simples realizados pelos enfermeiros, técnicos e auxiliares de enfermagem. Até o momento, não possui protocolos de prevenção e tratamento de lesões agudas e crônicas.

\section{Hospital e Pronto Socorro Dr. João Lúcio Pereira Machado}

Trata-se de uma instituição de Saúde da Administração Direta, criada pelo Decreto $n^{\circ} 19.402$ de 17/11/1998 e inaugurada no dia 25 de setembro de 1998, durante a gestão do superintendente Estadual de Saúde Dr. Tancredo Soares. Localiza-se na zona leste da cidade de Manaus em área com cerca de 320.000 habitantes. A instituição é referência em trauma no Estado do Amazonas, com especialidades em clínica geral, cirurgia geral, ortopedia, cirurgia vascular, nefrologia, neurocirurgia, anestesiologia, medicina intensiva e cirurgia de cabeça e pescoço. Seus profissionais atuam 
sob a forma de cooperativas médicas e de Enfermagem. Além disso, o Hospital possui profissionais qualificados em seu quadro de pessoal, contando com 740 funcionários, entre farmacêuticos, assistentes sociais, fisioterapeutas, bioquímicos, administradores, nutricionistas, enfermeiros, técnicos e auxiliares de enfermagem, agentes administrativos e auxiliares de serviços gerais. Possui 204 leitos, sendo 174 nas enfermarias e 30 na UTI, registrando média anual de 207 mil atendimentos, 900 atendimentos diários e média de ocupação de $100 \%$. Possui ainda quatro salas de cirurgia e quatro leitos de recuperação pós-anestésica. O Hospital não oferece serviço especializado de estomaterapia, sendo os curativos complexos e simples realizados por dois enfermeiros não especialistas que compõem a Comissão de Controle de Infecção Hospitalar (CCIH). Até o momento, o hospital não dispõe de protocolos de prevenção e tratamento de lesões agudas e crônicas.

$\checkmark$ Hospital e Pronto Socorro Dr. Aristóteles Platão Bezerra de Araújo

O Hospital e SPA (Serviço de Pronto Atendimento) Dr. Aristóteles Platão Bezerra de Araújo foi inaugurado em 27 de setembro de 2006, como resposta aos anseios das comunidades da Zona Leste, Norte e circunvizinhas da cidade. Atualmente conta com 208 leitos, sendo 62 de clínica médica; 24 de pediatria clínica; 37 de cirurgia geral; 37 de ortopedia e traumatologia; 10 de UTI Adulto; cinco de UTI Infantil; cinco de recuperação cirúrgica (RPA); 12 para observação de adultos; seis para observação pediátrica e 10 para unidades de isolamento, com média de ocupação de 100\%. Conta com 443 funcionários entre farmacêuticos, assistentes sociais, fisioterapeutas, bioquímicos, administradores, nutricionistas, enfermeiros, técnicos e auxiliares de enfermagem, agentes administrativos e auxiliares de serviços gerais, médicos. Oferece ainda serviços de tomografia, ultrassom, raio $\mathrm{X}$ e serviços de exames laboratoriais, garantindo o pleno atendimento em casos de emergências, traumatismos, hemorragias, fraturas, desmaios, ferimentos por armas de fogo ou armas brancas, afogamentos, 
envenenamentos por ingestão ou picada de animais peçonhentos e queimaduras. Neste contexto, o hospital está capacitado para realizar cirurgias ortopédicas de média e alta complexidade e destina leitos à cirurgia vascular e a pacientes com DM, com úlceras venosas e arteriais. O hospital não oferece serviço especializado de estomaterapia, sendo os curativos complexos e simples realizados por cinco enfermeiros da Comissão de Controle de Infecção Hospitalar $(\mathrm{CClH})$. Até o momento, não possui protocolos de prevenção e tratamento de lesões agudas e crônicas.

\section{$\checkmark$ Hospital Universitário Francisca Mendes}

O Hospital Universitário Francisca Mendes foi inaugurado no dia 21 de junho de 1999, sob o título de Hospital do Servidor Público do Estado Dona Francisca Mendes. Antes da inauguração, entretanto, o Governo do Estado já havia firmado, em abril de 1999, o contrato com a Associação Beneficente de Assistência Social e Hospitalar (Pró-Saúde) para a administração da unidade hospitalar, projetada para se tornar referência na Região Norte. Em abril de 2003, a Universidade Federal do Amazonas assumiu a direção do Francisca Mendes que passou a ser denominado Hospital Universitário Francisca Mendes. É referência no tratamento de doenças coronarianas na região norte, realizando duas cirurgias cardíacas por dia, além de oferecer consultas, exames especializados e serviços complementares ao diagnóstico e tratamento dessas doenças. Possui 186 leitos, sendo 125 leitos destinados ao pós-operatório de cirurgia cardíaca, 15 leitos para UTI adulto, 25 leitos de pediatria e 21 de UTI infantil. Tem área total de $2.500 \mathrm{~m}^{2}$, distribuídos em três andares. Atualmente os serviços oferecidos à população são: consulta ambulatorial, radiografia, ecocardiograma, eletrocardiografia, eletroencefalografia, endoscopia diagnóstica, teste ergométrico, cateterismo diagnóstico, cateterismo terapêutico, eletrofisiologia diagnóstico, eletrofisiologia terapêutico, implante de marca-passo, arteriografia/angiografia, laboratório de análises clínicas, mamografia, ressonância magnética, ultrassonografia, tomografia 
computadorizada, medicina nuclear, cirurgia geral/ginecologia, neurocirurgia/embolização, cirurgia cardíaca, cirurgia vascular e internações.

O Hospital não oferece serviço de estomaterapia, sendo os curativos complexos e simples realizados pela equipe de enfermagem assistencial da unidade e descritos no prontuário dos pacientes. Até o momento, o hospital não possui protocolos de prevenção e tratamento de lesões agudas e crônicas.

\section{$\checkmark$ Hospital Universitário Getúlio Vargas (HUGV)}

O Hospital Getúlio Vargas foi inaugurado em 1965, por iniciativa do Governo Estadual do Amazonas. Em 4 de fevereiro de 1983, o hospital passou a ser reconhecido e denominado Hospital Universitário Getúlio Vargas (HUGV). Atualmente ocupa área de 17.298,48 m², com 15.998,48 m² de área construída, e conta com 186 leitos, (médio porte), dos quais 13 são de UTI. Possui as seguintes especialidades: clínica cirúrgica; clínica médica; psiquiatria; ortopedia; uti; neurologia; nefrologia. A equipe do hospital é composta de farmacêuticos, assistentes sociais, fisioterapeutas, bioquímicos, administradores, nutricionistas, enfermeiros, psicólogos, técnicos e auxiliares de enfermagem, agentes administrativos e auxiliares de serviços gerais e médicos.

Dentre as especialidades de enfermagem, o HUGV conta com o serviço do Grupo de Estudos em Feridas (GEFE), existente desde 2006, que atende pacientes com feridas agudas e crônicas internados no hospital. $\mathrm{O}$ enfermeiro responsável pelo GEFE é estomaterapeuta e conta com auxílio de uma enfermeira assistencial e uma técnica de enfermagem. A equipe do GEFE trabalha com tecnologia especializada para o tratamento de feridas bem como com produtos fitoterápicos e produtos manipulados por farmacêuticos do HUGV. Atualmente, é o único serviço da rede pública no Estado do Amazonas a oferecer esse tipo de serviço à comunidade amazonense. 


\section{$\checkmark$ Fundação Centro de Controle de Oncologia do Estado do Amazonas (FCECON)}

A Fundação Centro de Controle de Oncologia do Estado do Amazonas (FCECON) foi fundada em 1977, tendo a missão de formular e executar a política estadual de combate ao câncer. Atualmente é considerada como referência no tratamento da doença em toda a Amazônia Ocidental, com 110 leitos distribuídos da seguinte forma: leitos para internação (90); leitos de urgência e emergência (15) e leitos de UTI (5). Possui as seguintes especialidades: clínica cirúrgica, cabeça e pescoço; cirurgia torácica; cirurgia plástica; cirurgia geral; ginecologia; mastologia; neurocirurgia; oftalmologia; ortopedia; urologia; clínica médica: cirurgia vascular; cirurgia geral; cirurgia plástica; cirurgia torácica; cardiologia; dermatologia; ginecologia; nefrologia; oftalmologia; otorrinolaringologia; ortopedia; oncologia clínica; pediatria; pneumologia; urologia, oncologia: radioterapia; quimioterapia e hemoterapia. Serviços especializados: enfermagem; serviço social; odontologia; psicologia; fonoaudiologia; nutrição; fisioterapia. Endoscopia: gastroduodenoscopia; laringoscopia; cistoscopia; retossigmoidoscopia; broncoscopia; colonoscopia; histeroscopia e toracocentese. Anatomia patológica: histopatológica; citopatologia oncótica e esp.; imunohistoquímica. Análise clínica; imagenologia: radiologia; raio $\mathrm{X}$; raio $\mathrm{X}$ contrastado; tomografia computadorizada; mamografia; mamografia $\mathrm{cl}$ estereotaxia; eletrocardiograma; ultrassonografia e nefrostomia. A equipe do hospital é composta de médicos, farmacêuticos, assistentes sociais, fisioterapeutas, fonodiólogos, bioquímicos, administradores, nutricionistas, enfermeiros, psicólogos, técnicos e auxiliar de enfermagem, agentes administrativos e auxiliares de serviços gerais.

O Hospital possui uma Comissão de Cuidados com a Pele, composta de uma equipe de 30 enfermeiros. A enfermeira responsável pela Comissão de cuidados com a pele e um enfermeiro da equipe são estomaterapeutas. Atendem os pacientes internados com feridas agudas e crônicas no hospital. A comissão já possui implantados protocolos de tratamento e cuidados com lesões de pele. 


\section{$\checkmark$ Fundação Hospital Adriano Jorge}

A Fundação Hospital Adriano Jorge, instituição (estadual), tem como finalidade a assistência à saúde, ao ensino e à pesquisa, fundada em 1953 e inaugurada como sanatório pela Companhia Nacional contra a Tuberculose do Ministério da Saúde. Em 1979, passou a ser denominado Hospital Geral Adriano Jorge e, em 2003, tornou-se fundação por meio da Lei $n^{\circ} 2.847$. Atualmente, é considerado um centro especializado em tuberculose, traumato-ortopedia e clínica médica. Possui uma área construída de $16.208,48 \mathrm{~m}^{2}$, dividida em cinco blocos, nos quais se localizam os serviços de Atendimento Ambulatorial, Hospitalar, Apoio Diagnóstico, Fisioterapia e Administração Geral. É composta de 290 leitos, nas especialidades de Clínicas Cirúrgicas I e II, Médica, Ortopédica, Neurologia, Tisiologia e Unidade de Tratamento Intensivo, com média diária de mil atendimentos. É composta por 1.068 servidores efetivos e terceirizados, farmacêuticos, assistentes sociais, fisioterapeutas, médicos, bioquímicos, administradores, nutricionistas, enfermeiros, psicólogos, técnicos e auxiliares de enfermagem, agentes administrativos e auxiliares de serviços gerais.

O Hospital não oferece serviço de especializado de estomaterapia, sendo os curativos complexos e simples realizados pela equipe de enfermagem assistencial da unidade e descritos no prontuário dos pacientes. Até o momento, o hospital não possui protocolos de prevenção e tratamento de lesões agudas e crônicas.

A média de ocupação desses hospitais é um torno de mil pacientes por mês. Embora a média de ocupação desses hospitais seja alta, no período da coleta de dados, identificamos uma média de ocupação baixa, que deveu-se a fatores socioeconômicos que o Estado do Amazonas estava enfrentando, pois não havia medicamentos para a realização de cirurgias, acarretando um número grande de leitos vagos nesses hospitais. Esse fato comprometeu a amostra geral desse estudo, resultando em uma prevalência das feridas agudas e crônicas baixa, se comparadas com outros estudos nacionais e internacionais. 


\subsection{POPULAÇÃO/ AMOSTRA}

A população da pesquisa foi constituída por 829 pacientes que estavam internados nos sete hospitais do estudo, no período da coleta de dados. Destes, 775 atenderam aos critérios de inclusão e compuseram a amostra final.

\section{Critérios de inclusão:}

Ter idade maior ou igual a 18 anos; e

Aceitar participar da pesquisa.

Do total de 829 pacientes, internados no período de coleta de dados, 54 foram excluídos. Destes, quatro pacientes foram excluídos devido à idade inferior a 18 anos; 48 devido à recusa em participar da pesquisa e 2 devido ao óbito.

\subsection{VARIÁVEIS DO ESTUDO}

As variáveis dependentes e independentes do estudo apresentam-se listadas no Quadro 6, de acordo com cada lesão de pele.

Quadro 6 - Variáveis dependentes e independentes do estudo

\begin{tabular}{|c|c|c|}
\hline \multicolumn{2}{|c|}{ VARIÁVEIS DEPENDENTES } \\
\hline LF & $\begin{array}{c}\text { Variável nominal/ } \\
\text { categórica }\end{array}$ & Presente/Ausente \\
\hline DAI & $\begin{array}{c}\text { Variável nominal/ } \\
\text { categórica }\end{array}$ & Presente/ Ausente \\
\hline FOC & $\begin{array}{c}\text { Variável nominal/ } \\
\text { categórica } \\
\text { LP }\end{array}$ & $\begin{array}{c}\text { Variável nominal/ } \\
\text { categórica }\end{array}$ \\
\hline UD & $\begin{array}{c}\text { Variável nominal/ } \\
\text { categórica }\end{array}$ & Presente/ Ausente \\
\hline
\end{tabular}


Quadro 6 - Variáveis dependentes e independentes do estudo (continuação)

\begin{tabular}{|c|c|c|}
\hline \multicolumn{3}{|c|}{ VARIÁVEIS INDEPENDENTES } \\
\hline \multicolumn{3}{|c|}{ DEMOGRÁFICAS } \\
\hline Idade & Variável continua & Em anos \\
\hline Sexo & Variável nominal & Masculino/feminino \\
\hline Raça & Variável nominal & Branca/indígena/preta/ parda/amarela \\
\hline Situação conjugal & Variável nominal & Com companheiro/sem companheiro \\
\hline Escolaridade & Variável nominal & $\begin{array}{c}\text { Ensino fundamental; Ensino médio; Ensino } \\
\text { superior }\end{array}$ \\
\hline Situação atual de trabalho & Variável nominal & $\begin{array}{c}\text { Trabalhador formal; trabalhador informal; } \\
\text { desempregado; aposentado; } \\
\text { Afastado (licença médica) }\end{array}$ \\
\hline \multicolumn{3}{|c|}{ CLÍNICAS PARA LF } \\
\hline Diabetes Mellitu (DM) & Variável Nominal & Sim (Tipo I e II) /não \\
\hline Perfusão tissular alterada & Variável Nominal & Sim/Não \\
\hline Infarto Agudo do miocárdio & $\begin{array}{l}\text { Variável Nominal } \\
\text { Nominal }\end{array}$ & Sim/não \\
\hline Acidente vascular cerebral & Variável Nominal & Sim/não \\
\hline Distúrbio da tireoide & Variável Nominal & Sim/não \\
\hline Doença Pulmonar crônica & Variável Nominal & Sim/não \\
\hline Anti-Hipertensivo & Variável Nominal & Usa/Não usa \\
\hline Rigidez & Variável Nominal & Presente/Ausente \\
\hline Espasticidade & Variável Nominal & Presente/Ausente \\
\hline $\begin{array}{l}\text { Índice de massa corporal } \\
\text { (IMC) }\end{array}$ & $\begin{array}{l}\text { Variável Numérica } \\
\text { Intervalar }\end{array}$ & $<18,4 ; 18,5-24,9 ; 25-30 ;>30$ \\
\hline Presença de equimose & Variável Nominal & Presente/Ausente \\
\hline Presença de hematomas & Variável Nominal & Presente/Ausente \\
\hline $\begin{array}{l}\text { Fitas e curativos adesivos na } \\
\text { pele }\end{array}$ & Variável Nominal & Presente/Ausente \\
\hline $\begin{array}{l}\text { Intensidade da dor no local da } \\
\text { lesão }\end{array}$ & Variável Ordinal & $\begin{array}{l}0 \text { (Ausência de dor); } 1 \text { a } 3 \text { (dor de baixa } \\
\text { intensidade); } 4 \text { A } 6 \text { (dor de moderada } \\
\text { intensidade com demanda relativa de } \\
\text { analgésico); } 7 \text { a } 9 \text { (dor de forte intensidade } \\
\text { com demanda de analgésico);10 (dor de } \\
\text { intensidade insuportável com demanda de } \\
\text { analgésico em horários específicos). }\end{array}$ \\
\hline Percepção Sensorial & Variável Ordinal & $\begin{array}{l}\text { 1. Totalmente limitado;2. Muito limitado;3. } \\
\text { Levemente limitado;4. Nenhuma limitação }\end{array}$ \\
\hline Umidade & Variável Ordinal & $\begin{array}{l}\text { 1.Completamente molhada; } 2 \text {. Muito } \\
\text { molhada; } 3 \text {. Ocasionalmente molhada; } 4 . \\
\text { Raramente molhada. }\end{array}$ \\
\hline Atividade & Variável Ordinal & $\begin{array}{l}\text { 1.Acamado;2. Confinado a cadeira;3. Anda } \\
\text { ocasionalmente; } 4 \text {. Anda frequentemente. }\end{array}$ \\
\hline
\end{tabular}


Quadro 6 - Variáveis dependentes e independentes do estudo (continuação)

\begin{tabular}{|c|c|c|}
\hline Mobilidade & Variável Ordinal & $\begin{array}{l}\text { 1.Totalmente Imóvel;2 Bastante limitado;3 } \\
\text { Levemente limitado; } 4 \text { Não apresenta } \\
\text { limitações }\end{array}$ \\
\hline Fricção/cisalhamento & Variável Ordinal & $\begin{array}{l}\text { 1.Problema;2 Problema em potencial;3 } \\
\text { Nenhum problema }\end{array}$ \\
\hline Escala de Braden & $\begin{array}{l}\text { Variável Numérica } \\
\text { Intervalar }\end{array}$ & Escore de 6 a 23 \\
\hline \multicolumn{3}{|c|}{ CLÍNICAS PARA DAI } \\
\hline Incontinência urinária & Variável Nominal & Sim/Não \\
\hline Incontinência fecal/anal & Variável Nominal & Sim/Não \\
\hline Diabetes Mellitus (DM) & Variável Nominal & Sim (Tipo I e II) /não \\
\hline Anti-Hipertensivo & Variável Nominal & Usa/Não usa \\
\hline Antibióticos & Variável Nominal & Usa/Não usa \\
\hline Uso de fralda descartável & Variável Nominal & Usa/Não usa \\
\hline Portador de colostomia & Variável Nominal & Sim/não \\
\hline Portador de ileostomia & Variável Nominal & Sim/não \\
\hline $\begin{array}{l}\text { Cateter vesical de demora } \\
\text { (CVD) }\end{array}$ & Variável Nominal & Presente/ausente \\
\hline $\begin{array}{l}\text { Índice de massa corporal } \\
\text { (IMC) }\end{array}$ & $\begin{array}{l}\text { Variável Numérica } \\
\text { Intervalar }\end{array}$ & $<18,4 ; 18,5-24,9 ; 25-30 ;>30$ \\
\hline $\begin{array}{l}\text { Intensidade da dor no local da } \\
\text { lesão }\end{array}$ & Variável Ordinal & $\begin{array}{l}0 \text { (Ausência de dor); } 1 \text { a } 3 \text { (dor de baixa } \\
\text { intensidade); } 4 \text { a } 6 \text { (dor de moderada } \\
\text { intensidade com demanda relativa de } \\
\text { analgésico); } 7 \text { a } 9 \text { (dor de forte intensidade } \\
\text { com demanda de analgésico);10 (dor de } \\
\text { intensidade insuportável com demanda de } \\
\text { analgésico em horários específicos). }\end{array}$ \\
\hline Uso de sabonete liquido & Variável Nominal & Usa/Não usa \\
\hline $\begin{array}{l}\text { Uso de sabonete/sabão em } \\
\text { barra }\end{array}$ & Variável Nominal & Usa/Não usa \\
\hline Uso de emoliente para a pele & Variável Nominal & Usa/Não usa \\
\hline Percepção Sensorial & Variável Ordinal & $\begin{array}{l}\text { 1.Totalmente limitado;2 Muito limitado;3. } \\
\text { Levemente limitado;4. Nenhuma limitação }\end{array}$ \\
\hline Rigidez & Variável Nominal & Presente/Ausente \\
\hline Espasticidade & Variável Nominal & Presente/Ausente \\
\hline Umidade & Variável Ordinal & $\begin{array}{l}\text { 1.Completamente molhada; } 2 \text {. Muito } \\
\text { molhada; } 3 \text {. Ocasionalmente molhada; } 4 . \\
\text { Raramente molhada. }\end{array}$ \\
\hline
\end{tabular}


Quadro 6 - Variáveis dependentes e independentes do estudo (continuação)

\begin{tabular}{|c|c|c|}
\hline Atividade & Variável Ordinal & $\begin{array}{l}\text { 1.Acamado;2 Confinado a cadeira;3. Anda } \\
\text { ocasionalmente; } 4 \text { Anda frequentemente. }\end{array}$ \\
\hline Mobilidade & Variável Ordinal & $\begin{array}{l}\text { 1.Totalmente imóvel;2 Bastante limitado;3 } \\
\text { Levemente limitado; } 4 \text { Não apresenta } \\
\text { limitações }\end{array}$ \\
\hline Fricção/cisalhamento & Variável Ordinal & $\begin{array}{l}\text { 1.Problema;2 Problema em potencial; } 3 \\
\text { Nenhum problema }\end{array}$ \\
\hline Escala de Braden & $\begin{array}{l}\text { Variável Numérica } \\
\text { Intervalar }\end{array}$ & Escore de 6 a 23 \\
\hline \multicolumn{3}{|c|}{ CLÍNICAS PARA FOC } \\
\hline Tabagista & Variável nominal & Fumante/ não fumante/ex-fumante \\
\hline Diabetes Mellitus (DM) & Variável Nominal & Sim (Tipo I e II) /não \\
\hline $\begin{array}{l}\text { Hipertensão Arterial Sistêmica } \\
\text { (HAS) }\end{array}$ & Variável Nominal & Sim/Não \\
\hline $\begin{array}{l}\text { Cateter vesical de demora } \\
\text { (CVD) }\end{array}$ & Variável Nominal & Presente/ ausente \\
\hline $\begin{array}{l}\text { Drenos (kehr; Penrose; } \\
\text { PortoVac) }\end{array}$ & Variável Nominal & Presente/ ausente \\
\hline $\begin{array}{l}\text { Índice de massa corporal } \\
\text { (IMC) }\end{array}$ & $\begin{array}{l}\text { Variável Numérica } \\
\text { Intervalar }\end{array}$ & $<18,4 ; 18,5-24,9 ; 25-30 ;>30$ \\
\hline $\begin{array}{l}\text { Intensidade da dor no local da } \\
\text { lesão }\end{array}$ & Variável Ordinal & $\begin{array}{l}0 \text { (Ausência de dor); } 1 \text { a } 3 \text { (dor de baixa } \\
\text { intensidade); } 4 \text { A } 6 \text { (dor de moderada } \\
\text { intensidade com demanda relativa de } \\
\text { analgésico); } 7 \text { a } 9 \text { (dor de forte intensidade } \\
\text { com demanda de analgésico); } 10 \text { (dor de } \\
\text { intensidade insuportável com demanda de } \\
\text { analgésico em horários específicos). }\end{array}$ \\
\hline Classificação da cirurgia & Variável nominal & Eletiva/ urgência /emergência \\
\hline $\begin{array}{l}\text { Uso de antibiótico para } \\
\text { prevenção de infecção }\end{array}$ & Variável Nominal & Sim/Não \\
\hline Uso de anti-inflamatório & Variável Nominal & Sim/Não \\
\hline Uso de anti-anticoagulante & Variável Nominal & Sim/Não \\
\hline Uso de esteróides & Variável Nominal & Sim/Não \\
\hline Rigidez & Variável Nominal & Presente/Ausente \\
\hline Espasticidade & Variável Nominal & Presente/Ausente \\
\hline Percepção Sensorial & Variável Ordinal & $\begin{array}{l}\text { 1.Totalmente limitado;2.Muito } \\
\text { limitado;3.Levemente limitado;4.Nenhuma } \\
\text { limitação }\end{array}$ \\
\hline Umidade & Variável Ordinal & $\begin{array}{l}\text { 1.Completamente molhada; } 2 \text {. Muito } \\
\text { molhada; } 3 \text {. Ocasionalmente molhada; } 4 . \\
\text { Raramente molhada. }\end{array}$ \\
\hline Atividade & Variável Ordinal & $\begin{array}{l}\text { 1.Acamado;2 Confinado a cadeira;3. Anda } \\
\text { ocasionalmente;4 Anda frequentemente. }\end{array}$ \\
\hline Mobilidade & Variável Ordinal & $\begin{array}{l}\text { 1.Totalmente Imóvel;2 Bastante limitado;3 } \\
\text { Levemente limitado; } 4 \text { Não apresenta } \\
\text { limitações }\end{array}$ \\
\hline
\end{tabular}


Quadro 6 - Variáveis dependentes e independentes do estudo (continuação)

\begin{tabular}{|c|c|c|}
\hline Fricção/cisalhamento & Variável Ordinal & $\begin{array}{l}\text { 1.Problema;2 Problema em potencial;3 } \\
\text { Nenhum problema }\end{array}$ \\
\hline Escala de Braden & $\begin{array}{l}\text { Variável Numérica } \\
\text { Intervalar }\end{array}$ & Escore de 6 a 23 \\
\hline \multicolumn{3}{|c|}{ CLÍNICAS PARA LP } \\
\hline Tabagismo & Variável nominal & Fumante/ não fumante/ex-fumante \\
\hline Diabetes Mellitus (DM) & Variável Nominal & Sim (Tipo I e II) /não \\
\hline $\begin{array}{l}\text { Hipertensão Arterial Sistêmica } \\
\text { (HAS) }\end{array}$ & Variável Nominal & Sim/Não \\
\hline Incontinência urinária & Variável Nominal & Sim/Não \\
\hline Incontinência fecal/anal & Variável Nominal & Sim/Não \\
\hline Insuficiência arterial periférica & Variável Nominal & Sim/Não \\
\hline Insuficiência venosa periférica & Variável Nominal & Sim/Não \\
\hline Perfusão tissular alterada & Variável Nominal & Sim/Não \\
\hline $\begin{array}{l}\text { Índice de massa corporal } \\
\text { (IMC) }\end{array}$ & $\begin{array}{l}\text { Variável Numérica } \\
\text { Intervalar }\end{array}$ & $<18,4 ; 18,5-24,9 ; 25-30 ;>30$ \\
\hline $\begin{array}{l}\text { Intensidade da dor no local da } \\
\text { lesão }\end{array}$ & Variável Ordinal & $\begin{array}{l}0 \text { (Ausência de dor); } 1 \text { a } 3 \text { (dor de baixa } \\
\text { intensidade); } 4 \text { A } 6 \text { (dor de moderada } \\
\text { intensidade com demanda relativa de } \\
\text { analgésico); } 7 \text { a } 9 \text { (dor de forte intensidade } \\
\text { com demanda de analgésico);10 (dor de } \\
\text { intensidade insuportável com demanda de } \\
\text { analgésico em horários específicos). }\end{array}$ \\
\hline Edema nos MMII & Variável Nominal & Presente/Ausente \\
\hline Edema nos MMSS & Variável Nominal & Presente/Ausente \\
\hline Rigidez & Variável Nominal & Presente/Ausente \\
\hline Espasticidade & Variável Nominal & Presente/Ausente \\
\hline Percepção Sensorial & Variável Ordinal & $\begin{array}{l}\text { 1.Totalmente limitado;2.Muito } \\
\text { limitado;3.Levemente limitado; } 4 \text {.Nenhuma } \\
\text { limitação }\end{array}$ \\
\hline Umidade & Variável Ordinal & $\begin{array}{l}\text { 1. Completamente molhada; } 2 \text {. Muito } \\
\text { molhada; } 3 \text {. Ocasionalmente molhada; } 4 . \\
\text { Raramente molhada. }\end{array}$ \\
\hline Atividade & Variável Ordinal & $\begin{array}{l}\text { 1.Acamado;2.Confinado a } \\
\text { cadeira;3.Andaocasionalmente; } 4 \text {.Anda } \\
\text { frequentemente. }\end{array}$ \\
\hline Mobilidade & Variável Ordinal & $\begin{array}{l}\text { 1.Totalmente Imóvel;2. Bastante } \\
\text { limitado;3.Levemente limitado; } 4 \text {.Não } \\
\text { apresenta limitações }\end{array}$ \\
\hline Fricção/cisalhamento & Variável Ordinal & $\begin{array}{l}\text { 1.Problema;2 Problema em } \\
\text { potencial;3.Nenhum problema }\end{array}$ \\
\hline Escala de Braden & $\begin{array}{l}\text { Variável Numérica } \\
\text { Intervalar }\end{array}$ & Escore de 6 a 23 \\
\hline
\end{tabular}


Quadro 6 - Variáveis dependentes e independentes do estudo (conclusão)

\begin{tabular}{|c|c|c|}
\hline \multicolumn{3}{|c|}{ CLINICAS PARA UD } \\
\hline Etilista & Variável nominal & Etilista/não etilista/ex-etilista \\
\hline Tabagista & Variável nominal & Fumante/ não fumante/ex-fumante \\
\hline Diabetes Mellitus (DM) & Variável Nominal & Sim (Tipo I e II) /não \\
\hline $\begin{array}{l}\text { Hipertensão Arterial Sistêmica } \\
\text { (HAS) }\end{array}$ & Variável Nominal & Sim/Não \\
\hline Acidente vascular cerebral & Variável Nominal & Sim/Não \\
\hline Doença Vascular Periférica & Variável Nominal & Sim/Não \\
\hline $\begin{array}{l}\text { Índice de massa corporal } \\
\text { (IMC) }\end{array}$ & $\begin{array}{l}\text { Variável Numérica } \\
\text { Intervalar }\end{array}$ & $<18,4 ; 18,5-24,9 ; 25-30 ;>30$ \\
\hline $\begin{array}{l}\text { Intensidade da dor no local da } \\
\text { lesão }\end{array}$ & Variável Ordinal & $\begin{array}{l}0 \text { (Ausência de dor); } 1 \text { a } 3 \text { (dor de baixa } \\
\text { intensidade); } 4 \text { A } 6 \text { (dor de moderada } \\
\text { intensidade com demanda relativa de } \\
\text { analgésico); } 7 \text { a } 9 \text { (dor de forte intensidade } \\
\text { com demanda de analgésico);10 (dor de } \\
\text { intensidade insuportável com demanda de } \\
\text { analgésico em horários específicos). }\end{array}$ \\
\hline Nível de glicemia em jejum & Variável Nominal & $\begin{array}{l}\text { PARÂMETRO*: } \\
\text { Glicemia normal: Em jejum: }<100 ; 2 \mathrm{~h} \text { após } \\
75 \mathrm{~g} \text { de glicose: }<140 \text {. Pacientes diabéticos: } \\
\text { Jejum: } \geq 126 ; 2 \mathrm{~h} \text { após } 75 \mathrm{~g} \text { de glicose: } \geq \\
\text { 200. (Normal/ Alterada/dado ausente) }\end{array}$ \\
\hline Uso de calçado ortopédico & Variável Nominal & Usa/Não usa \\
\hline Rigidez & Variável Nominal & Presente/Ausente \\
\hline Espasticidade & Variável Nominal & Presente/Ausente \\
\hline Percepção Sensorial & Variável Ordinal & $\begin{array}{l}\text { 1.Totalmente limitado;2.Muito } \\
\text { limitado;3.Levemente limitado; } 4 \text {.Nenhuma } \\
\text { limitação }\end{array}$ \\
\hline Umidade & Variável Ordinal & $\begin{array}{l}\text { 1.Completamente molhada; } 2 \text {. Muito } \\
\text { molhada; } 3 \text {. Ocasionalmente molhada; } 4 . \\
\text { Raramente molhada. }\end{array}$ \\
\hline Atividade & Variável Ordinal & $\begin{array}{l}\text { 1.Acamado;2.Confinado a } \\
\text { cadeira;3.Andaocasionalmente; } 4 \text {.Anda } \\
\text { frequentemente. }\end{array}$ \\
\hline Mobilidade & Variável Ordinal & $\begin{array}{l}\text { 1.Totalmente Imóvel;2. Bastante } \\
\text { limitado;3.Levemente limitado; } 4 \text {.Não } \\
\text { apresenta limitações }\end{array}$ \\
\hline Fricção/cisalhamento & Variável Ordinal & $\begin{array}{l}\text { 1.Problema;2 Problema em } \\
\text { potencial;3.Nenhum problema }\end{array}$ \\
\hline Escala de Braden & $\begin{array}{l}\text { Variável Numérica } \\
\text { Intervalar }\end{array}$ & Escore de 6 a 23 \\
\hline
\end{tabular}

*Diretrizes da Sociedade Brasileira de Diabetes: 2015-2016/Sociedade Brasileira de Diabetes; [organização José Egidio Paulo de Oliveira, Sérgio Vencio]. - São Paulo: AC Farmacêutica, 2016. 


\subsection{COLETA DE DADOS}

Após a autorização do estudo pela SUSAM, instituições hospitalares da capital amazonense e CEP, a pesquisadora procedeu à coleta de dados junto a todos os pacientes internados nas instituições hospitalares descritas, que atenderam os critérios de inclusão, no período de março a junho de 2015. Todo o processo da coleta de dados consta na Figura 2.

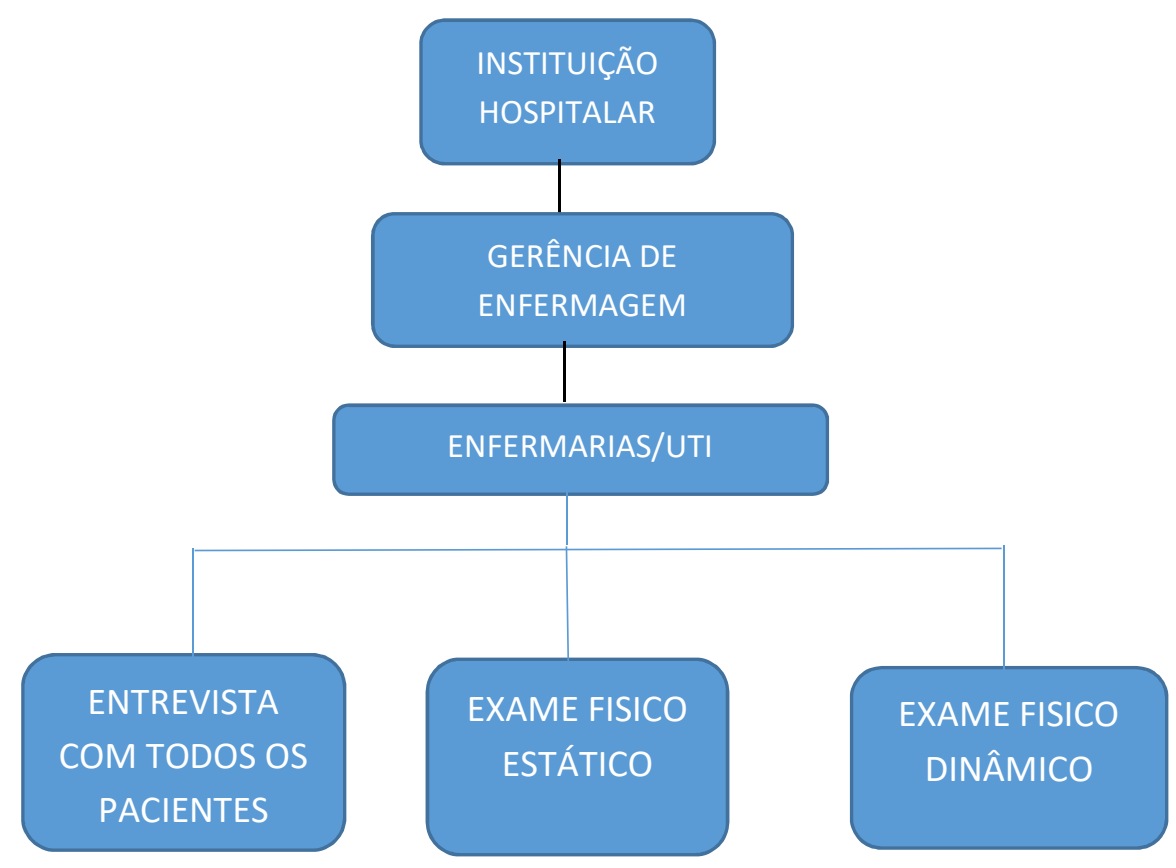

Figura 2 - Fluxograma da coleta de dados

\subsubsection{Procedimentos para a coleta de dados}

\subsubsection{Dados Gerais}

A coleta de dados foi realizada da seguinte maneira (Figura 2):

- Primeiramente foi solicitado a autorização aos gerentes de enfermagem de cada instituição do estudo, para fazer a coleta de dados com os pacientes internados nas enfermarias, onde informamos o conteúdo da pesquisa e apresentamos os termos de anuência e aprovação do CEP. Após 
os devidos esclarecimentos, nos encaminhamos para as enfermarias começando a coleta sempre pelo último andar do hospital ao térreo.

A abordagem aos pacientes foi feita na enfermaria, esclarecendo os objetivos do estudo e orientando para que assinassem o TCLE, caso concordassem em participar da pesquisa. Logo após, os pacientes foram abordados por meio de entrevista, questionando-se sobre os dados sociodemográficos. Na impossibilidade do paciente responder à entrevista, seu cuidador (formal ou informal) foi solicitado a fazê-lo. Nos casos dos pacientes da UTI, impossibilitados de responder, seus acompanhantes foram consultados na hora da visita no período da tarde, sobre a pesquisa.

Após a entrevista, no período da manhã, com a ajuda da equipe de enfermagem, todos os pacientes foram submetidos ao exame físico estático (para inspeção e palpação da pele) e dinâmico (para avaliação de rigidez, espasticidade e mobilidade física).

As informações relacionadas às características clínicas foram obtidas nos prontuários dos pacientes, no período da tarde como: os medicamentos em uso; hábitos; doenças pré-existentes e exames laboratoriais. Para estes últimos, adotaram-se os padrões de normalidade estabelecidos pelos laboratórios das instituições hospitalares.

Ao exame físico estático (para inspeção e palpação da pele): os pacientes foram examinados durante o banho no leito, no caso dos pacientes acamados, obedecendo-se o sentido céfalo-caudal, sendo inspecionadas as regiões da cabeça, tórax (frontal e dorsal), abdome, genitais (glúteos), membros superiores e inferiores. Os pacientes deambulantes, foram examinados obedecendo o mesmo sentido céfalocaudal e anteroposterior, também nas enfermarias, e no leito, com a proteção de biombo e exposição por parte das regiões do corpo.

Ao ser identificada qualquer lesão de pele, dentre os tipos aqui investigados, a mesma foi examinada quanto a: localização, classificação, tipo de tecido no leito da lesão, quantidade de exsudato e mensuração. A presença e características da lesão foram, então, registradas no prontuário 
do paciente e notificadas à equipe de enfermagem da unidade para os devidos cuidados.

\subsubsection{Exame físico estático}

- Exame físico da pele (inspeção e palpação)

$\mathrm{Na}$ inspeção e palpação da pele, buscaram-se as feridas previamente selecionadas (LF, DAI, FOC, LP e UD), conforme descrição a seguir:

a) LF

Desde a avaliação do risco para o desenvolvimento de LF, a pele foi avaliada quanto à presença de púrpura senil; pele seca e descamativa; equimoses e hematomas; coloração de características escura, pálida e opaca; além de edema nos membros superiores e inferiores. Durante o exame físico, checou-se ainda o uso de fitas e curativos adesivos na pele. As LF foram classificadas de acordo com o Sistema de Classificação STAR - Lesão por Fricção (ANEXO 9) (STRAZZIERI-PULIDO; SANTOS; CARVILLE, 2015).

\section{b) DAI}

No exame físico da pele, também foram verificadas as condições que poderiam indicar a presença da DAl: hiperemia, eritema, descamação na área da região perineal, vulva, grandes lábios, virilha, região glútea e o escroto; lesões ulcerativas e pústulas; lesões eritematosas associadas ao edema. É comum que essas lesões estejam infectadas com Candida albicans e/ou Staphylococcus aureus, podendo apresentar-se com eritema e lesões satélites pápulo-pustulosas.

Ao ser detectada a lesão, o paciente foi avaliado de acordo com a Incontinence Associated Dermatitis Intervention Tool (IAD-IT) - Consenso Internacional sobre DAI (2012) (ANEXO 10), que permite a classificação dessas lesões em: DAl precoce (early IAD); DAl moderada (moderate IAD); DAl grave (severe $I A D$ ) e fúngica - rash cutâneo aparente (fungal appearing rash). 


\section{c) $\mathrm{FOC}$}

A inspeção da pele do paciente com FOC visou à busca de sinais e sintomas de sangramento, hematoma e infecção (dor ou hipersensibilidade no local, edema, hiperemia, eritema, elevação da temperatura, secreção purulenta) no local da ferida operatória e pele periferida (DEALEY, 2008). Em caso de suspeita de fístulas, constatou-se o extravasamento de fluido do local da ferida operatória.

Para os casos de deiscência no sitio cirúrgico, avaliou-se ainda a presença de febre (temperatura axilar superior a $37,8^{\circ} \mathrm{C}$ ), dor ou hipersensibilidade no local operado (DEALEY, 2008; MAIA, 2006).

Tendo em vista que as lesões dos tipos FOC não contam com classificações específicas, foram avaliadas utilizando-se o Pressure Ulcer Scale for Healing - PUSH pernas (SANTOS; SELLMER; MASSULO, 2007) (ANEXO 11).

d) LP

Para avaliação das LP, a inspeção da pele foi feita à procura dos seguintes sinais de seu desenvolvimento: eritema persistente que não embranquece, bolhas, descoloração, áreas localizadas de calor e edema (NPUAP, 2014). Além disso, foram avaliados outros parâmetros como a consistência do tecido (rijo ou mole) e a sensibilidade (dor ou prurido), sempre comparados às características da pele adjacente à área suspeita ou nas regiões opostas do corpo (NPUAP, 2014).

Para detectar a presença do eritema persistente e que não embranquece foi utilizado o método de pressão digital sobre a área suspeita (NPUAP, 2014), que consiste na aplicação de pressão ligeira com o dedo na área avermelhada que embranquece desde que a microcirculação esteja intacta, indicando ausência de dano tissular. Quando isso não ocorreu e houve suspeita de LP estágio 1, procedeu-se ao afastamento da pressão sobre a área durante 30 minutos, após o que se utilizou o mesmo procedimento de pressão digital (NPUAP, 2014). 
Embora a coleta de dados tenha ocorrido em 2015 e, portanto, tenha se utilizado a classificação do NPUAP/ EPUAP (2014) (NPUAP, 2014), tendo em vista que suas descrições são similares, exceto por algumas pequenas mudanças em suas denominações e pela inclusão de duas outras categorias (Lesão por Pressão Relacionada a Dispositivo Médico e Lesão por Pressão em Membranas Mucosas), neste relatório utilizou-se a classificação mais recente (NPUAP, 2016) para os estágios de 1 a 4, Lesão por Pressão Não Classificável e Lesão por Pressão Tissular Profunda. Reitera-se que, na classificação de 2014, essas duas últimas categorias denominavam-se: Úlceras que não podem ser Classificadas e Suspeita de Lesão Tissular Profunda, respectivamente.

As características da LP foram avaliadas por meio do Pressure Ulcer Scale for Healing - PUSH UP (ANEXO 11) (SANTOS et al., 2005).

Para a avaliação do risco de desenvolvimento de LP, foi utilizada a EB (ANEXO 12); e para a interpretação dos resultados, adotaram-se os seguintes níveis de risco: em risco (escores 15 a 18); risco moderado (escores 13 e 14); alto risco (escores 10 a 12) e risco muito alto (escores $\leq$ 9) (AYELLO; BRADEN, 2002; SERPA et al., 2014).

\section{e) UD}

O exame físico do paciente com UD foi feito por meio de inspeção da pele dos pés à procura de sintomas como: pele ressecada, rachaduras, fissuras, calos, aumento da temperatura, edema, palidez dos pés à elevação, rubor postural, ulceração, necrose da pele e gangrena. Além disso, realizou-se a palpação dos pulsos das artérias tibiais posteriores e pediosas dorsais (Diretrizes da Sociedade Brasileira de Diabetes, 20152016).

A fim de detectar deformidades nos pés (calos) e pontos de pressão na região plantar, foi feita a inspeção dos calçados. A presença de deformações e desgastes irregulares nos solados denota a presença de alteração na biomecânica da marcha (Diretrizes da Sociedade Brasileira de Diabetes, 2015-2016). 
O teste de neuropatia periférica, que detecta as alterações de fibra grossa e sensibilidade protetora plantar, não foi realizado neste estudo devido não ser rotina nas instituições hospitalares da região bem como pela falta de financiamento para aquisição do material e realização do exame.

\section{- Avaliação do edema}

O edema foi avaliado utilizando-se a seguinte técnica: (AZOUBEL et al., 2010).

- com a polpa digital do polegar ou do indicador, fez-se uma compressão firme e sustentada de encontro a uma estrutura rígida, subjacente à área em exame; $\mathrm{e}$

$>$ avaliou-se a profundidade do cacifo (fóvea) formado a partir da pressão do dedo sobre os tecidos contra a estrutura óssea. Quanto mais profundo o cacifo (depressão), maior o número de cruzes do edema (Quadro 7).

Quadro 7 - Classificação do edema

\begin{tabular}{|l|l|}
\hline$>0 / 4+$ & sem edema \\
\hline$>1+/ 4+$ & leve cacifo, até $2 \mathrm{~mm}$ \\
\hline$>2+/ 4+$ & cacifo $<5 \mathrm{~mm}$, mas com pé e perna com contornos definidos \\
\hline$>3+/ 4+$ & cacifo entre 5 e $10 \mathrm{~mm}$, acompanhado por pé e perna edemaciados. \\
\hline$>4+/ 4+\quad$ cacifo $>1 \mathrm{~cm}$ acompanhado por edema severo da perna e pé \\
$>$ Esta avaliação não se aplica em caso de edema duro (linfedema). \\
\hline
\end{tabular}

Fonte: AZOUBEL, R.; TORRES, G.V.; SILVA, L.W.S.; GOMES, F.V.; REIS, L.A. Rev. Esc. Enferm. USP. 2010. 44(4):1085-92.

\section{- Avaliação da Intensidade da dor}

Para avaliação da intensidade da dor, utilizou-se a escala analógica visual, que foi aplicada, antes, durante e após o curativo. Essa consiste em uma linha reta, de $10 \mathrm{~cm}$, que varia de 0 a 10, sendo zero a ausência de dor e 10, a maior intensidade de dor. (Quadro 8) (CARVALHO; KOWACS, 2006). 
Quadro 8 - Classificação da dor

ZERO (0) = AUSÊNCIA DE DOR

UM A TRÊS (1 A 3) = DOR DE BAIXA INTENSIDADE

QUATRO A SEIS (4 A 6) = DOR DE MODERADA INTENSIDADE COM DEMANDA RELATIVA DE ANALGÉSICO

SETE A NOVE (7 A 9) = DOR DE FORTE INTENSIDADE COM DEMANDA DE ANALGÉSICO

DEZ (10) = DOR DE INTENSIDADE INSUPORTÁVEL COM DEMANDA DE ANALGÉSICO EM HORÁRIOS ESPECÍFICOS.

Fonte: CARVALHO DS, KOWACS PA. Avaliação da intensidade de dor. Rev. Migrâneas Cefaléias. 2006;9(4):164-8

Assim, foi questionado ao paciente antes, durante e após o curativo a intensidade de dor que ele estava sentindo no momento de acordo com a escala. Para os pacientes que não podiam responder por estarem entubados, com diminuição do nível de consciência, internados nas UTI, não foi possível realizar esta avaliação.

\section{- Peso e Altura}

Quanto ao peso e altura, foram coletados através dos registros contidos nos prontuários do paciente. No caso da ausência dessas informações, o peso dos pacientes foi verificado com auxílio de uma balança digital (marca G. Life Slim), devidamente calibrada.

Primeiramente os pacientes foram orientados a ficar descalços e, em seguida, subir na balança de forma ereta e pés juntos. Para os pacientes impossibilitados de ficar em posição ortostática, foi feita uma estimativa do peso corporal utilizando a fórmula de predição do peso corporal (Quadro 9), calculando-se a medida altura do joelho, circunferência do braço, prega cutânea subescapular e da circunferência da panturrilha descritas a seguir (CAMPOS et al., 2012):

- Medida da altura do joelho: esta foi obtida com o paciente deitado e com a perna dobrada em um ângulo de $90^{\circ}$. Uma régua com escalas foi posicionada do calcanhar à superfície anterior da coxa, próximo à patela.

- Medida da circunferência do braço: esta foi aferida no ponto médio entre o processo acrômio da escápula e o olecrano, determinado com 
o auxílio de uma fita métrica flexível e inelástica. No momento da medida, os membros superiores ficaram posicionados paralelamente ao tronco do paciente.

- Medida da prega cutânea subescapular: para essa medida, foi utilizado um adipômetro Harpenden $®$. A pele foi levantada em $1 \mathrm{~cm}$, no ponto abaixo do ângulo inferior da escápula, com o braço e o ombro do paciente relaxados. A prega deve ficar paralela às linhas naturais da pele, ou seja, posicionada a $45^{\circ}$ do plano horizontal, que se estende medial e cranialmente.

- Medida da circunferência da panturrilha: A fita inelástica é colocada ao redor da panturrilha (circunferência máxima no plano perpendicular a linha longitudinal da panturrilha). A fita métrica deve passar em toda a extensão da panturrilha, sem fazer compressão. 0 valor zero da fita é colocado abaixo do valor medido.

\section{Quadro 9 - Fórmula de predição do peso corporal}

\section{Mulher:}

$(1,27 \times \mathrm{CP})+(0,87 \times$ comprimento da perna $)+(0,98 \times \mathrm{CB})+(0,4 \times \mathrm{DCSE})-62,35$

\section{Homem:}

$(0,98 \times \mathrm{CP})+(1,16 \times$ comprimento da perna $)+(1,73 \times \mathrm{CB})+(0,37 \times \mathrm{DCSE})-81,69$

$\mathrm{CP}=$ circunferência da panturrilha, $\mathrm{CB}=$ circunferência do braço e $\mathrm{DCSE}=$ dobra cutânea subescapular.

Fonte: CAMPOS, J.A.D.B.; PRADO, C.D.; PINELLI, C.; GARCIA, P.P.N.S. Alim. Nutr., Araraquara. v. 23, n. 4, p.681-688, 2012.

Para a avaliação da altura, os pacientes foram orientados a ficar em posição ortostática sobre o chão, descalços e de pés juntos, encostados à parede onde foi feita a verificação da altura por meio de uma régua na cabeça (BARROS, 2015).

Nos casos de pacientes acamados, empregaram-se fita métrica e régua, com a verificação sendo feita no leito hospitalar. A medida foi feita em 
duas etapas. Inicialmente, a fita foi colocada na cabeça onde, com a régua, delimitou-se o início da marcação da altura, finalizada na parte mais distal da região sacrococcígea, servindo de limite para a medida posterior. Posteriormente, a fita métrica foi colocada da coxa até o joelho e do joelho descendo pela parte posterior da perna até o calcâneo, obtendo-se assim a avaliação final da altura (BARROS, 2015).

\section{- Estado Nutricional}

Para a avaliação do estado nutricional dos pacientes, foi utilizado o Índice de Massa Corporal (IMC) com base na fórmula IMC= (Peso/Altura $)^{2}$. Sua classificação seguiu os intervalos estabelecidos pela Organização Mundial de Saúde para adultos (OMS 2013): <18,4 baixo peso; 18,5 -24,9 peso normal; 25 -30 sobrepeso e $>30$ obeso (Figura 2).

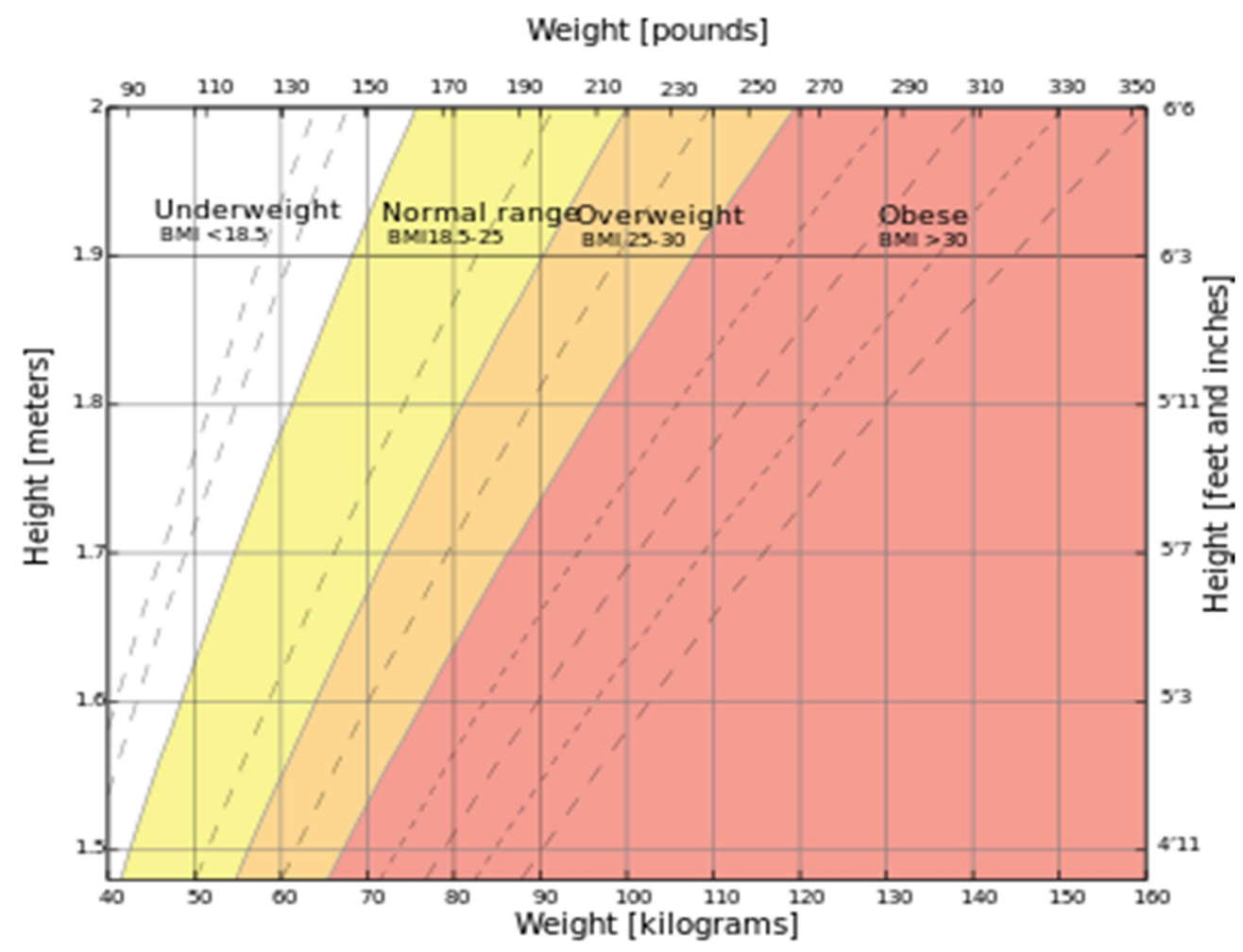

Figura 3 - Classificação do IMC adulto, segundo a Organização Mundial de Saúde

Fonte: World Health Organization. BMI. Classification. Global Database on Body Mass index: World Health Organization, 2013. Disponível em http://www.who.int/en/,2014. 


\subsubsection{Exame físico dinâmico}

Após o exame físico estático, prosseguiu-se com o exame físico dinâmico para avaliação de outras condições como a espasticidade, a rigidez e a mobilidade física.

$\mathrm{Na}$ avaliação da espasticidade, foram realizados movimentos passivos e rápidos como flexão e extensão das articulações dos membros inferiores e superiores do paciente. A presença de espasticidade foi confirmada nos casos de aumento da resistência no início do movimento e posterior diminuição da resistência ao longo de toda a execução do movimento. Este é conhecido como sinal do canivete (BARROS, 2015). Neste estudo, avaliou-se somente presença e ausência de espasticidade.

Quanto à rigidez, foram realizados movimentos nas articulações dos membros inferiores e superiores de forma passiva e lenta do paciente. A presença de rigidez foi confirmada na presença de resistência, durante a realização de todo o movimento, ao flexionar ou estender um membro. Este é conhecido como sinal de cano de chumbo (BARROS, 2015). Neste estudo, avaliou-se somente presença e ausência de rigidez.

A mobilidade física foi avaliada segundo os itens da Escala de Braden: totalmente imóvel; bastante limitado; levemente limitado e não apresenta limitações (PARANHOS; SANTOS, 1999).

\subsubsection{Instrumentos para a coleta de dados}

Seis instrumentos foram empregados para a coleta dos dados no presente estudo: Dados sociodemográficos e clínicos; Escala de Braden para avaliação do risco de desenvolvimento de LP (PARANHOS; SANTOS, 1999); Classificação STAR para LF (STRAZZIERI-PULIDO; SANTOS, 2011); IAD-IT (Incontinence Associated Dermatitis Intervention Tool) - para DAI (DOUGHTY et al., 2012); Pressure Ulcer Scale for Healing - PUSH pernas, para FOC e PUSH UP, para LP (SANTOS et al., 2005; SANTOS; SELLMER; MASSULO, 2007) e Classificação de Wagner para as UD (WAGNER, 1981). 


\subsubsection{Dados sociodemográficos e clínicos}

O primeiro instrumento de coleta de dados (APÊNDICE 2) inclui duas partes e destina-se à coleta de dados sociodemográficos e clínicos.

A primeira parte foi destinada à obtenção dos dados sociodemográficos: idade; sexo; raça; situação conjugal e escolaridade.

A segunda parte destinou-se ao levantamento dos dados clínicos, colhidos nos prontuários dos pacientes: etilismo; tabagismo; presença de comorbidades (Diabetes mellitus tipo I e II; hipertensão arterial sistêmica; acidente vascular cerebral; doença pulmonar obstrutiva crônica; insuficiência arterial ou venosa; infarto agudo do miocárdio; distúrbios na tireoide); presença de incontinência urinária e anal; perfusão tissular alterada; presença de infecção na pele; rigidez; espasticidade; presença de equimoses; edema nos MMII e MMSS; hematomas; IMC; uso de medicamentos (anti-hipertensivo; anti-inflamatório e antibiótico); nível de albumina; hemoglobina glicosilada; uso de calçados ortopédicos; mobilidade; uso de cateter vesical de demora e drenos; uso de fralda descartável; uso de fitas e curativos adesivos.

\subsubsection{Escala de Braden (EB)}

Para a complementação do levantamento das variáveis clínicas, utilizou-se a EB (PARANHOS; SANTOS, 1999), (ANEXO 12) para avaliação do risco para o desenvolvimento de LP.

No Brasil a EB, foi adaptada para a língua portuguesa e validada por Paranhos e Santos (1999). Atualmente, ela é a mais utilizada, tanto no Brasil como fora, por ser a mais estudada e apresentar propriedades de medida (sensibilidade e especificidade) mais adequadas em geral.

A EB é constituída de seis subescalas: percepção sensorial, umidade, atividade, mobilidade, nutrição, fricção e cisalhamento:

- Percepção sensorial: refere-se à incapacidade do paciente reagir ou sentir dor ou pressão, comprometendo a integridade da pele e aumentando o risco de desenvolver a LP (PARANHOS; SANTOS, 1999). 
- Mobilidade e Atividade: pacientes acamados ou em estado de coma, induzidos por medicamentos e utilizando recursos mecânicos para sobreviver perdem a capacidade de movimentação, agravando a possibilidade do surgimento de LP (PARANHOS; SANTOS, 1999).

- Fricção e Cisalhamento: mau posicionamento do paciente no leito e mudanças incorretas de posicionamento agravam o aparecimento de danos nos tecidos mais profundos (PARANHOS; SANTOS, 1999).

- Umidade: a presença de umidade sobre a pele é um grande fator de risco para o aparecimento da LP. A umidade tem como característica tornar a pele mais amolecida e, consequentemente, mais vulnerável a lesões. A recomendação é manter a pele seca e intacta. A umidade da pele origina-se de drenagem de feridas, sudorese excessiva e incontinência fecal e urinária (PARANHOS; SANTOS, 1999).

- Nutrição: a nutrição deficiente compromete a integridade dos tecidos moles, predispondo ao surgimento da LP (PARANHOS; SANTOS, 1999).

Para avaliar cada uma das subescalas, deve-se recorrer à definição dos parâmetros nela incluídos. A pontuação das subescalas varia de 1 a 4 , exceto na subescala friç̧ão e cisalhamento, que varia de 1 a 3 . A soma das seis categorias varia entre 6 e 23, correspondente ao escore total de Braden. Quanto menor o valor, maior será o comprometimento apresentado e, consequentemente, maior risco. Essa escala é considerada como altamente confiável para identificação de risco do surgimento de LP (SOUZA et al., 2010; SERPA et al., 2011; SERPA; SANTOS; CAMPINILI; QUEIROZ, 2011; SIMÃO et al., 2013; BARBOSA et al., 2014; SERPA; SANTOS, 2014; BORGHARD et al., 2015). 


\subsubsection{Sistema de Classificação STAR - Lesão por Fricção}

O terceiro instrumento, Sistema de Classificação STAR - Lesão por Friç̧ão (ANEXO 9), refere-se à avaliação das LF. Esse instrumento foi elaborado com o objetivo de se obter um sistema de classificação das LF, válido e universalmente aceito (CARVILLE et al., 2007). No Brasil, foi adaptado e validado para a língua portuguesa por Strazzieri-Pulido e Santos (STRAZZIERI-PULIDO; SANTOS; CARVILLE, 2015). Esse instrumento é composto de três partes:

- Diretrizes do Sistema de Classificação STAR - Lesão por Friç̧ão constituídas de seis tópicos relacionados aos cuidados com a ferida e a pele ao redor.

Sistema Classificação STAR - Lesão por Fricção - consta de cinco fotografias relacionadas às cinco categorias de LF, assim descritas:

- Categoria 1a - lesão por fricção cujo retalho de pele pode ser realinhado à posição anatômica normal (sem tensão excessiva) e a coloração da pele ou do retalho não se apresenta pálida, opaca ou escurecida;

- Categoria 1b - lesão por fricção cujo retalho de pele pode ser realinhado à posição anatômica normal (sem tensão excessiva) e a coloração da pele ou do retalho apresenta-se pálida, opaca ou escurecida;

- Categoria 2a - lesão por fricção cujo retalho de pele não pode ser realinhado à posição anatômica normal (sem tensão excessiva) e a coloração da pele ou do retalho não se apresenta pálida, opaca ou escurecida;

- Categoria $\mathbf{2 b}$ - lesão por fricção cujo retalho de pele não pode ser realinhado à posição anatômica normal (sem tensão excessiva) e a coloração da pele ou do retalho apresenta-se pálida, opaca ou escurecida;

- Categoria 3 - lesão por friç̧ão cujo retalho de pele está completamente ausente. 


\section{Glossário do Sistema de Classificação STAR - Lesão por Fricção}

- localizado no verso do instrumento, é composto da definição de LF e dos termos técnicos relacionados ao assunto (STRAZZIERI-PULIDO; SANTOS; CARVILLE, 2015).

\subsubsection{IAD-IT (Incontinence Associated Dermatitis Intervention Tool) - Consenso Internacional}

A DAI foi avaliada de acordo com o IAD-IT Consenso Internacional (Incontinence Associated Dermatitis Intervention Tool) (JUNKIN; SELEKOF, 2008; DOUGHTY et al., 2012) (ANEXO 10). Ela permite avaliar o risco de ocorrência da DAl e é composta de três partes. A primeira contém orientações sobre os cuidados à pessoa com incontinência. Na segunda, são feitas orientações quanto à identificação dos pacientes em risco com fotografias de eventos de DAl, propondo a classificação em: DAl precoce (early IAD); DAI moderada (moderate IAD); DAI grave (severe IAD) e fúngica - rash cutâneo aparente (fungal - appearing rash). Finalmente, a terceira parte propõe intervenções para as diferentes fases da DAl.

Essa ferramenta ainda está em processo de adaptação cultural e validação, tendo-se empregado apenas a sua versão traduzida livremente no presente estudo.

\subsubsection{Pressure Ulcer Scale for Healing - PUSH}

O quinto instrumento (ANEXO 11) foi utilizado para avaliar as FOC e as LP. Esse instrumento inclui parâmetros básicos de avaliação, como a medida, quantidade de exsudato e características do leito da ferida. Foi originalmente desenvolvido e validado em 1996, pelo PUSH Task Force do NPUAP, com o propósito de avaliar o processo de cicatrização das LP. No Brasil, foi adaptado e validado para o português por Santos et al., 2005, para uso em LP (PUSH UP) e por Santos; Sellmer; Massulo (2007) para uso em úlceras de perna (PUSH pernas).

Nesse instrumento, a ferida é avaliada segundo três parâmetros: comprimento x largura; quantidade de exsudato e tipo de tecido no leito da 
ferida. Para a melhor avaliação do processo de cicatrização da ferida, são estabelecidas definições operacionais para cada característica bem como os procedimentos de avaliação:

Etapa 1: comprimento x largura: Primeiro mede-se a ferida em seu maior comprimento, no sentido céfalo-caudal. A seguir, faz-se uma nova medida para avaliar a largura, do lado direito e esquerdo. Multiplicam-se as duas medidas para obter a área, em centímetros quadrados, onde pode-se encontrar valores que variam de $0>24 \mathrm{~cm}^{2}$, seleciona-se no instrumento a categoria a qual essa medida corresponde, registrando-se o sub-escore obtido, que pode variar de 0 a 10.

Etapa 2: Quantidade de exsudato: Deve-se observar após a remoção da cobertura e antes de qualquer aplicação de produto tópico. Devendo ser classificada como ausente (0), pequena (1), moderada (2), ou grande quantidade (3). Após a observação da quantidade de exsudato, seleciona-se a categoria correspondente no instrumento e registra-se o sub-escore obtido.

Etapa 3: Tipo de tecido: Nessa etapa avalia-se o tecido presente no leito da ferida utilizando-se os seguintes escores:

- Tecido necrótico: escore 4;

- Esfacelo ou ausência de tecido necrótico: escore 3;

- Ferida limpa e com tecido de granulação: escore 2;

- Ferida superficial e em processo de reepitalização: escore 1;

- Ferida fechada: escore 0.

Características dos tipos de tecido:

- Tecido necrótico (escara); escore 4. Apresenta tecido de coloração preta, marrom ou castanha, que adere firmemente ao leito e as bordas da ferida e pode apresentar-se mais endurecido ou mais amolecido, comparativamente à pele periferida.

- Esfacelo; escore 3. Tecido de coloração amarela ou branca que adere ao leito da ferida e apresenta-se como cordões ou crostas grossas, podendo ainda ser mucinoso.

- Tecido de granulação; escore 2. Tecido de coloração rósea ou vermelha, de aparência brilhante, úmida e granulosa. 
- Tecido epitelial; escore 1. São as feridas superficiais, que apresenta tecido róseo ou brilhante, que se desenvolve a partir das bordas ou como ilhas na superfície da lesão.

- Ferida fechada; escore 0. A ferida apresenta-se coberta com nova pele.

Somados os escores desses três parâmetros, resulta um escore total cuja avaliação pode ir de 0 a 17.

Etapa 4: Nessa etapa somam-se todos os subescores alcançados nas três características contidas no instrumento para obter o escore total do PUSH e registrá-los na tabela de cicatrização da Úlcera por pressão.

Etapa 5: Registra-se o escore total no gráfico de cicatrização da úlcera por pressão, conforme a data. Durante o período de avaliação da ferida, as mudanças nos escores indicam as mudanças nas condições da ferida. Escores que diminuem indicam que há melhora no processo de cicatrização. E escores maiores apontam para comprometimento do processo de cicatrização da ferida.

\subsubsection{Classificação de Wagner}

Para a avaliação das UD foi utilizada a Classificação de Wagner (WAGNER, 1981; DUARTE; GONÇALVES, 2011) (ANEXO 13).

A Classificação de Wagner é um sistema de classificação de lesões do pé diabético apresentado em 1981, por Wagner, que avalia a progressão do acometimento dos pés pela doença, desde a lesão superficial (Grau 0) até a gangrena disseminada (Grau 5). É o sistema de classificação de UD mais utilizado na prática clínica (WAGNER, 1981; PEREIRA et al., 2010; DUARTE; GONÇALVES, 2011). 


\subsection{ANÁLISE DOS DADOS}

Os dados coletados foram codificados e transferidos para uma planilha do aplicativo MS Office Excel囚, versão 2007, e para a execução de todas as análises estatísticas foi usado o SPSS (Statistical Package for the Social Science) versão 22.0. Para a caracterização sociodemográfica e clínica da amostra, os resultados são apresentados em frequências relativas e absolutas. As associações entre a variável dependente (presença de lesão) e as variáveis independentes foram obtidas primeiramente pelo teste qui-quadrado ou exato de Fisher para as variáveis categóricas e teste t para as numéricas.

Posteriormente, todas as variáveis independentes, cujo teste resultou em nível descritivo menor do que $5 \%$, foram incluídas no modelo de árvore de decisão com o algoritmo Classification and Regression Tree (CART), visando a identificar os fatores associados à presença das feridas de maneira simultânea e isoladamente.

O modelo de regressão CART fundamenta-se em regras de classificação baseadas em árvore de decisão. A árvore começa com um nó raiz que contém todas as observações da amostra. Os nós seguintes representam subconjuntos e subdivisões dos dados. Cada divisão resulta em exatamente dois nós que permitem a identificação de subgrupos homogêneos de pacientes, pela comparação sistemática de suas características, estabelecendo relações entre as variáveis explicativas e uma única variável resposta. $O$ processo de divisão repete-se até que nenhuma das variáveis selecionadas mostre influência significativa na divisão ou quando o tamanho do subconjunto for muito pequeno (BREIMAN, 1984).

Para o estudo foram considerados significativos os testes que obtiveram nível descritivo menor do que $5 \%$.

\section{$\checkmark$ Prevalência}

Neste estudo, utilizou-se a prevalência-ponto, que é a proporção de indivíduos que apresentam uma condição clínica em determinado ponto do 
tempo. No cálculo da prevalência, o numerador abrange o total de pessoas que apresentam a condição específica em um período determinado, enquanto o denominador é a amostra total estudada no mesmo período (FLETCHER, 2006).

Para o seu cálculo, foi utilizada a seguinte fórmula (FLETCHER, 2006):

Prevalência $=\frac{n^{\circ} \text { de pacientes internados com Lesão }}{n^{\circ} \text { total de pacientes avaliados }} \times 100$ 
5 RESULTADOS 


\section{RESULTADOS}

Os resultados são apresentados na forma de tabelas e figuras, sendo divididos em: caracterização sociodemográfica e clínica da amostra; características clínicas das feridas agudas e crônicas dos pacientes hospitalizados, prevalência de lesões e fatores associados.

\subsection{CARACTERIZAÇÃO DEMOGRÁFICA E CLÍNICA DA AMOSTRA}

A Tabela 1 mostra a distribuição demográfica dos 775 pacientes que compuseram a amostra. A média de idade da amostra estudada foi de 60,4 anos ( $D P=18,7)$, sendo a maioria do sexo masculino (59\%), e predomínio das seguintes variáveis: raça parda $(31 \%)$; situação conjugal com companheiro $(53,3 \%)$ e ensino fundamental $(52 \%)$.

Tabela 1 - Variáveis sociodemográficas dos pacientes da amostra. Manaus, 2015

\begin{tabular}{|c|c|c|c|c|}
\hline Média & DP & Mediana & Mínimo & Máximo \\
\hline $\begin{array}{l}\text { Idade } \\
\text { VARIÁVEIS }\end{array}$ & 18,7 & 57,0 & $\begin{array}{c}18 \\
\mathbf{n}\end{array}$ & $\begin{array}{c}100 \\
\%\end{array}$ \\
\hline \multicolumn{5}{|l|}{ Sexo } \\
\hline Masculino & & & 457 & 59,0 \\
\hline Feminino & & & 318 & 41,0 \\
\hline \multicolumn{5}{|l|}{ Raça } \\
\hline Parda & & & 240 & 31,0 \\
\hline Branca & & & 184 & 23,7 \\
\hline Negra & & & 168 & 21,7 \\
\hline Amarela & & & 181 & 23,3 \\
\hline Indígena & & & 2 & 0,3 \\
\hline \multicolumn{5}{|l|}{ Situação conjugal } \\
\hline Com companheiro & & & 413 & 53,3 \\
\hline Sem companheiro & & & 362 & 46,7 \\
\hline \multicolumn{5}{|l|}{ Escolaridade } \\
\hline Fundamental & & & 403 & 52,0 \\
\hline Médio & & & 227 & 29,3 \\
\hline Analfabeto & & & 79 & 10,2 \\
\hline Superior & & & 66 & 8,5 \\
\hline
\end{tabular}


Quanto aos dados clínicos da amostra total (Tabela 2), destacam-se: as presenças de Hipertensão arterial sistêmica (337/43,5\%) e Diabetes Mellitus (229/29,5\%), com alterações glicêmicas em 242 pessoas (31,2\%); uso de sabão/sabonete em barra (422/54,5\%) e de fralda (337/43,5\%); não emprego de emoliente (469/60,5\%); uso de anti-hipertensivos $(306 / 39,5)$, anti-inflamatórios (177/22,8\%), antibióticos (344/44,4\%) e anticoagulantes (251/32,4\%); cirurgia eletiva (184/23,7\%). Duzentos e setenta e quatro pacientes (35,4\%) apresentavam sobrepeso e 123 (15,9\%) obesidade; 368 pacientes $(47,4 \%)$ da amostra apresentaram risco para desenvolvimento de LP.

Tabela 2 - Variáveis clínicas dos pacientes da amostra. Manaus, 2015

\begin{tabular}{|c|c|c|}
\hline VARIÁVEIS & $\mathbf{n}$ & $\%$ \\
\hline \multicolumn{3}{|l|}{ Etilismo } \\
\hline Sim & 63 & 8,1 \\
\hline Não & 251 & 32,4 \\
\hline Não informado & 461 & 59,5 \\
\hline \multicolumn{3}{|l|}{ Tabagismo } \\
\hline Sim & 37 & 4,8 \\
\hline Não & 261 & 33,7 \\
\hline Não informado & 477 & 61,5 \\
\hline \multicolumn{3}{|c|}{ Perfusão tissular alterada } \\
\hline Sim & 69 & 8,9 \\
\hline Não & 706 & 91,1 \\
\hline \multicolumn{3}{|c|}{ Insuficiência venosa } \\
\hline Sim & 58 & 7,5 \\
\hline Não & 717 & 92,5 \\
\hline \multicolumn{3}{|c|}{ Insuficiência arterial } \\
\hline Sim & 29 & 3,7 \\
\hline Não & 746 & 96,3 \\
\hline \multicolumn{3}{|c|}{ Doença vascular periférica } \\
\hline Sim & 112 & 14,5 \\
\hline Não & 663 & 85,5 \\
\hline \multicolumn{3}{|c|}{ Hipertensão arterial sistêmica } \\
\hline Sim & 337 & 43,5 \\
\hline Não & 438 & 56,5 \\
\hline \multicolumn{3}{|c|}{ Acidente vascular cerebral } \\
\hline Sim & 121 & 15,6 \\
\hline Não & 654 & 84,4 \\
\hline \multicolumn{3}{|c|}{ Infarto agudo do miocárdio } \\
\hline Sim & 119 & 15,4 \\
\hline Não & 656 & 84,6 \\
\hline \multicolumn{3}{|c|}{ Distúrbio da tireoide } \\
\hline Sim & 17 & 2,2 \\
\hline Não & 758 & 97,8 \\
\hline \multicolumn{3}{|c|}{ Doença pulmonar obstrutiva crônica } \\
\hline & 49 & 6,3 \\
\hline Não & 726 & 93,7 \\
\hline
\end{tabular}


Tabela 2 - Variáveis clínicas dos pacientes da amostra. Manaus, 2015 (continuação)

\begin{tabular}{|c|c|c|}
\hline VARIÁVEIS & $\mathbf{n}$ & $\%$ \\
\hline \multicolumn{3}{|l|}{ Diabetes mellitus } \\
\hline Sim & 229 & 29,5 \\
\hline Não & 546 & 70,5 \\
\hline \multicolumn{3}{|c|}{ Sapato ortopédico } \\
\hline Usa & 1 & 0,1 \\
\hline Não usa & 774 & 99,9 \\
\hline \multicolumn{3}{|c|}{ Cateter vesical de demora } \\
\hline Usa & 132 & 17,0 \\
\hline Não usa & 643 & 83,0 \\
\hline \multicolumn{3}{|c|}{ Drenos (Kehr; Penrose; Portovac) } \\
\hline Usa & 36 & 4,6 \\
\hline Não usa & 739 & 95,4 \\
\hline \multicolumn{3}{|l|}{ Sabonete líquido } \\
\hline Usa & 417 & 53,8 \\
\hline Não usa & 358 & 46,2 \\
\hline \multicolumn{3}{|c|}{ Sabão/sabonete em barra } \\
\hline Usa & 422 & 54,5 \\
\hline Não usa & 353 & 45,5 \\
\hline \multicolumn{3}{|l|}{ Emoliente } \\
\hline Usa & 306 & 39,5 \\
\hline Não usa & 469 & 60,5 \\
\hline \multicolumn{3}{|l|}{ Fralda } \\
\hline Usa & 337 & 43,5 \\
\hline Não usa & 438 & 56,5 \\
\hline \multicolumn{3}{|l|}{ Anti-hipertensivo } \\
\hline $\operatorname{Sim}$ & 306 & 39,5 \\
\hline Não & 469 & 60,5 \\
\hline \multicolumn{3}{|l|}{ Anti-inflamatório } \\
\hline Sim & 177 & 22,8 \\
\hline Não & 598 & 77,2 \\
\hline \multicolumn{3}{|l|}{ Antibiótico } \\
\hline Sim & 344 & 44,4 \\
\hline Não & 431 & 55,6 \\
\hline \multicolumn{3}{|l|}{ Anticoagulante } \\
\hline $\operatorname{Sim}$ & 251 & 32,4 \\
\hline Não & 524 & 67,6 \\
\hline \multicolumn{3}{|l|}{ Esteroide } \\
\hline Sim & 89 & 11,5 \\
\hline Não & 686 & 88,5 \\
\hline \multicolumn{3}{|l|}{ Glicemia } \\
\hline Normal & 142 & 18,3 \\
\hline Alterada & 242 & 31,2 \\
\hline Não avaliada & 391 & 50,5 \\
\hline \multicolumn{3}{|l|}{ Cirurgia } \\
\hline Não fez & 523 & 67,5 \\
\hline Eletiva & 184 & 23,7 \\
\hline Não eletiva & 68 & 8,8 \\
\hline
\end{tabular}


Tabela 2 - Variáveis clínicas dos pacientes da amostra. Manaus, 2015 (conclusão)

\begin{tabular}{|c|c|c|}
\hline VARIÁVEIS & $\mathbf{n}$ & $\%$ \\
\hline \multicolumn{3}{|l|}{ Curativo } \\
\hline Presente & 130 & 16,8 \\
\hline Ausente & 645 & 83,2 \\
\hline \multicolumn{3}{|l|}{ Equimose } \\
\hline Presente & 121 & 15,6 \\
\hline Ausente & 654 & 84,4 \\
\hline \multicolumn{3}{|l|}{ Hematoma } \\
\hline Presente & 33 & 4,3 \\
\hline Ausente & 742 & 95,7 \\
\hline \multicolumn{3}{|l|}{ Edema MMSS } \\
\hline Presente & 62 & 8,0 \\
\hline Ausente & 713 & 92,0 \\
\hline \multicolumn{3}{|l|}{ Edema MMII } \\
\hline Presente & 65 & 8,4 \\
\hline Ausente & 710 & 91,6 \\
\hline \multicolumn{3}{|l|}{ Rigidez } \\
\hline Presente & 77 & 9,9 \\
\hline Ausente & 542 & 70,0 \\
\hline Não avaliada & 156 & 20,1 \\
\hline \multicolumn{3}{|l|}{ Espasticidade } \\
\hline Presente & 65 & 8,5 \\
\hline Ausente & 554 & 71,4 \\
\hline Não avaliada & 156 & 20,1 \\
\hline \multicolumn{3}{|l|}{ IMC } \\
\hline Baixo peso & 59 & 7,6 \\
\hline Peso normal & 319 & 41,1 \\
\hline Sobrepeso & 274 & 35,4 \\
\hline Obeso & 123 & 15,9 \\
\hline \multicolumn{3}{|l|}{ Escala de Braden } \\
\hline Com risco & 368 & 47,4 \\
\hline Sem risco & 407 & 52,6 \\
\hline \multicolumn{3}{|l|}{ Incontinência Urinária } \\
\hline Sim & 63 & 8,1 \\
\hline Não & 712 & 91,9 \\
\hline \multicolumn{3}{|l|}{ Incontinência Anal } \\
\hline Sim & 6 & 0,8 \\
\hline Não & 769 & 99,2 \\
\hline \multicolumn{3}{|l|}{ Estomias } \\
\hline Traqueostomia & 28 & 3,6 \\
\hline Colostomia & 11 & 1,4 \\
\hline Derivação urinária & 8 & 1,0 \\
\hline Gastronomia & 7 & 1,0 \\
\hline Ileostomia & 6 & 0,8 \\
\hline Sem estomia & 715 & 92,2 \\
\hline
\end{tabular}




\subsection{CARACTERISTIICAS CLÍNICAS DAS FERIDAS AGUDAS E CRÔNICAS DOS PACIENTES HOSPITALIZADOS}

No presente estudo, 178 pacientes apresentaram 201 lesões, com média de 1,1 lesão por paciente; 144 apresentaram apenas uma lesão e os demais, duas e três lesões respectivamente para 21 e 5 pacientes.

Com relação à presença de dor na ferida (Tabela 3), constatou-se que apenas $(58 / 6,2 \%)$ pacientes a referiram, de intensidade média moderada (Média=6,2; DP=2,8). Os escores médios variaram de 5,1 a 10,0, denotando níveis moderado a forte de sensação dolorosa. De acordo com o tipo de lesão, 28 pacientes com UD manifestaram a dor em suas lesões, com intensidade também moderada a forte (Média=6,6; DP=2,8; Mediana $=7$ ).

Tabela 3 - Intensidade de dor nos pacientes hospitalizados, total e de acordo com o tipo de lesão. Manaus, 2015

\begin{tabular}{lcccccc}
\hline $\begin{array}{l}\text { Tipo de } \\
\text { lesão }\end{array}$ & $\begin{array}{c}\mathbf{n}^{\mathbf{0}} \text { de } \\
\text { pacientes }\end{array}$ & Média & DP & Mediana & Mínimo & Máximo \\
\hline LF & 1 & 10,0 & - & 10 & 10 & 10 \\
DAl & 1 & 6,0 & - & 6 & 6 & 6 \\
FOC & 11 & 6,7 & 2,4 & 8 & 3 & 10 \\
LP & 17 & 5,1 & 2,8 & 6 & 0 & 10 \\
UD & 28 & 6,6 & 2,8 & 7 & 0 & 10 \\
Total & 58 & 6,2 & 2,8 & 6 & 0 & 10 \\
\hline
\end{tabular}

DP: desvio padrão.

As Figuras a seguir apresentam as distribuições e características de cada tipo de lesão estudadas. 


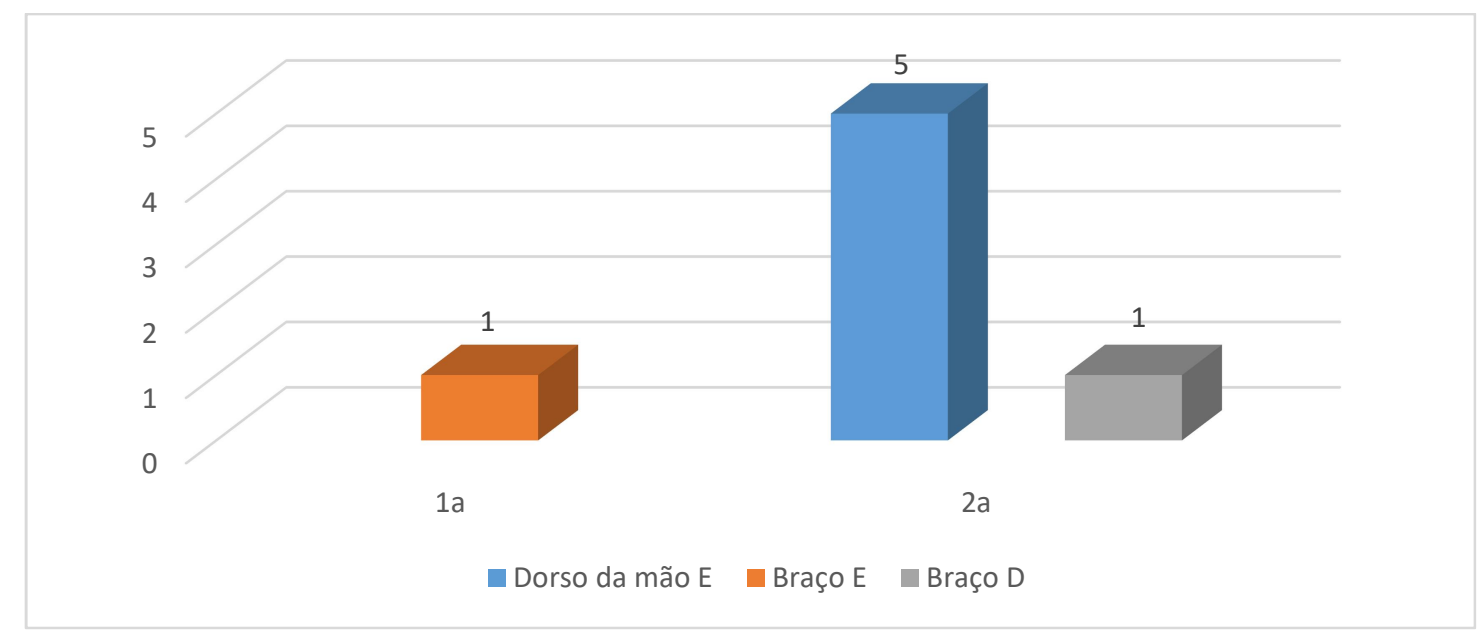

Figura 4 - Distribuição das LF, segundo a região corporal e sua classificação. Manaus, 2015

As LF localizaram-se mais frequentemente no dorso da mão $E$ $(5 / 71,4 \%)$, com classificação STAR 2a (5/83,4\%) (Figura 4). Seis lesões apresentaram-se com tecido de granulação no leito da ferida e sem exsudato.

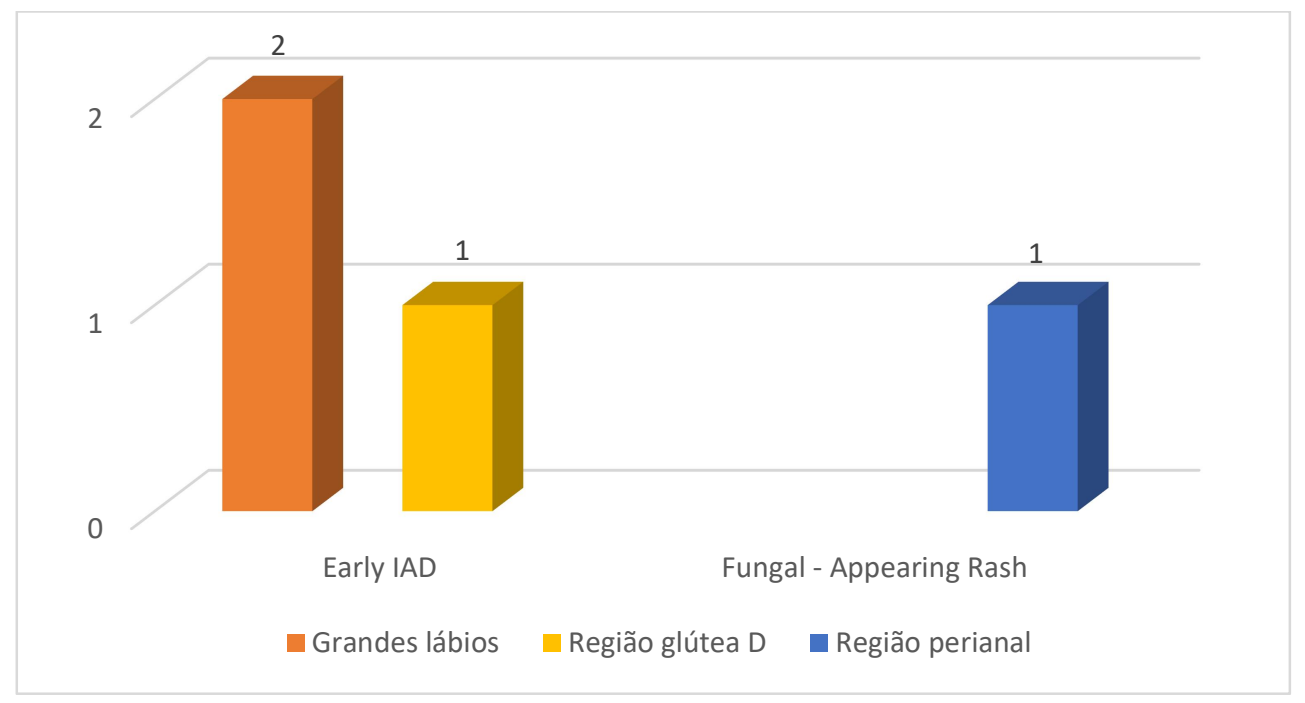

Figura 5 - Distribuição das lesões do tipo DAI, segundo a região corporal e a classificação da lesão. Manaus, 2015 
As quatro lesões DAl identificadas distribuíram-se quase homogeneamente entre diferentes regiões (grandes lábios, região glútea $\mathrm{D}$ e perianal), predominando o tipo precoce/ early (IAD-IT - Incontinence Associated Dermatitis Intervention Tool) duas das quatro ocorrências (Figura 5). Houve semelhança entre os tecidos encontrados nas lesões, com epitélio e granulação presentes; o exsudato estava ausente em duas lesões.

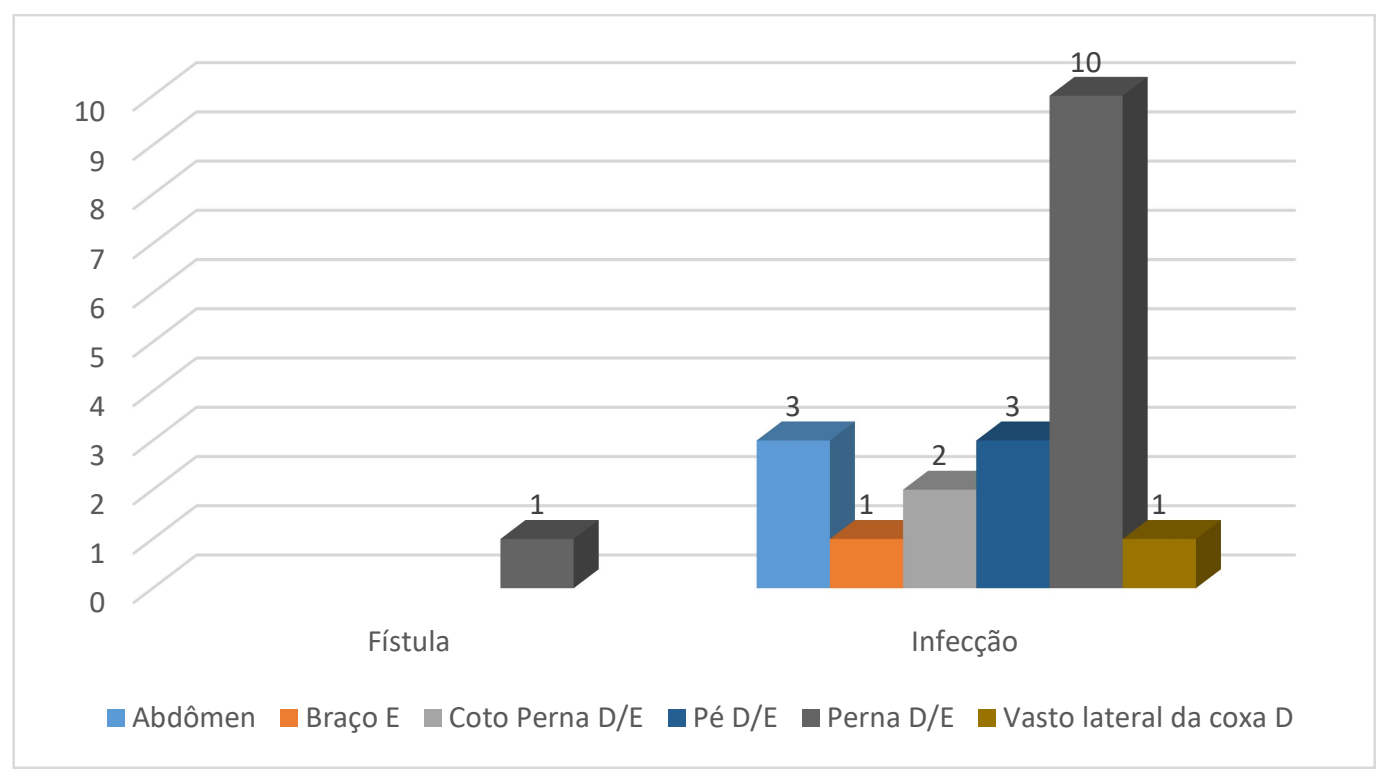

Figura 6 - Distribuição das lesões do tipo FOC, segundo a região corporal e a classificação da lesão. Manaus, 2015

Na Figura 6, observa-se que somente uma das 21 FOC foi do tipo fístula, sendo as demais por infecção. A localização predominante foi na perna $D / E(10 / 47,6 \%)$. O tecido predominante no leito da ferida foi 0 esfacelo, com moderada quantidade de exsudato. 


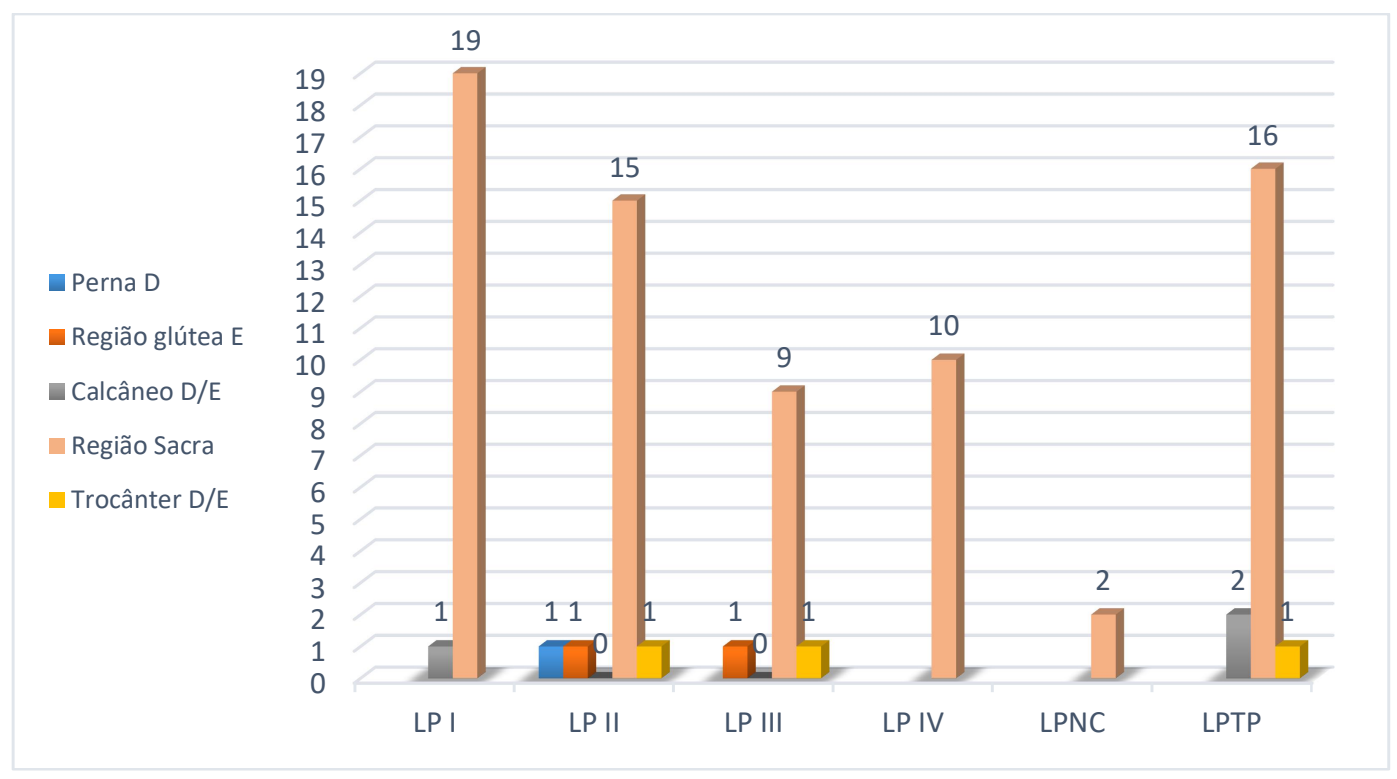

Figura 7 - Distribuição do número de $L P$, segundo a região corporal e o estágio da lesão. Manaus, 2015

A Figura 7 mostra a distribuição das 80 LP identificadas, com amplo predomínio da localização na região sacra $(71 / 88,7 \%)$ e em estágio 1 (19/23,7\%). No entanto, ao somarem-se as lesões em estágio $4(10 / 10,4 \%)$ e LPTP (16/16,6\%), teremos um percentual de $32,5 \%$ dessas lesões que são mais graves, sendo superior ao número de lesões em estágio 1 , quando relacionado ao número de lesões.

O tecido de granulação esteve mais frequentemente presente no leito da ferida, com pequena quantidade de exsudato. 


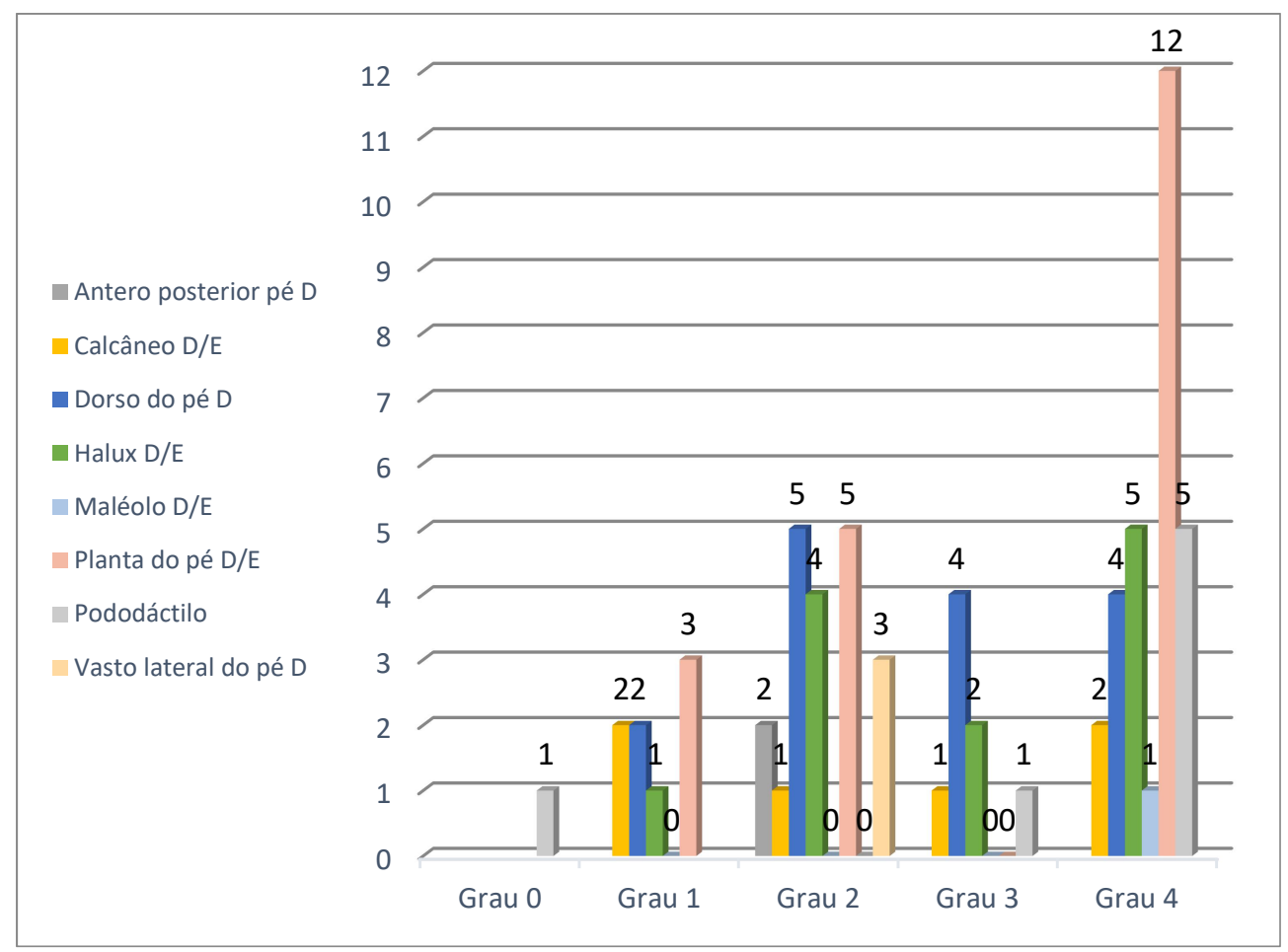

Figura 8 - Distribuição das UD, segundo a região corporal e a classificação da lesão. Manaus, 2015

Na Figura 8 constata-se que, dentre as 66 UD observadas, 23(34,8\%) localizavam-se na planta dos pés D/E, e Grau 4 na classificação de Wagner $(12 / 30,3 \%)$. O esfacelo foi o tecido predominante no leito da ferida, com moderada quantidade de exsudato. 


\subsection{PREVALÊNCIA DAS FERIDAS AGUDAS E CRÔNICAS E FATORES ASSOCIADOS}

A prevalência global de feridas agudas e crônicas em 775 pacientes hospitalizados na cidade de Manaus foi 23\%. O Quadro 10, traz a prevalência das feridas agudas e crônicas segundo as instituições hospitalares.

Quadro 10 - Prevalência das feridas agudas e crônicas segundo instituição hospitalar. Manaus, AM, 2015

\begin{tabular}{|l|c|c|c|}
\hline Instituição Hospitalar & $\begin{array}{c}\text { Número de } \\
\text { pacientes } \\
\text { avaliados }\end{array}$ & $\begin{array}{c}\text { Número de } \\
\text { pacientes com } \\
\text { feridas }\end{array}$ & $\begin{array}{c}\text { Prevalência } \\
\text { Global por } \\
\text { instituição }\end{array}$ \\
\hline $\begin{array}{l}\text { Fundação Centro de Controle de } \\
\text { Oncologia do Estado do Amazonas } \\
\text { (FCECON) }\end{array}$ & 58 & 11 & $19 \%$ \\
\hline $\begin{array}{l}\text { Hospital e Pronto Socorro 28 de } \\
\text { Agosto }\end{array}$ & 258 & 68 & $26,3 \%$ \\
\hline Fundação Hospital Adriano Jorge & 95 & 5 & $5,2 \%$ \\
\hline $\begin{array}{l}\text { Hospital e Pronto Socorro Dr. João } \\
\text { Lúcio Pereira Machado }\end{array}$ & 113 & 30 & $37,1 \%$ \\
\hline $\begin{array}{l}\text { Hospital e Pronto Socorro Dr. } \\
\text { Aristóteles Platão Bezerra de Araújo }\end{array}$ & 95 & 13 & $31,6 \%$ \\
\hline $\begin{array}{l}\text { Hospital Universitário Francisca } \\
\text { Mendes }\end{array}$ & 75 & 9 & $178,3 \%$ \\
\hline Hospital Universitário Getúlio Vargas & 775 & & $11,1 \%$ \\
\hline $\begin{array}{l}\text { Total/ Prevalência Global das sete } \\
\text { instituições }\end{array}$ & & $23 \%$ \\
\hline
\end{tabular}


A Figura 9 mostra a distribuição dos pacientes de acordo com os tipos de feridas agudas e crônicas.

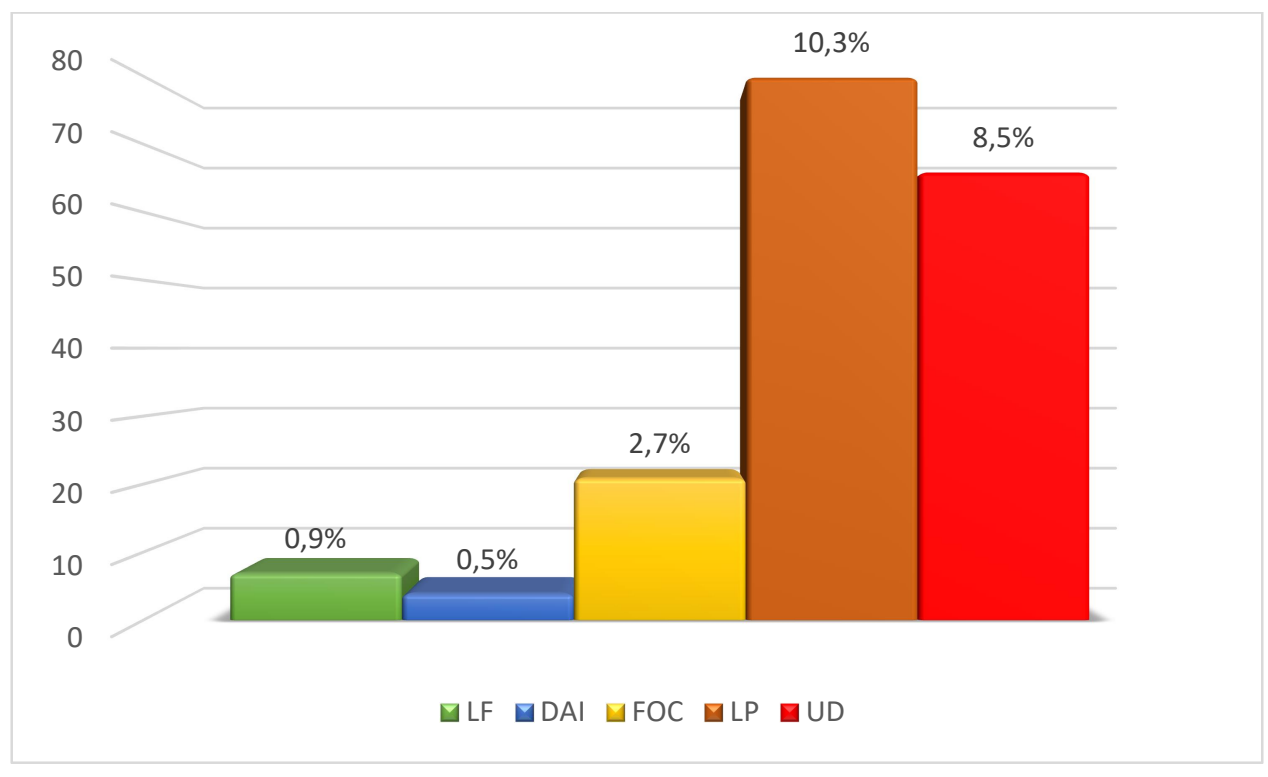

Figura 9 - Prevalência de acordo com o tipo de lesão em pacientes hospitalizados. Manaus, 2015

A Figura 9, mostra predomínio das prevalências de LP $(10,3 \%)$ e de UD $(8,5 \%)$.

A seguir, são apresentados os fatores associados à ocorrência de cada tipo de lesão aqui investigado (Tabelas 4 a 8 e Figuras 9 a 13). 


\subsubsection{LF}

Tabela 4 - Variáveis sociodemográficas e clínicas dos pacientes hospitalizados com e sem LF. Manaus, 2015

\begin{tabular}{|c|c|c|c|c|}
\hline \multirow{2}{*}{ Variáveis } & \multicolumn{2}{|c|}{ LF } & \multirow{2}{*}{$\begin{array}{c}\text { Total } \\
(100 \%)\end{array}$} & \multirow{2}{*}{$\mathbf{p}^{*}$ valo } \\
\hline & Ausente $\mathrm{n}(\%)$ & Presente $n(\%)$ & & \\
\hline \multicolumn{5}{|l|}{ Sexo } \\
\hline Feminino & $313(98,4)$ & $5(1,6)$ & 318 & 0,130 \\
\hline Masculino & $455(99,6)$ & $2(0,4)$ & 457 & \\
\hline \multicolumn{5}{|l|}{ Raça } \\
\hline Branca & $181(98,4)$ & $3(1,6)$ & 184 & \\
\hline Parda & $237(98,8)$ & $3(1,3)$ & 240 & 0,457 \\
\hline Negra & $168(100)$ & - & 168 & \\
\hline Amarela & $180(99,4)$ & $1(0,6)$ & 181 & \\
\hline Indígena & $2(100)$ & - & 2 & \\
\hline \multicolumn{5}{|l|}{ Situação conjugal } \\
\hline Sem companheiro & $358(98,9)$ & $4(1,1)$ & 362 & 0,711 \\
\hline Com companheiro & $410(99,3)$ & $3(0,7)$ & 413 & \\
\hline \multicolumn{5}{|l|}{ Escolaridade } \\
\hline Analfabeto & $78(98,7)$ & $1(1,3)$ & 79 & \\
\hline Ensino fundamental & $398(98,8)$ & $5(1,2)$ & 403 & 0,692 \\
\hline Ensino médio & $226(99,6)$ & $1(0,4)$ & 227 & \\
\hline Ensino Superior & $66(100)$ & - & 66 & \\
\hline \multicolumn{5}{|l|}{ Diabetes mellitus } \\
\hline Não & $542(99,3)$ & $4(0,7)$ & 546 & 0,428 \\
\hline Sim & $226(98,7)$ & $3(1,3)$ & 229 & \\
\hline \multicolumn{5}{|c|}{ Perfusão tissular alterada } \\
\hline Não & $700(99,2)$ & $6(0,8)$ & 706 & 0,481 \\
\hline Sim & $68(98,6)$ & $1(1,4)$ & 69 & \\
\hline \multicolumn{5}{|c|}{ Infarto agudo do miocárdio } \\
\hline Não & $650(99,1)$ & $6(0,90)$ & 656 & $>0.999$ \\
\hline Sim & $118(99,2)$ & $1(0,8)$ & 119 & \\
\hline \multicolumn{5}{|c|}{ Acidente vascular cerebral } \\
\hline Não & $649(99,2)$ & $5(0,8)$ & 654 & 0,300 \\
\hline Sim & $119(98,3)$ & $2(1,7)$ & 121 & \\
\hline \multicolumn{5}{|l|}{ Distúrbio da tireoide } \\
\hline Não & $751(99,1)$ & $7(0,9)$ & 758 & $>0.999$ \\
\hline Sim & $17(100,0)$ & - & 17 & \\
\hline \multicolumn{5}{|l|}{ Anti-hipertensivo } \\
\hline Não & $466(99,4)$ & $3(0,6)$ & 469 & 0,443 \\
\hline Sim & $302(98,7)$ & $4(1,3)$ & 306 & \\
\hline \multicolumn{5}{|l|}{ Rigidez } \\
\hline Ausente & $539(99,4)$ & $3(0,6)$ & 542 & 0,119 \\
\hline Presente & $75(97,4)$ & $2(2,6)$ & 77 & \\
\hline Não avaliado & $161(20,8)$ & $2(0,3)$ & 156 & \\
\hline
\end{tabular}


Tabela 4 - Variáveis sociodemográficas e clínicas dos pacientes hospitalizados com e sem LF. Manaus, 2015 (conclusão)

\begin{tabular}{|c|c|c|c|c|}
\hline \multirow{2}{*}{ Variáveis } & \multicolumn{2}{|c|}{ LF } & \multirow{2}{*}{$\begin{array}{l}\text { Total } \\
(100 \%)\end{array}$} & \multirow{2}{*}{$\mathrm{p}^{*}$ valor } \\
\hline & Ausente $n(\%)$ & Presente $\mathrm{n}(\%)$ & & \\
\hline \multicolumn{5}{|l|}{ Espasticidade } \\
\hline Ausente & $550(99,3)$ & $4(0,7)$ & 554 & 0,427 \\
\hline Presente & $64(98,5)$ & $1(1,5)$ & 65 & \\
\hline Não avaliado & $161(20,8)$ & $2(0,3)$ & 156 & \\
\hline \multicolumn{5}{|c|}{$\begin{array}{l}\text { IMC (índice de massa } \\
\text { corporal) }\end{array}$} \\
\hline Baixo peso & $58(7,5)$ & $1(2,0)$ & 59 & 0,136 \\
\hline Peso normal & $315(98,7)$ & $4(1,3)$ & 319 & \\
\hline Sobrepeso & $274(100)$ & - & 274 & \\
\hline Obeso & $121(98,4)$ & $2(1,6)$ & 123 & \\
\hline \multicolumn{5}{|l|}{ Glicemia } \\
\hline Alterada & $240(99,2)$ & $2(0,8)$ & 242 & 0,363 \\
\hline Normal & $139(97,9)$ & $3(2,1)$ & 142 & \\
\hline Dado ausente & $396(51,1)$ & $2(0,2)$ & 391 & \\
\hline \multicolumn{5}{|l|}{ Equimose } \\
\hline Ausente & $650(99,4)$ & $4(0,6)$ & 654 & 0,081 \\
\hline Presente & $118(97,5)$ & $3(2,5)$ & 121 & \\
\hline \multicolumn{5}{|l|}{ Hematoma } \\
\hline Ausente & $739(99,6)$ & $3(0,4)$ & 742 & $<0,001^{* *}$ \\
\hline Presente & $29(87,9)$ & $4(12,1)$ & 33 & \\
\hline \multicolumn{5}{|l|}{ Curativos } \\
\hline Ausente & $641(99,4)$ & $4(0,6)$ & 645 & 0,096 \\
\hline Presente & $127(97,7)$ & $3(2,3)$ & 130 & \\
\hline \multicolumn{5}{|c|}{ Sabão/sabonete em barra } \\
\hline Não usa & $349(98,9)$ & $4(1,1)$ & 353 & 0,708 \\
\hline Usa & $419(99,3)$ & $3(0,7)$ & 422 & \\
\hline \multicolumn{5}{|c|}{ Drenos (Kehr; Penrose; Portovac) } \\
\hline Não usa & $723(99,1)$ & $7(0,9)$ & 739 & 1,000 \\
\hline Usa & $36(100,0)$ & $0(0,0)$ & 36 & \\
\hline \multicolumn{5}{|l|}{ Cirurgia } \\
\hline Não fez & $518(99,0)$ & $5(1,0)$ & 523 & 1,000 \\
\hline Eletiva & $182(98,9)$ & $2(1,1)$ & 184 & \\
\hline Não eletiva & $68(100,0)$ & $0(0,0)$ & 68 & \\
\hline \multicolumn{5}{|c|}{ Escala de Braden } \\
\hline Sem risco & $402(98,8)$ & $5(1,2)$ & 407 & 0,455 \\
\hline Com risco & $366(99,5)$ & $2(0,5)$ & 368 & \\
\hline
\end{tabular}

*Teste Qui-Quadrado ou Exato de Fisher. ${ }^{* *}$ Estatisticamente significante $(p<0,05)$. 
Detectou-se diferença estatisticamente significativa entre os grupos com e sem LF apenas quanto à presença de hematoma $(p<0,001)$, na Tabela 4. No entanto, ao ser inserida no modelo CART, a variável hematoma não se manteve associada à presença de LF na amostra estudada (Figura 10).

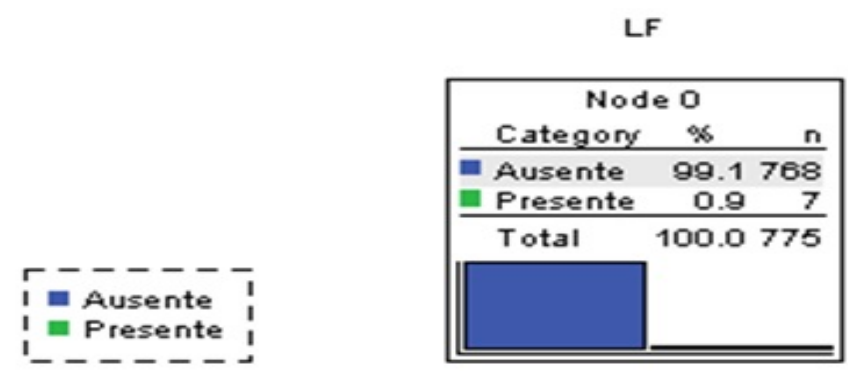

Figura 10 - Fatores associados à presença de LF, segundo a análise CART. Manaus, 2015 


\subsubsection{DAl}

Tabela 5 - Variáveis sociodemográficas e clínicas dos pacientes hospitalizados com e sem DAI. Manaus, 2015

\begin{tabular}{|c|c|c|c|c|}
\hline \multirow{2}{*}{ Variáveis } & \multicolumn{2}{|c|}{ DAl } & \multirow{2}{*}{$\begin{array}{c}\text { Total } \\
(100 \%)\end{array}$} & \multirow{2}{*}{$\mathbf{p}^{*}$ valor } \\
\hline & Ausente $\mathrm{n}(\%)$ & Presente $\mathrm{n}(\%)$ & & \\
\hline \multicolumn{5}{|l|}{ Sexo } \\
\hline Feminino & $314(98,7)$ & $4(1,3)$ & 318 & 0,585 \\
\hline Masculino & $457(100)$ & - & 457 & \\
\hline \multicolumn{5}{|l|}{ Raça } \\
\hline Branca & $184(100,0)$ & - & 184 & 0,795 \\
\hline Parda & $239(99,6)$ & $1(0,4)$ & 240 & \\
\hline Negra & $167(99,4)$ & $1(0,6)$ & 168 & \\
\hline Amarela & $179(98,9)$ & $2(1,1)$ & 181 & \\
\hline Indígena & $2(100)$ & - & 2 & \\
\hline \multicolumn{5}{|l|}{ Situação conjugal } \\
\hline Sem companheiro & $360(99,4)$ & $2(0,6)$ & 362 & $>0,999$ \\
\hline Com companheiro & $411(99,5)$ & $2(0,5)$ & 413 & \\
\hline \multicolumn{5}{|l|}{ Escolaridade } \\
\hline Analfabeto & $78(98,7)$ & $1(1,3)$ & 79 & 0,187 \\
\hline Ensino fundamental & $402(99,8)$ & $1(0,2)$ & 403 & \\
\hline Ensino médio & $226(99,6)$ & $1(0,4)$ & 227 & \\
\hline Ensino superior & $65(98,5)$ & $1(1,5)$ & 66 & \\
\hline \multicolumn{5}{|l|}{ Incontinência urinária } \\
\hline Não & $709(99,6)$ & $3(0,4)$ & 712 & 0,288 \\
\hline Sim & $62(98,4)$ & $1(1,6)$ & 63 & \\
\hline \multicolumn{5}{|l|}{ Incontinência anal } \\
\hline Não & $765(99,5)$ & $4(0,5)$ & 769 & $>0,999$ \\
\hline Sim & $6(100)$ & - & 6 & \\
\hline \multicolumn{5}{|l|}{ Diabetes mellitus } \\
\hline Não & $543(99,5)$ & $3(0,5)$ & 546 & $>0,999$ \\
\hline Sim & $228(99,6)$ & $1(0,4)$ & 229 & \\
\hline \multicolumn{5}{|l|}{ Anti-hipertensivo } \\
\hline Não & $466(99,4)$ & $3(0,6)$ & 469 & $>0,999$ \\
\hline Sim & $305(99,7)$ & $1(0,3)$ & 306 & \\
\hline \multicolumn{5}{|l|}{ Antibiótico } \\
\hline Não & $430(99,8)$ & $1(0,2)$ & 431 & 0,328 \\
\hline Sim & $341(99,1)$ & $3(0,9)$ & 344 & \\
\hline \multicolumn{5}{|l|}{ Fralda } \\
\hline Não usa & $438(100)$ & - & 438 & $0,035^{\star *}$ \\
\hline Usa & $333(98,8)$ & $4(1,2)$ & 337 & \\
\hline \multicolumn{5}{|c|}{ Cateter vesical de demora (CVD) } \\
\hline Não usa & $642(99,8)$ & $1(0,2)$ & 643 & $0,017^{* *}$ \\
\hline Usa & $129(97,7)$ & $3(2,3)$ & 132 & \\
\hline
\end{tabular}


Tabela 5 - Variáveis sociodemográficas e clínicas dos pacientes hospitalizados com e sem DAI. Manaus, 2015 (conclusão)

\begin{tabular}{|c|c|c|c|c|}
\hline \multirow{2}{*}{ Variáveis } & \multicolumn{2}{|c|}{ DAI } & \multirow{2}{*}{$\begin{array}{c}\text { Total } \\
(100 \%)\end{array}$} & \multirow{2}{*}{$\mathbf{p}^{*}$ valo } \\
\hline & Ausente $n(\%)$ & Presente $\mathrm{n}(\%)$ & & \\
\hline \multicolumn{5}{|l|}{ Cirurgia } \\
\hline Não fez & $520(99,4)$ & $3(0,6)$ & 523 & 1,000 \\
\hline Eletiva & $183(99,5)$ & $1(0,5)$ & 184 & \\
\hline Não eletiva & $68(100)$ & - & 68 & \\
\hline \multicolumn{5}{|c|}{ Drenos (Kehr; Penrose; Portovac) } \\
\hline Não usa & $735(99,5)$ & $4(0,5)$ & 739 & 1,000 \\
\hline Usa & $36(100)$ & - & 36 & \\
\hline \multicolumn{5}{|c|}{ IMC (índice de massa corporal) } \\
\hline Baixo peso & $59(100)$ & - & 59 & 0,178 \\
\hline Peso normal & $319(100)$ & - & 319 & \\
\hline Sobrepeso & $272(99,3)$ & $2(0,7)$ & 274 & \\
\hline Obeso & $121(98,4)$ & $2(1,6)$ & 123 & \\
\hline \multicolumn{5}{|l|}{ Rigidez } \\
\hline Ausente & $541(99,8)$ & $1(0,2)$ & 542 & $0,042^{\star *}$ \\
\hline Presente & $75(97,4)$ & $2(2,6)$ & 77 & \\
\hline Não avaliado & $159(20,5)$ & $1(0,1)$ & 156 & \\
\hline \multicolumn{5}{|l|}{ Espasticidade } \\
\hline Ausente & $552(99,6)$ & $2(0,4)$ & 554 & 0,284 \\
\hline Presente & $64(98,5)$ & $1(1,5)$ & 65 & \\
\hline Não avaliado & $159(20,5)$ & $1(0,1)$ & 156 & \\
\hline \multicolumn{5}{|l|}{ Glicemia } \\
\hline Alterada & $241(99,6)$ & $1(0,4)$ & 242 & 1,000 \\
\hline Normal & $141(99,3)$ & $1(0,7)$ & 142 & \\
\hline Dado ausente & $393(50,7)$ & $2(0,2)$ & 391 & \\
\hline \multicolumn{5}{|l|}{ Sabonete líquido } \\
\hline Não usa & $358(100)$ & - & 358 & 0,128 \\
\hline Usa & $413(99,0)$ & $4(1,0)$ & 417 & \\
\hline \multicolumn{5}{|c|}{ Sabão/sabonete em barra } \\
\hline Não usa & $349(98,9)$ & $4(1,1)$ & 353 & $0,043^{* *}$ \\
\hline Usa & $422(100)$ & - & 422 & \\
\hline \multicolumn{5}{|l|}{ Emoliente } \\
\hline Não usa & $469(100)$ & - & 469 & $0,024^{* *}$ \\
\hline Usa & $302(98,7)$ & $4(1,3)$ & 306 & \\
\hline \multicolumn{5}{|l|}{ Escala de Braden } \\
\hline Sem risco & $403(99,0)$ & $4(1,0)$ & 407 & 0,126 \\
\hline Com risco & $368(100)$ & - & 368 & \\
\hline
\end{tabular}

*Teste Qui-Quadrado ou Exato de Fisher. ${ }^{* *}$ Estatisticamente significante $(p<0,05)$. 
Detectaram-se diferenças estatisticamente significativas entre os grupos com e sem DAl quanto às seguintes variáveis: uso de fralda $(p=0,035)$, CVD $(p=0,017)$, rigidez $(p=0,042)$, uso de sabão/sabonete em barra $(p=0,043)$ e emoliente $(p=0,024)$, na Tabela 5 . No entanto, da mesma maneira que para as LF, não se confirmaram como associadas à ocorrência de DAI na amostra estudada (Figura 11).

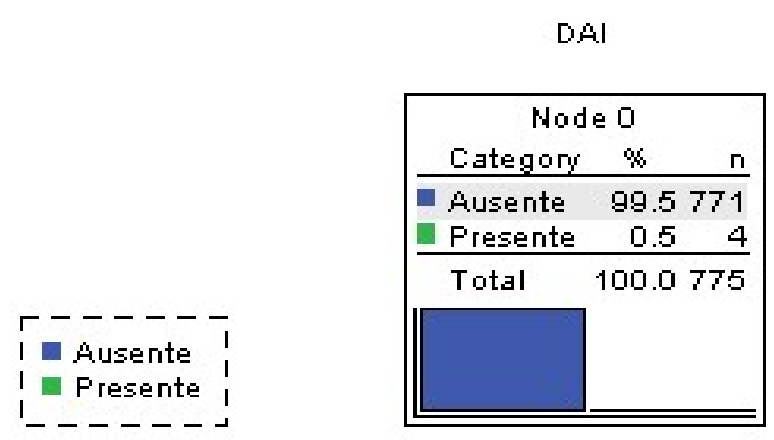

Figura 11 - Fatores associados à presença de DAl, segundo a análise CART. Manaus, 2015 


\subsubsection{FOC}

Tabela 6 - Variáveis sociodemográficas e clínicas dos pacientes hospitalizados com e sem FOC. Manaus, 2015

\begin{tabular}{|c|c|c|c|c|}
\hline \multirow{2}{*}{ Variáveis } & \multicolumn{2}{|c|}{ FOC } & \multirow{2}{*}{$\begin{array}{c}\text { Total } \\
(100 \%)\end{array}$} & \multirow{2}{*}{$\mathbf{p}^{*}$ valor } \\
\hline & Ausente $\mathrm{n}(\%)$ & Presente $n(\%)$ & & \\
\hline \multicolumn{5}{|l|}{ Sexo } \\
\hline Feminino & $313(98,4)$ & $5(1,6)$ & 318 & 0,104 \\
\hline Masculino & $441(96,5)$ & $16(3,5)$ & 457 & \\
\hline \multicolumn{5}{|l|}{ Raça } \\
\hline Branca & $175(95,1)$ & $9(4,9)$ & 184 & 0,108 \\
\hline Parda & $235(97,9)$ & $5(2,1)$ & 240 & \\
\hline Negra & $167(99,4)$ & $1(0,6)$ & 168 & \\
\hline Amarela & $175(96,7)$ & $6(3,3)$ & 181 & \\
\hline Indígena & $2(100)$ & - & 2 & \\
\hline \multicolumn{5}{|l|}{ Situação conjugal } \\
\hline Sem companheiro & $236(98,6)$ & $5(1,4)$ & 362 & $0,033^{* *}$ \\
\hline Com companheiro & $397(96,1)$ & $16(3,9)$ & 413 & \\
\hline \multicolumn{5}{|l|}{ Escolaridade } \\
\hline Analfabeto & $79(100)$ & - & 79 & 0,237 \\
\hline Ensino fundamental & $393(97,5)$ & $10(2,5)$ & 403 & \\
\hline Ensino médio & $219(96,5)$ & $8(3,5)$ & 227 & \\
\hline Ensino superior & $63(95,5)$ & $3(4,5)$ & 66 & \\
\hline \multicolumn{5}{|l|}{ Tabagismo } \\
\hline Não & $257(98,5)$ & $4(1,5)$ & 261 & 0,163 \\
\hline Sim & $35(94,6)$ & $2(5,4)$ & 37 & \\
\hline Dado ausente & $483(62,3)$ & $15(1,9)$ & 477 & \\
\hline \multicolumn{5}{|l|}{ Diabetes mellitus } \\
\hline Não & $534(97,8)$ & $12(2,2)$ & 546 & 0,175 \\
\hline Sim & $220(96,1)$ & $9(3,9)$ & 229 & \\
\hline \multicolumn{5}{|c|}{ Hipertensão arterial sistêmica } \\
\hline Não & $423(96,6)$ & $15(3,4)$ & 438 & 0,162 \\
\hline $\operatorname{Sim}$ & $331(98,2)$ & $6(1,8)$ & 337 & \\
\hline \multicolumn{5}{|c|}{ Cateter vesical de demora } \\
\hline Não usa & $624(97,0)$ & $19(3,0)$ & 643 & 0,556 \\
\hline Usa & $130(98,5)$ & $2(1,5)$ & 132 & \\
\hline \multicolumn{5}{|c|}{ Drenos (Kehr; Penrose; Portovac) } \\
\hline Não usa & $719(97,3)$ & $20(2,7)$ & 739 & 1,000 \\
\hline Usa & $35(97,2)$ & $1(2,8)$ & 36 & \\
\hline \multicolumn{5}{|c|}{ Sabão/sabonete em barra } \\
\hline Não usa & $344(97,5)$ & $9(2,5)$ & 353 & 0,802 \\
\hline Usa & $410(97,2)$ & $12(2,8)$ & 422 & \\
\hline
\end{tabular}


Tabela 6 - Variáveis sociodemográficas e clínicas dos pacientes hospitalizados com e sem FOC. Manaus, 2015 (conclusão)

\begin{tabular}{|c|c|c|c|c|}
\hline \multirow{2}{*}{ Variáveis } & \multicolumn{2}{|c|}{ FOC } & \multirow{2}{*}{$\begin{array}{l}\text { Total } \\
(100 \%)\end{array}$} & \multirow{2}{*}{$\mathbf{p}^{*}$ valor } \\
\hline & Ausente $\mathrm{n}(\%)$ & Presente n(\%) & & \\
\hline \multicolumn{5}{|c|}{ IMC (índice de massa corporal) } \\
\hline Baixo peso & $57(95,9)$ & $2(4,1)$ & 59 & 0,826 \\
\hline Normal & $309(96,9)$ & $10(3,1)$ & 319 & \\
\hline Sobrepeso & $268(97,8)$ & $6(2,2)$ & 274 & \\
\hline Obeso & $120(97,6)$ & $3(2,4)$ & 123 & \\
\hline \multicolumn{5}{|l|}{ Glicemia } \\
\hline Alterada & $232(95,9)$ & $10(4,1)$ & 242 & 0,387 \\
\hline Normal & $139(97,9)$ & $3(2,1)$ & 142 & \\
\hline Dado ausente & $404(52,1)$ & $8(1,0)$ & 391 & \\
\hline \multicolumn{5}{|l|}{ Cirurgia } \\
\hline Não fez & $517(98,9)$ & $6(1,1)$ & 523 & $0,001^{* *}$ \\
\hline Eletiva & $176(95,7)$ & $8(4,3)$ & 184 & \\
\hline Não eletiva & $61(89,7)$ & $7(10,3)$ & 68 & \\
\hline \multicolumn{5}{|l|}{ Rigidez } \\
\hline Ausente & $524(96,7)$ & $18(3,3)$ & 542 & 1,000 \\
\hline Presente & $75(97,4)$ & $2(2,6)$ & 77 & \\
\hline Não avaliado & $176(22,7)$ & $1(0,1)$ & 156 & \\
\hline \multicolumn{5}{|l|}{ Espasticidade } \\
\hline Ausente & $536(96,8)$ & $18(3,2)$ & 554 & 1,000 \\
\hline Presente & $63(96,9)$ & $2(3,1)$ & 65 & \\
\hline Não avaliado & $176(22,7)$ & $1(0,1)$ & 156 & \\
\hline \multicolumn{5}{|l|}{ Anti-inflamatório } \\
\hline Não & $584(97,7)$ & $14(2,3)$ & 598 & 0,289 \\
\hline Sim & $170(96,0)$ & $7(4,0)$ & 177 & \\
\hline \multicolumn{5}{|l|}{ Antibiótico } \\
\hline Não & $426(98,8)$ & $5(1,2)$ & 431 & $0,003^{* *}$ \\
\hline Sim & $328(95,3)$ & $16(4,7)$ & 344 & \\
\hline \multicolumn{5}{|l|}{ Anticoagulante } \\
\hline Não & $508(96,9)$ & $16(3,1)$ & 524 & 0,394 \\
\hline Sim & $246(98,0)$ & $5(2,0)$ & 251 & \\
\hline \multicolumn{5}{|l|}{ Esteroide } \\
\hline Não & $666(97,1)$ & $20(2,9)$ & 686 & 0,497 \\
\hline Sim & $88(98,9)$ & $1(1,1)$ & 89 & \\
\hline \multicolumn{5}{|l|}{ Escala de Braden } \\
\hline Sem risco & $394(96,8)$ & $13(3,2)$ & 407 & 0,382 \\
\hline Com risco & $360(97,8)$ & $8(2,2)$ & 368 & \\
\hline
\end{tabular}

*Teste Qui-Quadrado ou Exato de Fisher. ${ }^{* \star}$ Estatisticamente significante $(p<0,05)$. 
Os grupos com e sem FOC mostraram-se estatisticamente diferentes quanto às seguintes variáveis: situação conjugal $(p=0,033)$, cirurgia $(p=0,001)$ e antibiótico ( $p=0,003)$, na Tabela 6. Da mesma maneira que para as LF e DAI, essas variáveis não se confirmaram como associadas à ocorrência de FOC na amostra estudada (Figura 12).

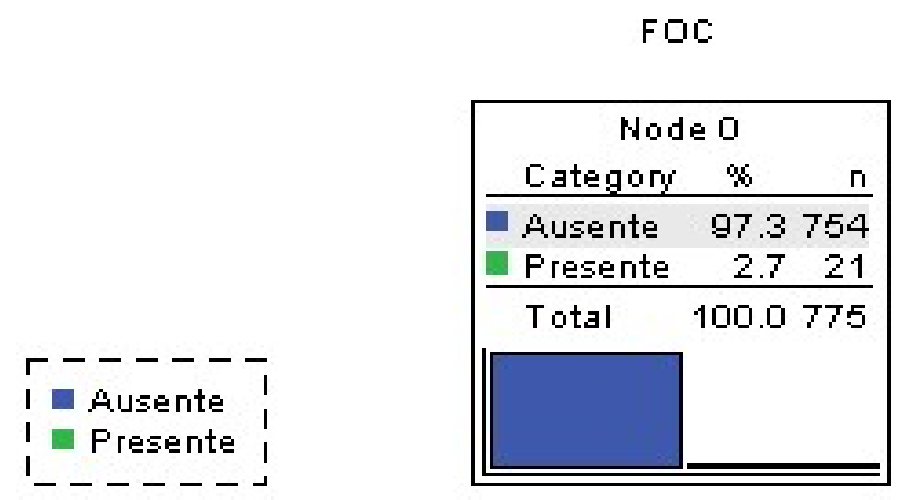

Figura 12 - Fatores associados à presença de FOC, segundo a análise CART. Manaus, 2015 


\subsubsection{LP}

Tabela 7 - Variáveis sociodemográficas e clínicas dos pacientes hospitalizados com e sem LP. Manaus, 2015

\begin{tabular}{|c|c|c|c|c|}
\hline \multirow{2}{*}{ Variáveis } & \multicolumn{2}{|c|}{ LP } & \multirow{2}{*}{$\begin{array}{c}\text { Total } \\
(100 \%)\end{array}$} & \multirow{2}{*}{$\mathbf{p}^{*}$ valor } \\
\hline & Ausente $\mathrm{n}(\%)$ & Presente $\mathrm{n}(\%)$ & & \\
\hline \multicolumn{5}{|l|}{ Sexo } \\
\hline Feminino & $285(89,6)$ & $33(10,4)$ & 318 & \multirow[t]{2}{*}{0,967} \\
\hline Masculino & $410(89,7)$ & $47(10,3)$ & 457 & \\
\hline \multicolumn{5}{|l|}{ Raça } \\
\hline Branca & $164(89,1)$ & $20(10,9)$ & 184 & \multirow{5}{*}{0,967} \\
\hline Parda & $216(90,0)$ & $24(10,0)$ & 240 & \\
\hline Negra & $152(90,5)$ & $16(9,5)$ & 168 & \\
\hline Amarela & 161(89) & $20(11)$ & 181 & \\
\hline Indígena & $2(100)$ & - & 2 & \\
\hline \multicolumn{5}{|l|}{ Situação conjugal } \\
\hline Sem companheiro & $312(86,2)$ & $50(13,8)$ & 362 & \multirow[t]{2}{*}{$0,003^{* *}$} \\
\hline Com companheiro & $383(92,7)$ & $30(7,3)$ & 413 & \\
\hline \multicolumn{5}{|l|}{ Escolaridade } \\
\hline Analfabeto & $67(84,8)$ & $12(15,2)$ & 79 & \multirow[t]{4}{*}{0,119} \\
\hline Ensino fundamental & $357(88,6)$ & $46(11,4)$ & 403 & \\
\hline Ensino médio & $208(91,6)$ & $19(8,4)$ & 227 & \\
\hline Ensino superior & $63(95,5)$ & $3(4,5)$ & 66 & \\
\hline \multicolumn{5}{|l|}{ Tabagismo } \\
\hline Não & $235(90,0)$ & $26(10,0)$ & 261 & \multirow{3}{*}{$>0,999$} \\
\hline $\operatorname{Sim}$ & $34(91,9)$ & $3(8,1)$ & 37 & \\
\hline Dado ausente & $506(65,2)$ & $51(6,6)$ & 477 & \\
\hline \multicolumn{5}{|l|}{ Glicemia } \\
\hline Alterada & $215(88,8)$ & $27(11,2)$ & 242 & \multirow[t]{3}{*}{0,517} \\
\hline Normal & $123(86,6)$ & $19(13,4)$ & 142 & \\
\hline Dado ausente & $437(56,4)$ & $34(4,4)$ & 391 & \\
\hline \multicolumn{5}{|l|}{ Diabetes mellitus } \\
\hline Não & $489(89,6)$ & $57(10,4)$ & 546 & \multirow[t]{2}{*}{0,869} \\
\hline Sim & $206(90,0)$ & $23(10,0)$ & 229 & \\
\hline \multicolumn{5}{|l|}{ Hipertensão arterial } \\
\hline Não & $394(90,0)$ & $44(10,0)$ & 438 & \multirow{2}{*}{0,773} \\
\hline Sim & $301(89,3)$ & $36(10,7)$ & 337 & \\
\hline \multicolumn{5}{|l|}{ Incontinência urinária } \\
\hline Não & $663(88,9)$ & $79(11,1)$ & 473 & \multirow[t]{2}{*}{$0,047^{* *}$} \\
\hline Sim & $62(98,4)$ & $1(1,6)$ & 44 & \\
\hline \multicolumn{5}{|l|}{ Incontinência anal } \\
\hline Não & $689(89,6)$ & $80(10,4)$ & 769 & \multirow[t]{2}{*}{$>0,999$} \\
\hline $\mathrm{Sim}$ & $6(100)$ & 1 & 6 & \\
\hline Insuficiência venosa & & & & \\
\hline Não & $641(89,4)$ & $76(10,6)$ & 717 & 0,373 \\
\hline Sim & $54(93,1)$ & $4(6,9)$ & 58 & \\
\hline Insuficiência arterial & & & & \\
\hline Não & $667(89,4)$ & $79(10,6)$ & 746 & 0,349 \\
\hline Sim & $28(96,6)$ & $1(3,4)$ & 29 & \\
\hline
\end{tabular}


Tabela 7 - Variáveis sociodemográficas e clínicas dos pacientes hospitalizados com e sem LP. Manaus, 2015 (conclusão)

\begin{tabular}{|c|c|c|c|c|}
\hline \multirow{2}{*}{ Variáveis } & \multicolumn{2}{|c|}{ LP } & \multirow{2}{*}{$\begin{array}{c}\text { Total } \\
(100 \%) \\
\end{array}$} & \multirow{2}{*}{$\mathbf{p}^{*}$ valor } \\
\hline & Ausente n(\%) & Presente $n(\%)$ & & \\
\hline \multicolumn{5}{|l|}{ Cirurgia } \\
\hline Não fez & $457(87,4)$ & $66(12,6)$ & 523 & $0,007^{* *}$ \\
\hline Eletiva & $172(93,5)$ & $12(6,5)$ & 184 & \\
\hline Não eletiva & $66(89,7)$ & $2(2,9)$ & 68 & \\
\hline \multicolumn{5}{|l|}{ Rigidez } \\
\hline Ausente & $528(97,4)$ & $14(2,6)$ & 542 & $0,000^{* *}$ \\
\hline Presente & $63(81,8)$ & $14(18,2)$ & 77 & \\
\hline Não avaliado & $184(23,7)$ & $52(6,7)$ & 156 & \\
\hline \multicolumn{5}{|l|}{ Espasticidade } \\
\hline Ausente & $537(96,9)$ & $17(3,1)$ & 554 & $0,000^{\star *}$ \\
\hline Presente & $54(83,1)$ & $11(16,9)$ & 65 & \\
\hline Não avaliado & $184(23,7)$ & $52(6,7)$ & 156 & \\
\hline \multicolumn{5}{|c|}{ Drenos (Kehr; Penrose; Portovac) } \\
\hline Não usa & $661(89,4)$ & $78(10,6)$ & 739 & 0,571 \\
\hline Usa & $34(94,4)$ & $2(5,6)$ & 36 & \\
\hline \multicolumn{5}{|c|}{ Perfusão tissular alterada } \\
\hline Não & $633(89,7)$ & $73(10,3)$ & 706 & 0,959 \\
\hline Sim & $62(89,9)$ & $7(10,1)$ & 69 & \\
\hline \multicolumn{5}{|c|}{ IMC (índice de massa corporal) } \\
\hline Baixo peso & $46(81,6)$ & $13(18,4)$ & 59 & $0,006^{* *}$ \\
\hline Normal & $284(89,0)$ & $35(11,0)$ & 319 & \\
\hline Sobrepeso & $249(90,9)$ & $25(9,1)$ & 274 & \\
\hline Obeso & $116(94,3)$ & $7(5,7)$ & 123 & \\
\hline \multicolumn{5}{|l|}{ Edema MMSS } \\
\hline Ausente & $650(91,2)$ & $63(8,8)$ & 713 & $<0.001^{* *}$ \\
\hline Presente & $45(72,6)$ & $17(27,4)$ & 62 & $<0,001$ \\
\hline \multicolumn{5}{|l|}{ Edema MMII } \\
\hline Ausente & $646(91,0)$ & $64(9,0)$ & 710 & $<0,001^{* *}$ \\
\hline Presente & $49(75,4)$ & $16(24,6)$ & 65 & \\
\hline \multicolumn{5}{|l|}{ Sabonete líquido } \\
\hline Não usa & $300(83,8)$ & $58(7,5)$ & 358 & $<0,001^{\text {** }}$ \\
\hline Usa & $305(73,1)$ & $22(2,8)$ & 417 & \\
\hline \multicolumn{5}{|c|}{ Sabão/sabonete em barra } \\
\hline Não usa & $289(81,9)$ & $64(18,1)$ & 353 & $0,000^{* *}$ \\
\hline Usa & $406(96,2)$ & $16(3,8)$ & 422 & \\
\hline \multicolumn{5}{|l|}{ Curativo } \\
\hline Ausente & $601(77,5)$ & $44(5,6)$ & 645 & 0,120 \\
\hline Presente & $94(12,1)$ & $36(4,6)$ & 130 & \\
\hline \multicolumn{5}{|l|}{ Fralda } \\
\hline Não usa & $433(55,8)$ & $05(0,6)$ & 438 & 0,421 \\
\hline Usa & $262(33,8)$ & $75(9,6)$ & 337 & \\
\hline \multicolumn{5}{|l|}{ Emoliente } \\
\hline Não usa & $384(81,9)$ & $05(18,1)$ & 469 & $0,002^{* *}$ \\
\hline Usa & $221(72,2)$ & $75(27,8)$ & 306 & \\
\hline \multicolumn{5}{|l|}{ Escala de Braden } \\
\hline Sem risco & $330(81,1)$ & $77(18,9)$ & 407 & $0,000^{* *}$ \\
\hline Com risco & $365(99,2)$ & $3(0,8)$ & 368 & \\
\hline
\end{tabular}

*Teste Qui-Quadrado ou Exato de Fisher. ${ }^{* *}$ Estatisticamente significante $(p<0,05)$. 
Detectaram-se diferenças estatisticamente significativas entre os grupos com e sem LP quanto às seguintes variáveis: situação conjugal $(p=0,003)$, presença de incontinência urinária $(p=0,047)$, rigidez $(p=0,000)$, espasticidade $(p=0,000)$, IMC $(p=0,006)$, edema de membros superiores e membros inferiores $(p<0,001)$, uso de sabonete líquido $(p<0,001)$ e sabão/sabonete em barra $(p=0,000)$, uso de emoliente $(p=0,002)$ e escore de Braden ( $p=0,000)$, na Tabela 7 .

As variáveis que melhor descreveram a presença de LP, na amostra estudada, de acordo com a árvore de decisão CART foram o uso de fralda e presença de curativo (Figura 13).

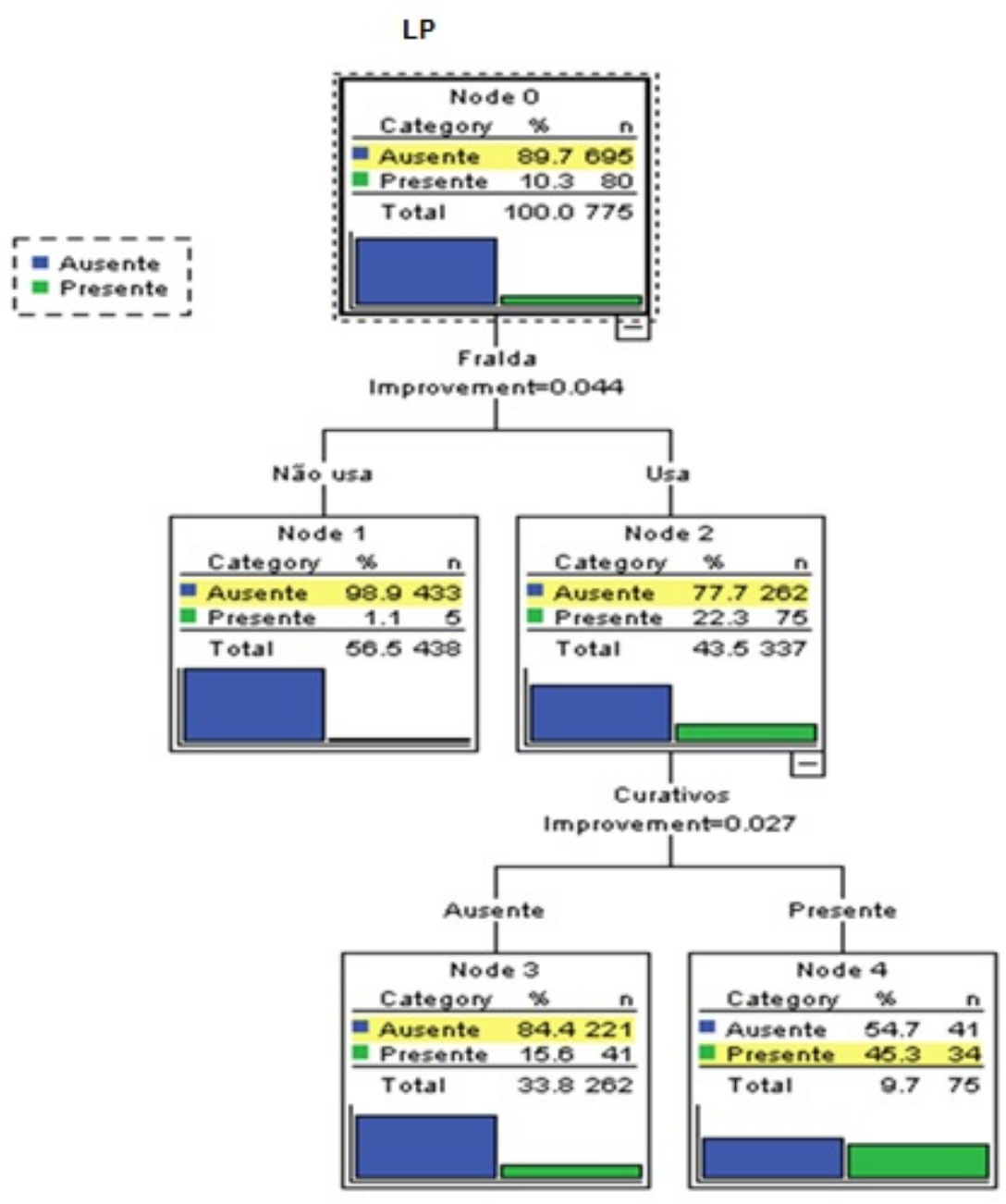

Figura 13 - Fatores associados à presença de LP, segundo a análise CART. Manaus, 2015 


\subsubsection{UD}

Tabela 8 - Variáveis sociodemográficas e clínicas dos pacientes hospitalizados com e sem UD. Manaus, 2015

\begin{tabular}{|c|c|c|c|c|}
\hline \multirow{2}{*}{ Variáveis } & \multicolumn{2}{|c|}{ UD } & \multirow{2}{*}{$\begin{array}{l}\text { Total } \\
(100 \%)\end{array}$} & \multirow{2}{*}{$P^{*}$ valor } \\
\hline & Ausente $\mathrm{n}(\%)$ & Presente $n(\%)$ & & \\
\hline \multicolumn{5}{|l|}{ Sexo } \\
\hline Feminino & $295(92,8)$ & $23(7,2)$ & 318 & 0,286 \\
\hline Masculino & $414(90,6)$ & $43(9,4)$ & 457 & \\
\hline \multicolumn{5}{|l|}{ Raça } \\
\hline Branca & $167(90,8)$ & $17(9,2)$ & 184 & 0,175 \\
\hline Parda & $212(88,3)$ & $28(11,7)$ & 240 & \\
\hline Negra & $157(93,5)$ & $11(6,5)$ & 168 & \\
\hline Amarela & $171(94,5)$ & $10(5,5)$ & 181 & \\
\hline Indígena & $2(100)$ & - & 2 & \\
\hline \multicolumn{5}{|l|}{ Situação conjugal } \\
\hline Sem companheiro & $333(92,0)$ & $29(8,0)$ & 362 & 0,637 \\
\hline Com companheiro & $376(91,0)$ & $37(0,9)$ & 413 & \\
\hline \multicolumn{5}{|l|}{ Escolaridade } \\
\hline Analfabeto & $65(82,3)$ & $14(17,7)$ & 79 & $0,005^{* *}$ \\
\hline Ensino fundamental & $367(91,1)$ & $36(8,9)$ & 403 & \\
\hline Ensino médio & $213(93,8)$ & $14(6,2)$ & 227 & \\
\hline Ensino superior & $64(97,0)$ & $2(3,0)$ & 66 & \\
\hline \multicolumn{5}{|l|}{ Etilismo } \\
\hline Não & $225(89,6)$ & $26(10,4)$ & 251 & 0,074 \\
\hline Sim & $61(96,8)$ & $2(3,2)$ & 63 & \\
\hline Dado ausente & $489(63,1)$ & $38(4,9)$ & 461 & \\
\hline \multicolumn{5}{|l|}{ Tabagismo } \\
\hline Não & $238(91,2)$ & $23(8,8)$ & 261 & 0,332 \\
\hline Sim & $36(97,3)$ & $1(2,7)$ & 37 & \\
\hline Dado ausente & $501(64,4)$ & $42(5,4)$ & 477 & \\
\hline \multicolumn{5}{|c|}{ Hipertensão arterial sistêmica } \\
\hline Não & $417(95,2)$ & $21(4,8)$ & 438 & $<0,001 * *$ \\
\hline Sim & $292(86,6)$ & $45(13,4)$ & 337 & \\
\hline \multicolumn{5}{|c|}{ Acidente vascular cerebral } \\
\hline Não & $599(91,6)$ & $55(8,4)$ & 654 & 0,805 \\
\hline Sim & $110(90,9)$ & $11(9,1)$ & 121 & \\
\hline \multicolumn{5}{|c|}{ Doença vascular periférica } \\
\hline Não & $629(94,9)$ & $34(5,1)$ & 663 & $<0,001^{* *}$ \\
\hline Sim & $80(71,4)$ & $32(28,6)$ & 112 & \\
\hline \multicolumn{5}{|l|}{ Rigidez } \\
\hline Ausente & $484(89,3)$ & $58(10,7)$ & 542 & 0,253 \\
\hline Presente & $72(93,5)$ & $5(6,5)$ & 77 & \\
\hline Não avaliado & $219(28,2)$ & $3(0,4)$ & 156 & \\
\hline
\end{tabular}


Tabela 8 - Variáveis sociodemográficas e clínicas dos pacientes hospitalizados com e sem UD. Manaus, 2015 (conclusão)

\begin{tabular}{|c|c|c|c|c|}
\hline \multirow{2}{*}{ Variáveis } & \multicolumn{2}{|c|}{ UD } & \multirow{2}{*}{$\begin{array}{c}\text { Total } \\
(100 \%)\end{array}$} & \multirow{2}{*}{$\mathbf{P}^{*}$ valor } \\
\hline & Ausente $\mathrm{n}(\%)$ & Presente $n(\%)$ & & \\
\hline \multicolumn{5}{|l|}{ Espasticidade } \\
\hline Ausente & $495(89,4)$ & $59(10,6)$ & 554 & 0,257 \\
\hline Presente & $61(93,8)$ & $4(6,2)$ & 65 & \\
\hline Não avaliado & $219(28,2)$ & $3(0,4)$ & 156 & \\
\hline \multicolumn{5}{|l|}{ Cirurgia } \\
\hline Não fez & $476(91,0)$ & $47(9,0)$ & 523 & 0,088 \\
\hline Eletiva & $166(90,2)$ & $18(9,8)$ & 184 & \\
\hline Não eletiva & $67(98,5)$ & $1(1,5)$ & 68 & \\
\hline \multicolumn{5}{|c|}{ Drenos (Kehr; Penrose; Portovac) } \\
\hline Não usa & $673(91,1)$ & $66(8,9)$ & 739 & 0,064 \\
\hline Usa & $36(100)$ & $0(0,0)$ & 36 & \\
\hline \multicolumn{5}{|l|}{ IMC } \\
\hline Baixo peso & $56(95,9)$ & $3(4,1)$ & 59 & 0,393 \\
\hline Normal & $295(92,5)$ & $24(7,5)$ & 319 & \\
\hline Sobrepeso & $244(89,1)$ & $30(10,9)$ & 274 & \\
\hline Obeso & $114(92,7)$ & $9(7,3)$ & 123 & \\
\hline \multicolumn{5}{|l|}{ Glicemia } \\
\hline Alterada & $192(79,3)$ & $50(20,7)$ & 242 & $0,000^{* *}$ \\
\hline Normal & $133(93,7)$ & $9(6,3)$ & 142 & \\
\hline Dado ausente & $450(58,0)$ & $7(0,1)$ & 391 & \\
\hline \multicolumn{5}{|l|}{ Sapato ortopédico } \\
\hline Não usa & $709(91,6)$ & $65(8,4)$ & 774 & 0,085 \\
\hline Usa & - & $1(0,1)$ & 1 & \\
\hline \multicolumn{5}{|c|}{ Sabão/sabonete em barra } \\
\hline Não usa & $328(92,9)$ & $25(7,1)$ & 353 & 0,191 \\
\hline Usa & $381(90,3)$ & $41(9,7)$ & 422 & \\
\hline \multicolumn{5}{|l|}{ Escala de Braden } \\
\hline Sem risco & $373(91,6)$ & $34(8,4)$ & 407 & 0,865 \\
\hline Com risco & $336(91,3)$ & $32(8,7)$ & 368 & \\
\hline
\end{tabular}

*Teste Qui-Quadrado ou Exato de Fisher. ${ }^{* *}$ Estatisticamente significante $(p<0,05)$.

Detectaram-se diferenças estatisticamente significativas entre os grupos com e sem UD quanto às seguintes variáveis: escolaridade $(p=0,005)$, HAS $(p<0,001)$, DVP $(p<0,001)$ e glicemia $(p=0,000)$, na Tabela 8.

As variáveis que melhor descreveram a presença de UD, na amostra estudada, de acordo com a árvore de decisão CART foram: pacientes com doença vascular periférica e sem uso de emolientes (Figura 14). 


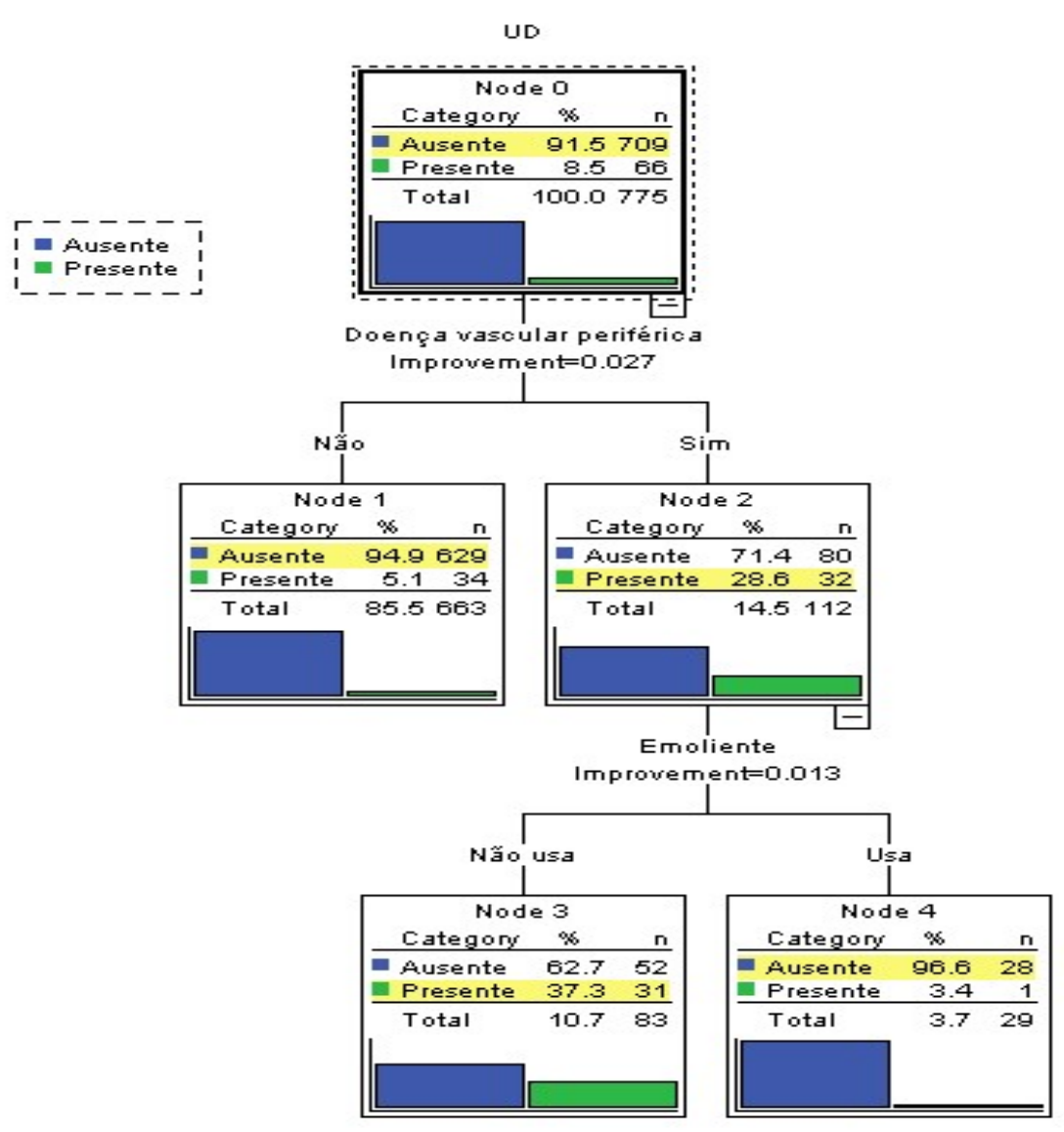

Figura 14 - Fatores associados à presença de UD, segundo a análise CART. Manaus, 2015.

Ao analisarem-se as variáveis associadas à presença de lesões agudas e crônicas como um todo, em pacientes hospitalizados na cidade de Manaus, constatou-se que: pacientes diabéticos, que utilizaram anticoagulantes e com rigidez; pacientes diabéticos que não utilizaram anticoagulantes; pacientes não diabéticos, sem risco para desenvolvimento de LP e com curativo; pacientes não diabéticos, sem risco para desenvolvimento de LP, sem curativo e com hematoma são aqueles cujas características melhor explicam a ocorrência de lesões na amostra estudada (Figura 15). 


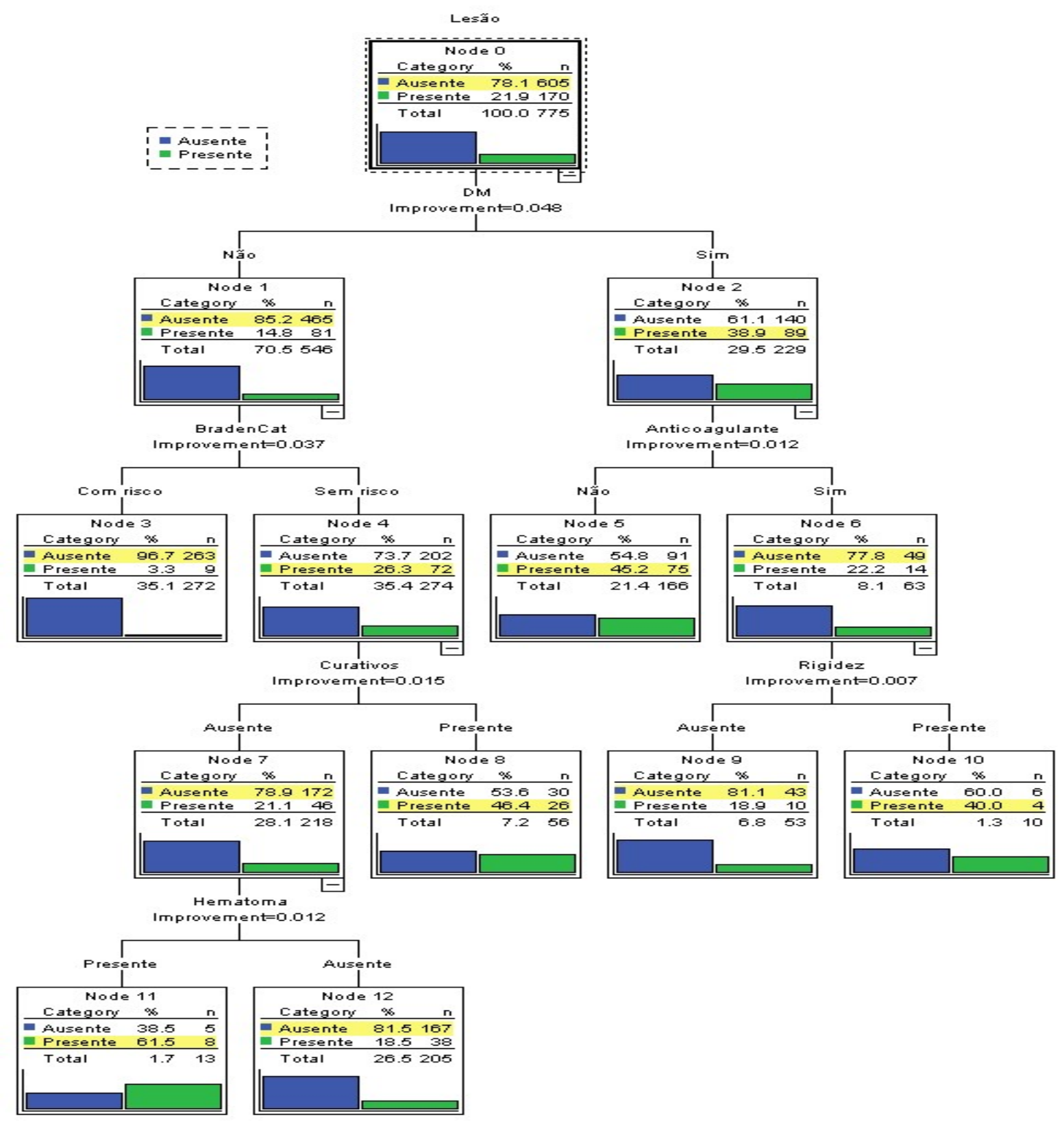

Figura 15 - Fatores associados à presença de feridas agudas e crônicas, segundo a análise CART. Manaus, 2015 


\section{DISCUSSÃO}

O estudo sobre a prevalência de cinco feridas agudas e crônicas (LF, DAI, FOC, LP e UD) e respectivos fatores associados em pacientes hospitalizados na cidade de Manaus-AM, mostrou prevalência global de $23 \%$, sendo as LP $(10,3 \%)$ e as UD $(8,5 \%)$ as mais frequentes. Em estudo de prevalência de feridas agudas e crônicas (FARIA, 2010), realizado com 1311 pacientes em um hospital na cidade de Palmas, a prevalência encontrada foi $(82 / 6,3 \%)$.

Média aproximada de 1,1 lesão por paciente é corroborada por autores nacionais e internacionais, independentemente do cenário de cuidado (MARTIN et al., 2012; BRITO et al., 2013; QUEIROZ et al., 2014; SARDO et al., 2016).

Somente para as LP e as UD, obtiveram-se fatores associados, respectivamente, uso de fralda e presença de curativo; e doença vascular periférica e sem uso de emoliente. Somente a presença de curativo repetiuse como fator associado à presença de feridas agudas e crônicas em geral na amostra estudada.

A discussão é apresentada de acordo com a prevalência e fatores associados a cada tipo de lesão investigada.

\subsection{PREVALÊNCIA DE LF E FATORES ASSOCIADOS}

A prevalência de LF encontrada neste estudo foi apenas $0,9 \%$. Poucos são os estudos epidemiológicos nacionais e internacionais sobre essa temática em pacientes hospitalizados. Em revisão sistemática recente, do total de 236 artigos nacionais e internacionais encontrados, somente oito atenderam aos critérios de seleção do estudo sobre a prevalência e os fatores associados à LF, independentemente do cenário. As autoras encontraram valores de 3,3\% a 22,0\% em pacientes hospitalizados e 5,5\% a 19,5\% no domicílio (STRAZZIERI-PULIDO et al., 2015). 
A primeira publicação brasileira sobre a epidemiologia das $L F$ - pelo menos com a nomenclatura atual - foi realizada no Instituto do Câncer do Estado de São Paulo Octavio Frias de Oliveira (ICESP), onde nove pacientes apresentaram LF $(n=157)$, acarretando prevalência de $3,3 \%$ (AMARAL et al., 2012), considerada elevada em comparação ao presente estudo. Há que se mencionar que o estudo foi desenvolvido em hospital oncológico e, portanto, junto a pacientes com maior fragilidade e vulnerabilidade da pele (PIRES et al., 2008; CRIADO, 2010; AMARAL et al., 2012).

Nos estudos de Leblanc et al. (2013), no Canadá, e de Koyano et al. (2014), no Japão, ocorridos em Unidades de Longa Permanência, a prevalência apontada foi $22,0 \%$ e $3,9 \%$ respectivamente, com resultados bem divergentes, tanto entre si como comparativamente aos aqui obtidos.

A região anatômica preferencial das LF, no presente estudo, foi o dorso da mão esquerda $(5 / 71,4 \%)$ que, embora distinto daquela verificada no estudo japonês (KOYANO et al., 2014), os autores também encontraram o membro superior como localização predominante (mesmo que no antebraço direito). Esses resultados divergem de outros estudos realizados em cenários não hospitalares, como na publicação de Leblanc et al. (2013), onde a região das pernas $(46,0 \%)$ foi o local prevalente para a ocorrência de LF em residentes em Unidades de Longa permanência, em Ontário, Canadá.

Quanto à classificação das LF, no presente estudo houve predomínio da categoria $2 a(83,4 \%)$, diferentemente dos estudos de Koyano et al. (2014), com predomínio de classificação 1b (68,8\%); ou de Amaral et al. (2012), para os quais cinco das nove LF encontradas estavam na categoria 3; ou ainda de LeBlanc et al. (2013), onde prevaleceram as LF categoria 1a $(32,0 \%)$.

Apesar da presença do hematoma não ter sido confirmada como variável associada à presença da LF, após realização da regressão CART, merece ser discutida ao ser corroborada em alguns outros estudos. Sabe-se que o hematoma é, geralmente, ocasionado pelo rompimento de vasos sanguíneos, decorrente das quedas e traumas sofridos principalmente pela 
população mais idosa, que causam pequenas hemorragias na pele (LEBLANC; BARANOSKI, 2014). Em revisão integrativa (RAYNER et al. 2015) sobre as características da pele do paciente com LF, a presença de hematoma $(9 / 70 \%)$ foi encontrada como fator de risco para a formação de LF. Em estudo brasileiro ainda não publicado, a presença do hematoma também se associou à ocorrência de LF, em residentes de instituições asilares $(p=0,017)$ (PERES, 2014).

$\mathrm{Na}$ literatura internacional, Carville et al, 2007 também identificaram a presença de hematoma como um fator de risco para a formação de LF. Já, LeBlanc et al. (2013) encontraram somente a equimose $(14,7 \%)$, como fator de risco para a formação da LF.

\subsection{PREVALÊNCIA DE DAI E FATORES ASSOCIADOS}

Nos dias atuais, a DAl é considerada como um fator de impacto negativo na vida diária das pessoas, por comprometer além do convívio social, ocasionados pela depressão e redução da autoestima, a qualidade de vida, devido ao desconforto, dor e prurido (CUNHA et al., 2015). Provoca também problemas clínicos como quedas e traumas (causados pela urgência em chegar ao banheiro) e maior vulnerabilidade à ocorrência de infecções perineais, genitais, no trato urinário e cutâneas (principalmente a candidíase) (CUNHA et al., 2015; CHAIMOWICZ, 2013; REIS et al., 2003).

No presente estudo, a prevalência de DAl foi apenas $0,5 \%$, resultado bem abaixo dos valores encontrados em outras publicações, como em estudo brasileiro, desenvolvido no Paraná, em que 11 dos 72 pacientes da amostra, internados em UTI, apresentaram DAI, com prevalência de 15,2\% (BAESSA et al., 2014).

Entre as pesquisas internacionais, destaca-se um estudo multicêntrico de prevalência de DAI, em cenários hospitalar e asilar, ocorridos concomitantemente nas cidades da Áustria e Holanda (KOTTNER et al. 2014), apontando prevalência de 4,3\% e 7,0\% respectivamente. Outros estudos sobre a prevalência de DAI, também realizados com pacientes 
hospitalizados, mostraram valores de $52,5 \%$ e $24 \%$, respectivamente para Rohwer et al. (2013), nos Estados Unidos, e Campbell et al. (2014), na Austrália.

A localização anatômica de DAl foi predominante na região dos grandes lábios (2/40\%), resultado semelhante ao encontrado nos estudos de Rohwer et al. (2013) e Baessa et al. (2014).

Quanto à sua classificação, segundo o Incontinence Associated Dermatitis Intervention Tool (JUNKIN; SELEKOF, 2008), a DAI precoce (early IAD) foi a mais frequente (2/40\%).

Similarmente às LF, também para a DAI não se verificaram fatores associados à sua ocorrência (segundo a CART). Porém, alguns fatores como o uso de fralda ( $p=0,035$, na Tabela 5) e a presença de rigidez ( $p=0,042$, na Tabela 5) merecem ser comentados, mesmo que não tenham permanecido no modelo CART, neste estudo.

O uso de fraldas em pacientes incontinentes é importante fator associado à DAI. Sabe-se que a presença de fezes líquidas e urina na fralda em contato prolongado com a pele causam irritação e maceração decorrentes da umidade e do calor local. As enzimas digestivas lipases e proteases são as maiores agentes de irritação e responsáveis por essas alterações na pele (GRAY et al., 2012). As áreas mais afetadas são geralmente a região anogenital, abdome, glúteos e porção superior das coxas (AQUINO et al., 2012).

No estudo de Baessa et al. (2014), realizado com 72 pacientes críticos no Paraná, a prevalência de DAI em relação ao uso de fraldas foi de $(11 / 90 \%)$.

No estudo com pacientes australianos (CAMPBELL et al., 2014), já referido anteriormente, $80 \%$ dos pacientes em UTI, que usavam fraldas, apresentaram DAI, resultado bastante significativo e preocupante.

Em revisão sistemática de literatura $(n=54)$, Coleman et al., (2013) encontraram a rigidez como um dos fatores associados à presença de lesões, além de DM, umidade da pele, idade avançada e nutrição prejudicada. Em idosos institucionalizados, os autores (FREITAS et al., 
2011) constataram a presença de AVC e HAS como fatores associados à prevalência de feridas crônicas. A rigidez pode constituir uma das manifestações das alterações neurológicas. Neste segmento, pode-se inferir a gravidade do paciente com DAl do ponto de vista neurológico e suas consequências no âmbito da continência.

\subsection{PREVALÊNCIA DE FOC E FATORES ASSOCIADOS}

As FOC são consideradas como uma das maiores complicações pósoperatórias devidas, principalmente, aos altos índices de morbidade e mortalidade delas decorrentes (BATISTA; RODRIGUES, 2012).

No presente estudo, constataram-se 21 pacientes com FOC, totalizando prevalência de 2,7\%, com amplo predomínio das infecções de sítio cirúrgico.

Dentre os estudos nacionais sobre prevalência de FOC, realizados em cenário hospitalar, têm-se os de Ribeiro et al. (2013) e de Bellusse et al. (2015), na cidade de São Paulo, com amostras de 93 e 85 pacientes, respectivamente. Ambas as prevalências obtidas por esses autores, 17,2\% e $9,4 \%$ respectivamente, foram bastante superiores àquela aqui encontrada. Cirurgias ortopédica e neurocirúrgica foram os procedimentos cirúrgicos a que esses pacientes foram submetidos, respectivamente, ambas consideradas eletivas e limpas.

Em outro estudo brasileiro, na cidade de Rio Branco, no Acre, Aguiar et al. (2012) constataram valor mais baixo, de 3,68\% $(n=2.203$ pacientes hospitalizados). Quanto ao potencial de contaminação cirúrgica, dos 81 pacientes com ISC, $72,84 \%$ (59 pacientes) foram submetidos a cirurgias potencialmente contaminadas, 16,05\% (13 pacientes) eram cirurgias limpas, $8,64 \%$ (sete pacientes) cirurgias contaminadas e $2,47 \%$ (dois pacientes) cirurgias infectadas.

Valor ainda inferior aos anteriores $(0,8 \%)$ foi verificado por Melo et al. (2013), em seu estudo documental retrospectivo, realizado com 247 prontuários de pacientes da Fundação Prof. Martiniano Fernandes e Instituto 
de Medicina Integral Prof. Fernando Figueira, em Recife, submetidos à colecistectomia videolaparoscópica. Resultado similar foi constatado em estudo realizado no Hospital de Uberaba, em Minas Gerais, com pacientes de alta complexidade. Em 12.101 cirurgias de urgência e emergência, 91 pacientes apresentaram ISC (0,75\%). Dessas, $38(41,8 \%)$ cirurgias eram contaminadas, $26(28,6 \%)$ potencialmente contaminadas, $24(26,4 \%)$ limpas e três (3,3\%) infectadas. O tempo médio de internação foi 19,3 dias, com variação de 1 a 112 dias (BARBOSA et al., 2011).

No estudo de Soares et al. (2011), a prevalência de ISC em cirurgia cardíaca foi $6,56 \%$ em 211 pacientes hospitalizados investigados. O tempo médio de internação foi 6,63 dias e as cirurgias mais realizadas foram: revascularização miocárdica, troca valvar e valvoplastia. No estudo de Lichtenfels et al. (2014), dos 680 pacientes submetidos à cirurgia de revascularização arterial periférica, 70 (65,7\%) desenvolveram ISC no pósoperatório.

Nos EUA, 48 dentre 1.320 pacientes hospitalizados apresentaram FOC (4\%), após cirurgia de correção de fratura no cotovelo. O uso de placa e parafuso de fixação (odds ratio ajustado $[\mathrm{OR}]=2,2 ; 95 \% \mathrm{Cl}, 1,0-4,5 ; \mathrm{p}=$ 0,041 ) e uso de fixador externo antes da cirurgia (OR ajustada $=4,7 ;$ IC95\% $1,1-21 ; p=0,035)$ foram associados com maiores taxas de infecção (CLAESSEN et al., 2016). A região corporal mais acometida, foi na perna D/E (10/47,6\%), e classificação da lesão causada por infecção, resultado semelhante a outros estudos (BATISTA; RODRIGUES, 2012; MELO et al., 2013; RIBEIRO et al., 2013; BELLUSE et al., 2015). O tecido predominante no leito da ferida foi o esfacelo, com moderada quantidade de exsudato.

De maneira semelhante às duas lesões anteriores, LF e DAI, também para as FOC não foram identificados fatores a elas associados quando os dados foram submetidos à regressão (CART).

No entanto, a literatura menciona inúmeros fatores de risco ou associados ao desenvolvimento de complicações da ferida operatória, principalmente a ISC, como no presente estudo. 
Ribeiro et al. (2013) descrevem apenas a variável tempo total de internação com relação estatisticamente significativa à presença ou não de ISC (Wald $=11,072 ; p=0,01$ ). Também no estudo de Aguiar et al. (2012), os fatores associados à ISC foram tempo cirúrgico prolongado e uso de drenos.

Outros estudos também apontam o tempo de internação como associado à ISC (MONGE et al., 2006; SILVA; BARBOSA, 2012; OLIVEIRA et al., 2012; MELO et al., 2013; BELLUSSE et al., 2015). Além de associarse ao maior risco de ISC, o longo período de internação também eleva os custos das instituições de saúde, retarda a recuperação do paciente e aumenta o risco de desenvolvimento de outras complicações, podendo levar à morte (RIBEIRO et al., 2013).

O procedimento cirúrgico também foi mencionado como fator relacionado à formação de FOC (AGUIAR et al., 2012).

\subsection{PREVALÊNCIA DE LP E FATORES ASSOCIADOS}

A prevalência de LP surge como a mais elevada entre as lesões aqui estudadas $(10,3 \%)$, não somente as crônicas como também comparativamente às agudas.

Em geral, esse resultado encontra-se abaixo dos valores identificados em outros estudos nacionais e mesmo alguns internacionais.

Em cenário hospitalar, constata-se variação de 12,5\% a 28,1\% para autores nacionais (ROGENSKI, SANTOS, 2006; CHAYAMITI; CALIRI, 2010; FREITAS et al., 2011; BRITO et al., 2013; QUEIROZ et al., 2014; COSTA et al., 2015; VIEIRA et al., 2016). Salomé (2010) obteve valor bastante superior, em seu estudo, dos 21 dentre 31 pacientes internados em UTI com LP, a prevalência encontrada foi $67,7 \%$. Em estudo mais recente, realizado em unidade de emergência do Hospital das Clinicas da Faculdade de Medicina de Ribeirão Preto da Universidade de São Paulo, Bernardes; Caliri (2016), encontraram $40 \%$ dos pacientes hospitalizados com LP, bastante elevada, se comparada com os outros estudos. 
Dentre os estudos internacionais, para o mesmo tipo de pacientes, obtiveram-se algumas discrepâncias entre os resultados.

No estudo de Moore et al. (2015), acerca da prevalência de LP em hospitais da Noruega e da Irlanda, encontraram-se $54,0 \%$ dos pacientes com LP na Noruega e 12,0\% na Irlanda (em amostra geral de 180 pacientes). Metha et al. (2015) identificaram prevalência intermediária de 24,3\%, na Índia, com pacientes internados no setor de emergência hospitalar. Com valores gradativamente inferiores, têm-se 17\% (63/294) no México (MARTINEZ et al., 2014); 16\% ( $n=295)$ na Jordânia (TUBAISHAT; ALJEZAWI, 2013; 11\% na Nigeria (IYUN et al., 2016); 7,9\% em Portugal (SARDO et al., 2016); e 4,5 (91/1132) na Indonésia (AMIR et al., 2017).

Quanto às características das LP, a região corporal mais frequentemente afetada foi a sacral (73\%), o que vai ao encontro da literatura nacional (CHACON et al., 2009; SALOMÉ, 2010; GOMES et al., 2010; BRITO et al., 2013; QUEIROZ et al., 2014; COSTA et al., 2015; GALVÃO et al., 2015) e internacional (GUNNINGBERG et al., 2013; IGARASHI et al., 2013; MARTINEZ et al., 2014; SARDO et al., 2016; GARCEZ et al., 2016), sobre LP em pacientes agudos e críticos hospitalizados.

A LP em estágio 1 foi a mais frequente $(19 / 23,7 \%)$ no presente estudo, semelhante a outros estudos. Os resultados descritos por Sardo et al. (2016), com porcentagem de 42,3\%; Bredesen et al. (2015), com 16,6\%; Manglano et al. (2016), com 27\%; Baath et al. (2014), com 16,6\%; Garcez et al. (2016), com 4,9\%; Gunningberg et al. (2013), com 17,6\%; Moore et al. (2015), com 69,0\%; Chayamiti; Caliri (2010), com 35,3\% e Igarashi et al. (2013), com 15,4\% corroboram a elevada frequência do estágio 1 . Em alguns outros estudos, o estágio 2 foi o mais frequente, com porcentagens diversas, como 57,0\% para Gomes et al. (2010); 32,9\% para Brito et al. (2013); 32,0\% para Martinez et al. (2014); 14,2\% para Salomé (2010) e $64,2 \%$ para Khor et al. (2014), todos acima do percentual encontrado (18/80; $22,5 \%$ ) no presente estudo. Nos estudos de Queiroz et al. (2014) e de Mehta et al. (2015), o predomínio foi de LP em estágio 3, com 47,3\% e 43,0\%, 
respectivamente. O estágio $4(77,5 \%)$ prevaleceu somente no estudo de Costa et al. (2015).

A necrose foi o tecido predominante no leito da ferida dos pacientes com LP, seguindo-se o tecido de granulação.

Quanto aos fatores associados ao desenvolvimento de LP, no presente estudo, verificou-se que o uso de fraldas e a presença de curativo, simultaneamente, foram os fatores que melhor explicaram a sua ocorrência. Setenta e cinco dentre 80 pacientes com LP usavam fraldas e, destes, 34 também possuíam um curativo. Embora a presença de curativo em associação ao emprego de fraldas tenha se mostrado fatores associados conjuntamente à presença de LP, os estudos não realizam esse tipo de análise, daí considera-los separadamente para a discussão.

Sabe-se que a fralda é utilizada para a absorção da urina e das fezes e que a exposição prolongada e/ou repetida da pele a esses efluentes causa hiper-hidratação da pele. O excesso de umidade torna a pele mais susceptível à lesão. A umidade tem como característica tornar a pele mais amolecida.

A uréia proveniente da urina é convertida em amônia por bactérias e eleva o $\mathrm{pH}$ da pele, tornando-o alcalino e diminuindo a tolerância da pele à fricção/ atrito entre a pele e as roupas, lençóis e fralda (JUNKIN; SELEKOF, 2008; GRAY et al., 2011).

A utilização frequente de fraldas também ocasiona aumento na temperatura da pele, ocorrendo à vasodilatação com inflamação e aumento da umidade local, com consequente maceração da derme. Atualmente, o uso de fraldas descartáveis e a evolução tecnológica em sua produção tem reduzido o risco de desenvolvimento de lesões na pele. No entanto, o excesso de fricção entre a pele e a fralda durante os movimentos ainda é fator predisponente para a formação de lesões (GRAY et al., 2004).

A recomendação, portanto, baseia-se na seleção adequada das fraldas descartáveis, sua troca frequente, higiene adequada e uso de produtos como barreiras de proteção da pele, a fim de evitar umidade excessiva e a formação de lesões (COELHO et al., 2012). 
Mais recentemente, tem havido preocupação quanto ao diagnóstico diferencial entre as LP e outros tipos de lesões relacionadas à umidade, como a DAl. Alguns pacientes estão propensos a desenvolver lesões de etiologia mista como a DAl e a LP. Tendo em vista que tanto a DAI como a LP em estágio 1 apresentam-se clinicamente com eritema de pele intacta, os fatores etiológicos devem ser estabelecidos. O eritema associado à LP em estágio 1 representa uma resposta inflamatória à isquemia em tecidos mais profundos, como o muscular, devido à pressão. Já o eritema associado à DAl também representa resposta inflamatória porém a irritantes como os sais biliares e lipases pancreáticas expondo a epiderme e a derme. Uma lesão, em que há exposição da pele à pressão e às fezes ou urina pode não permitir que o clínico determine com precisão a profundidade da lesão e magnitude da inflamação na inspeção visual e palpação. Em consenso desenvolvido para a DAI (DOUGHTY et al., 2012) a recomendação indica que o examinador exerça leve pressão sobre a área eritematosa para determinar o embranquecimento ou não da pele. As lesões que não o fazem e estão localizadas sobre uma proeminência óssea devem ser classificadas como LP estágio 1 ou 2. As lesões ocasionadas pela DAl apresentam-se com os seguintes sinais e sintomas: ardência, dor, prurido e formigamento; como lesões superficiais, irregulares com bordas difusas e espalhadas, ou também sob a forma linear, limitada ao sulco anal e à região genital. Também os sinais podem variar conforme a gravidade: eritema brilhante, com ou sem exsudato claro, edema, fissuras, pápulas, vesículas, descamação e erosões (DOUGHTY et al., 2012).

Sabe-se que a cobertura constitui importante etapa na terapia tópica de feridas crônicas como as LP, protegendo a lesão, prevenindo seu resfriamento e invasão microbiana, e desempenhando algumas das funções da própria pele. Estabelecer relação da presença de curativo e LP pode se realizar direta ou indiretamente. O curativo deve ser executado com habilidade e baseado em cuidadoso e criterioso processo de avaliação para a escolha das melhores estratégias locais de manejo, desde a limpeza e desbridamento à cobertura a ser utilizada. Portanto, deve-se ter cuidado 
para que o curativo não se torne um fator de agressão e adverso, controlando a pressão excessiva durante a oclusão da ferida com bandagem ou atadura de crepe, evitando aplicação de pressão excessiva que pode ser fator contribuinte para o desenvolvimento de LP no local (BLANES; FERREIRA, 2014). Além disso, na classificação atual das LP pelo NPUAP (2016), incluiu-se a categoria de LP Relacionada a Dispositivo Médico, o que deve ser considerado nessa situação, fazendo-se adequadamente o diagnóstico diferencial com as LF.

\subsection{PREVALÊNCIA DE UD E FATORES ASSOCIADOS}

Quanto às UD, a prevalência foi $8,5 \%$, também considerada baixa quando comparada com outros estudos nacionais, como na publicação de Oliveira et al. (2016), que as encontraram em 13 dentre 42 pacientes hospitalizados, correspondendo à prevalência de $31 \%$. O estudo ocorreu em um hospital geral, no estado de Goiás.

Dentre os estudos internacionais, destacam-se os de Nehring et al. (2014), na Polônia, e de Pedras et al. (2016), em Portugal, também realizados com pacientes hospitalizados, mostrando valores superiores, de 16,1\% e 29,1\% respectivamente. Em Calcutá (SINHARAY et al., 2012), a prevalência de UD em 1674 pacientes internados em unidade hospitalar foi $4,8 \%$.

Em uma clínica especializada em cuidados com o pé diabético, na Jamaica, Ferguson et al. (2013) constataram prevalência inferior (4,3\%) àquela aqui verificada, apesar de se tratar de cenário distinto, o que pode indicar a eficiência de um programa de seguimento sistemático especializado.

Com relação à classificação das UD segundo a escala de Wagner, houve predomínio do Grau 4 (34,4\%), semelhante ao encontrado em outros estudos, também em cenário hospitalar (PEREIRA et al., 2010; OLIVEIRA et al., 2016). No estudo de Martin et al. (2012), junto a pacientes atendidos no 
ambulatório da cidade de Ribeirão Preto, UD de Grau 1 (83,3\%) prevaleceram.

Pacientes diabéticos com doença vascular periférica e sem uso de emolientes foram fatores associados simultaneamente à ocorrência de UD em manauaras internados nos hospitais públicos de Manaus. Igualmente às LP, esses fatores são discutidos separadamente, tendo em vista as análises encontradas na literatura consultada.

Segundo a literatura, a DM é considerada uma doença crônica degenerativa que vem apresentando índices bastante elevados de morbimortalidade, principalmente a DM do Tipo 2. Torna-se assim um grave problema de saúde pública, pois também aumenta os gastos com tratamento, além de prejudicar a qualidade de vida das pessoas que a apresentam (DUARTE; GONÇALVES, 2011).

A UD surge em decorrência de alterações vasculares periféricas e/ou neurológicas. A doença vascular periférica (DVP) é o fator mais importante relacionado à ocorrência das UD, devido a interrupção no fornecimento de nutrientes e oxigênio ao leito da ferida, e favorecer o processo infeccioso na lesão, pelo prejuízo da ação do antibiótico ocasionado pela isquemia (KUO et al., 2008). A DVP também pode ser considerada como um sinal de doença aterosclerótica, que ocorre devido ao acúmulo de colesterol nas paredes dos vasos, ocasionando placas na camada íntima, as quais podem gerar a trombose. Ainda não se sabe precisar, qual a associação da aterosclerose e os pacientes com DM, uma das hipóteses, seria a presença de lipoproteínas circulantes, resultando em um perfil lipídico aterogênico, com baixo colesterol-HDL e elevação de triglicérides (GRUPO DE TRABALHO INTERNACIONAL SOBRE PÉ DIABÉTICO, 2001).

A DVP associada à neuropatia é responsável pelos casos de amputações não traumáticas. A neuropatia diabética ocorre devido à disfunção dos nervos periféricos atribuída exclusivamente ao DM. As causas da neuropatia relacionam-se a hiperglicemia de longa duração e a isquemia das fibras nervosas sensitivas, motoras e autonômicas (GRUPO DE TRABALHO INTERNACIONAL SOBRE PÉ DIABÉTICO, 2001). 
Avaliando o risco de UD em 48 pacientes atendidos em Unidade de Saúde da Família (USF), em Recife, os autores (BEZERRA et al., 2015) encontraram três $(6,3 \%)$ pacientes com risco 3 (úlcera/amputação prévia). Em outro estudo em Sergipe, 44 (55\%) de 80 pacientes hospitalizados com UD tiveram amputação dos membros inferiores (NUNES et al., 2006). Ferguson et al. (2013), na Jamaica, em estudo sobre prevalência de complicações em UD, encontraram $8,5 \%$ para amputações predominando entre os homens $(22,2 \%)$.

Outro achado importante no presente estudo foi o não emprego de emolientes, como fator significativamente associado à presença de UD. Sabe-se que os emolientes são substâncias hidratantes que tem a propriedade de amolecer e abrandar a pele íntegra, manter a hidratação cutânea e evitar o ressecamento da pele e o surgimento de fissuras. A aplicação de emolientes na pele substitui a função de barreira decorrente da perda da lubrificação natural, como ocorre em pacientes com DM, cuja produção de sebo está comprometida (BLANES; FERREIRA, 2014).

Os emolientes possuem os ácidos graxos essenciais, que são metabólitos considerados importantes para impedir o processo inflamatório como a contração vascular, quimiotaxia, adesão, diapedese, ativação e morte celular. Em se tratando do tratamento de feridas, os ácidos graxos essenciais considerados mais importantes, por não serem sintetizados pelos mamíferos, são os ácidos linoleico e linolênico. O ácido linolênico é um lipídio localizado na camada epidérmica e tem como função formar uma barreira de proteção para a pele ao agir como restaurador tecidual (promove a quimiotaxia e a angiogênese, mantendo o meio úmido e acelerando o processo de granulação tecidual). O ácido linoleico é responsável pelo desbridamento autolitico no leito da lesão, pois contribui com a produção de metaloproteinas, que induzem a formação do tecido de granulação e aceleram o processo de cicatrização tecidual. Tem ainda a função de proteger a pele contra infecções por Staphylococus aureus, pois regula a permeabilidade da barreira de água proporcionando a nutrição celular (DECLAIR, 2002). Mas, poucos são os estudos sobre a eficácia desse 
produto na cicatrização de feridas, portanto é necessária cautela quanto ao uso diário dessa substância na pele com lesões, devido à escassez de evidências sobre o assunto (BLANES; FERREIRA, 2014).

\subsection{FATORES ASSOCIADOS DAS FERIDAS AGUDAS E CRÔNICAS}

Além dos fatores associados às LP e UD, resultantes das análises de regressão do tipo CART, bem como outros identificados somente através das análises univariadas, todos já discutidos anteriormente, alguns outros fatores relacionados à ocorrência das lesões agudas e crônicas em geral merecem alguns comentários.

É fundamental considerar que as feridas em geral podem surgir com mais frequência em indivíduos com DM, em função das inúmeras alterações que acometem esses indivíduos. Alterações imunológicas causadas pelo DM, como a diminuição da quimiotaxia de granulócitos para a ferida, acarretam menor capacidade de adesão das bactérias à fagocitose, predispondo a infecções e complicações no tratamento dessas lesões. A presença de bactérias na ferida dificulta as fases do processo cicatricial, pois prolonga a fase inflamatória, retarda a epitelização, a contração e a deposição de colágeno (BOWLING et al., 2009).

Por outro lado, a hiperglicemia crônica também altera o mecanismo cicatricial. O tecido de granulação de pacientes com DM apresenta deficiência quanto ao número de macrófagos, crescimento de fibroblastos, deposição de matriz e alteração da angiogênese. A epitelização da ferida também é mais vagarosa, devido os macrófagos produzirem menos fatores de crescimento de queratinócitos (KGH) (PAGGIARO et al., 2010).

Finalmente, indivíduos com UD possuem limitações de suas atividades cotidianas, devido à redução das funções musculoesqueléticas e sensoriais dos pés, as quais, se não diagnosticadas e tratadas/ minimizadas, podem acarretar a piora de suas condições até à amputação do membro afetado (PEREIRA et al., 2010). 
O uso de certos medicamentos interfere diretamente no processo de cicatrização de feridas ou mesmo favorece o seu desenvolvimento, como o uso contínuo de anticoagulantes. Esses inibem a síntese de vitamina K, essencial para a formação de fatores de coagulação, além de diminuir a hemostasia e a inflamação (FREITAS et al., 2011), podendo prolongar a fase inflamatória no processo de cicatrização.

No presente estudo, escores de Braden superiores a 18, ou seja, ausência de risco para desenvolvimento de LP, também constituíram um dos fatores associados ao desenvolvimento de feridas agudas e crônicas em geral. Esse resultado é bastante intrigante, uma vez que a escala de Braden inclui subescalas que se referem a fatores comuns na gênese de outras lesões além das LP, como DAl (umidade), LF (fricção e cisalhamento; atividade e mobilidade; percepção sensorial), FOC (nutrição, atividade e mobilidade), dentre outras. 
7 CONCLUSÃO 


\section{CONCLUSÃO}

O presente estudo sobre a prevalência de lesões agudas e crônicas (LF, DAI, FOC, LP e UD) em 775 pacientes internados em sete unidades hospitalares na cidade de Manaus-AM, permitiu identificar prevalência global de $23 \%$, sendo as mais prevalentes as LP $(80 / 10,3 \%)$ e as UD $(66 / 8,5 \%)$.

Constataram-se diferentes fatores associados à presença das feridas, isoladamente (LP e UD) e de maneira global. Uso de fralda e curativo associaram-se à ocorrência de LP; e doença vascular periférica e não uso de emoliente à presença de UD. Para a ocorrência de todas as feridas agudas e crônicas de forma simultânea, os fatores associados encontrados foram: pacientes diabéticos, que utilizaram anticoagulantes e com rigidez; pacientes diabéticos que não utilizaram anticoagulantes; pacientes não diabéticos, sem risco para desenvolvimento de LP e com curativo; pacientes não diabéticos, sem risco para desenvolvimento de LP, sem curativo e com hematoma. 


\section{CONSIDERAÇÕES FINAIS}

Esta pesquisa, considerada inédita na região amazônica, principalmente pela sua abrangência, proporcionará aos profissionais de saúde informações atualizadas sobre a prevalência das principais feridas agudas e crônicas (LF, DAI, FOC, LP e UD), contribuindo para a identificação de diagnósticos mais precisos, possibilitando, então, a oferta de melhor qualidade de tratamento aos pacientes hospitalizados.

Os resultados obtidos nesta pesquisa apontam prevalência global elevada de lesões nas instituições investigadas, indicando a necessidade de mudanças paradigmáticas no processo de trabalho dos profissionais de saúde, principalmente de enfermeiros e sua equipe, buscando melhores evidências para sua prática quotidiana no sentido da melhoria da qualidade de atenção e bem-estar da clientela hospitalizada, iniciando-se pela cidade de Manaus, na região amazônica.

Tais resultados diagnósticos contribuem para a definição de algumas estratégias de intervenção que podem vir a constituir fundamentos para o desenvolvimento de diretrizes voltadas à prevenção e ao tratamento dessas lesões, sempre em busca da melhoria da qualidade assistencial.

Mesmo tendo-se realizado o estudo em todos os hospitais públicos da cidade de Manaus, não foi possível identificar fatores associados a três das cinco lesões investigadas, exatamente as lesões agudas (LF, DAI e FOC), nas análises de regressão (CART), provavelmente em função do reduzido número de pacientes que apresentaram essas lesões.

Assim, os resultados deste estudo devem ser analisados considerando as limitações do mesmo que além do tamanho pequeno da amostra, a coleta de dados foi realizada em um período em que os hospitais estavam com baixa ocupação de leitos devido à dificuldade financeira enfrentada pelo estado do Amazonas, no período da coleta de dados, uma vez, que observou-se uma quantidade muito grande de leitos vagos. E a coleta de dados ter sido realizada por uma única pessoa, dificultando a realização da mesma em somente um dia. Isto tudo indica a necessidade de 
replicar o estudo também em instituições privadas e em ambos os tipos de instituições hospitalares fora de Manaus. Estudos de incidência também são altamente desejáveis e necessários. 
REFERÊNCIAS 


\section{REFERÊNCIAS}

AGUIAR, A.P.L. et al. Fatores associados à infecção de sítio cirúrgico em um hospital na Amazônia ocidental brasileira. Rev. SOBECC, v.17, n. 3, p. 6070, 2012.

ALBUQUERQUE, E.R.; ALVES, E.F. Análise da Produção Bibliográfica sobre Qualidade de Vida de portadores de feridas crônicas. Revista Saúde e Pesquisa, v.4, n. 2, p. 147-52, 2011.

ALJA'AFREH, M.; MOSLEH, S.M. Pressure ulcers in Jordan: a snapshot survey of a tertiary public hospital. Br. J. Nurs., v.22, n. 20.p.14-6, 2013.

ALJEZAWI, M.; QADIRE, M.A.L.; TUBAISHAT, A. Pressure ulcers in longterm care: a point prevalence study in Jordan. Br. J. Nurs., v.9, n. 23. p.10-1, 2014.

ALMEIDA, A.S. et al. Avaliação da qualidade de vida em pacientes com diabetes mellitus e pé ulcerado. Rev. Bras. Cir. Plást., v.28, n.1, p.142-6, 2013.

ALVES, A.G.P.; BORGES, J.W.P.; BRITO, M.A. Assessment of risk for pressure ulcers in intensive care units: an integrative review. J. Res. Fundam. Care, v. 6, n.2, p.793-804, 2014.

AMARAL, A.F.S.; PULIDO, K.C.S.; SANTOS, V.L.C.G. Prevalência de lesões por friç̧ão em pacientes hospitalizados com câncer. Rev. Esc. Enferm. USP, v.46, p.44-50, 2012.

AMIR, Y. et al. Pressure ulcers in four Indonesian hospitals: prevalence, patient characteristics, ulcer characteristics, prevention and treatment. Int. Wound J., v.14, n.1, p.184-93, 2017.

APOLLONIO, A. et al.; SUV Study Group. A large Italian observational multicentre study on vascular ulcers of the lower limbs (Studio Ulcere Vascolari). Int. Wound J., v.13, n.1, p.27-34, 2016.

AQUINO, A.L.; CHIANCA, T.C.M.; BRITO, R.C.S. Integridade da pele prejudicada, evidenciada por dermatite da área das fraldas: revisão integrativa. Rev. Eletr. Enf., v.14, n.2, p.414-24, 2012.

AYELLO, E.A.; BRADEN, B. How and Why to do pressure ulcer risk assessment. Adv. Skin Wound Care., v.15, n.3, p.125-32, 2002. 
AZOUBEL, R.; et al. Efeitos da terapia física descongestiva na cicatrização de úlceras venosas. Rev. Esc. Enferm. USP, v.44, n.4, p.1085-92, 2010.

BAATH, C. et al. Pressure-reducing interventions among persons with pressure ulcers: results from the first three national pressure ulcer prevalence surveys in Sweden. J. Eval. Clin. Pract., v.20, p.58-65, 2014.

BABA, M.; DAVIS, W.A.; DAVIS, T.M. A longitudinal study of foot ulceration and its risk factors in community-based patients with type 2 diabetes: The Fremantle Diabetes Study. Diabetes Res. Clin. Pract., v.106, n.1, p.42-9, 2014.

BAESSA, C.E.B.; MEIRELES, V.C.; BALAN, M.A.J. Ocorrência de Dermatite Associada à Incontinência em Pacientes Internados na Unidade de Terapia Intensiva. Revista Estima, v.12, n.2, 2014.

BARBOSA, M.H. et al. Ocorrência de infecção de sítio cirúrgico em cirurgias de urgência e emergência. REME Revista Mineira de Enfermagem, v.15, n.2, p.254-8, 2011.

BARBOSA, T.P.; BECCARIA, L.M.; POLETTI, N.A.A. Avaliação do risco de úlcera por pressão em UTI e assistência preventiva de enfermagem. Rev. Enferm. UERJ., v.22, n.3, p.353-8, 2014.

BARROS, A.L.B.L. Anamnese e Exame Físico - Avaliação Diagnóstica de Enfermagem no adulto. $3^{a}$ Ed. Porto Alegre: Artmed; 2015.

BATISTA, T.F.; RODRIGUES, M.C.S. Vigilância de infecção de sítio cirúrgico pós-alta hospitalar em hospital de ensino do Distrito Federal, Brasil: estudo descritivo retrospectivo no período 2005-2010. Epidemiol. Serv. Saúde, v.21, n.2, p.253-64, 2012.

BELLUSSE, G.C. et al. Fatores de risco de infecção da ferida operatória em neurocirurgia. Acta Paul. Enferm., v.28, n.1, p.66-73, 2015.

BERGSTROM, N.; et al. The Braden Scale for Predicting Pressure Sore Risk. Nurs. Res., v.36, n.4, p.205-10, 1987.

BERNARDES, R.M.; CALIRI, M.H.L. Pressure ulcer prevalence in emergency hospitals: a cross-sectional study. Online Braz. J. Nurs. [internet], v.15, n.2, p.236-44, 2016.

BEZERRA, G.C. et al. Avaliação do risco para desenvolver pé diabético na atenção básica. Revista Estima, v.13, n.3, 2015. 
BLANES, L.; FERREIRA, L.M. Prevenção e tratamento de úlcera por pressão. São Paulo: Atheneu, 2014.

BLISS, D.Z.; et al. Prevalence and correlates of perineal dermatidis in nursing home residents. Nurs. Res., v.55, n.4, p.243-51, 2006.

BORGHARDT, A.T.; et al. Avaliação das escalas de risco para úlcera por pressão em pacientes críticos: uma coorte prospectiva. Rev. Latino-Am. Enfermagem, v.23, n.1, p.28-35, 2015.

BOWLING, F.L.; JUDE, E.B.; BOULTON, A.J. MRSA and diabetic foot wounds: contaminating or infecting organisms? Curr. Diab. Rep., v.9, n.6, p.440-4, 2009.

BRASIL. Fundação Oswaldo Cruz. PROQUALIS. Instituto de comunicação e informação Cientifica e Tecnológica em saúde. Indicadores de Segurança do Paciente. Prevenção e Controle de Infecção. Organização para a Cooperação e Desenvolvimento Econômico (OECD); Safetylmprovement for Patients in Europe (SIMPATIE); ANVISA. Brasília: Ministério da Saúde, 2014.

BRASIL. Ministério da Saúde. Resolução CNS № 466, de 12 de dezembro de 2012. Aprovar diretrizes e normas regulamentadoras de pesquisas envolvendo seres humanos. Diário Oficial da República Federativa do Brasil, Brasília, 12 de dezembro de 2012.

BREDESEN, I.M. et al. The prevalence, prevention and multilevel variance of pressure ulcers in Norwegian hospitals: A cross-sectional study. Int. J. Nurs. Stud., v.52, n.1, p.149-56, 2015.

BREIMAN L. et al. Classification and regression trees. Pacific Grove. Califórnia: Wadsworth and Brooks, 1984.

BRITO, P.A.; GENEROSO, S.V.; CORREIA, M.I.T.V. Prevalence of pressure ulcers in hospitals in Brazil and association with nutritional statusda multicenter, cross-sectional study. Rev. Nutrition, v.29, p.646-9, 2013.

CALIRI, M.H.L. et al. Classificação de lesões por pressão - consenso NPUAP 2016 - adaptada culturalmente para o Brasil. Disponível em: http://sobest.org.br/textod/35.

CAMPBELL, J.L.; COYER, F.M.; OSBORNE, S.R. Incontinence-associated dermatitis: a cross-sectional prevalence study in the Australian acute care hospital setting. Int. Wound J., v.13, n.3, p. 403-11, 2014. 
CAMPOS, J.A.D.B. et al. Métodos de estimativa de peso e altura na avaliação de desnutrição de pacientes com câncer. Alim. Nutr., Araraquara, v.23, n.4, p.681-8, 2012.

CARDOSO, J.R.S. et al. Prevalence of pressure ulcers in a Brazilian hospital: results of a cross-sectional study. Ostomy Wound Manage., v.56, n.10, p.52-7, 2010.

CARVALHO, D.S.; KOWACS, P.A. Avaliação da intensidade de dor. Migrâneas Cefaléias, v.9, n.4, p.164-8, 2006.

CARVALHO, D.V.; BORGES, E.L. Tratamento ambulatorial de pacientes com ferida cirúrgica abdominal e pélvica. REME - Revista Mineira de Enfermagem, v.15, n.1, p.25-33, 2011.

CARVILLE, K. et al. STAR: a consensus for skin tear classification. Primary Intention. v.15, n.1, 2007.

CDC. Centers for disease control. Procedure-associated Events SSI. Janeiro, 2016.

CDC. Centers for disease control. Procedure-associated Events SSI. Janeiro, 1992.

CHACON, J.M.F.; et al. Prevalence of pressure ulcers among the elderly living in long-stay institutions in São Paulo. São Paulo Med. J., v.127, n.4, p.211-5, 2009.

CHAIMOWICZ F. SAÚDE DO IDOSO. NESCON/UFMG - Curso de Especialização em Atenção Básica em Saúde da Família. 2 ed. Belo Horizonte: Nescon UFMG; 2013. p.67.

CHAYAMITI, E.M.P.C.; CALIRI, M.H.L. Úlcera por pressão em pacientes sob assistência domiciliária. Acta Paul. Enferm., v.23, n.1, p.29-34, 2010.

CLAESSEN, F.M. et al. What factors are associated with a surgical site infection after operative treatment of an elbow fracture?. Clin. Orthop. Relat. Res., v.474, n.2, p.562-70, 2016.

COÊLHO, A. et al. O idoso e a úlcera por pressão em serviço de atendimento domiciliar. Rev. Rene., v.13, n.3, p.639-49, 2012.

COLEMAN, S. et al. Patient risk factors for pressure ulcer development: systematic review. Int. J. Nurs. Stud., v. 50, n.7, p.974-1003, 2013. 
COSTA, A.M. et al. Custos do tratamento de úlceras por pressão em unidade de cuidados prolongados em uma instituição hospitalar de Minas Gerais. Rev. Enfermagem Revista, v.18, n.1, p.58-74, 2015.

CRIADO, P.R. et al. Reações tegumentares adversas relacionadas aos agentes antineoplásicos: parte II. An. Bras. Dermatol., v.85, n.5, p.591-608, 2010.

CUNHA, C.V. et al. Dermatite associada à incontinência em idosos: caracterização, prevenção e tratamento. Revista Estima, v.3, n.3, 2015.

DEALEY, C. Cuidando de feridas: um guia para as enfermeiras, Tradução: Rúbia Aparecida Lacerda, Vera Lucia Conceição Gouveia Santos, 3.ed. São Paulo: Atheneu, 2008.

DECLAIR, V. Tratamento de úlceras crônicas de difícil cicatrização com ácido linoleico. J. Bras. Med. v.82, n.6, p.36-41, 2002.

DIRETRIZES DA SOCIEDADE BRASILEIRA DE DIABETES: 20152016/Sociedade Brasileira de Diabetes; [organização José Egidio Paulo de Oliveira, Sérgio Vencio]. São Paulo: AC Farmacêutica, 2016.

DOUGHTY, D. et al. Incontinence associated dermatitis. Wound Ostomy Continence Nurse. v.39, n.3, p.303-315, 2012.

DUARTE, N.; GONÇALVES, A. Pé diabético. Angiologia e Cirurgia Vascular, v.7, n.2, p.65-79, 2011.

FARIA, M.M.P. Prevalência, perfil clinico e sociodemográficos dos portadores de feridas e usuários do Sistema Único de Saúde, internados em hospital geral do Tocantins. [Dissertação]. Brasília: Universidade de Brasília; 2010.

FERGUSON, T.S.; et al. Diabetic foot complications among patients attending a specialist diabetes clinic in Jamaica: prevalence and associated factors. West Indian Med. J., v.62, n.3, p.216-23, 2013.

FERNÁNDEZ, F.P.G.; et al. Incontinência e úlceras por pressão. Série Documento Técnico GNEAUPP $\mathrm{n}^{\circ}$ 10. Madrid: GNEAUPP Grupo Nacional para el Estudio y Asesoramiento en Úlceras por Presión y Heridas Crónicas, 2006.

FLETCHER, R.H.; FLETCHER, S.W. Epidemiologia clínica: elementos essenciais. $4^{\text {a }}$ ed. Porto Alegre, RS: Artmed; 2006. 
FREITAS, J.P.C.; ALBERTI, L.R. Aplicação da Escala de Braden em domicílio: incidência e fatores associados a úlcera por pressão. Acta Paul Enferm., v.26, n.6, p.515-21, 2013.

FREITAS, M.C. et al. Úlcera por pressão em idosos institucionalizados: análise da prevalência e fatores de risco. Rev. Gaúcha Enferm., v.32, n.1, p.143-50, 2011.

GALVÃO, N.S.; NETO, D.L.; OLIVEIRA, A.P.P. Aspectos epidemiológicos e clínicos de pacientes com úlcera por pressão internados em uma instituição hospitalar, Manaus. Revista Estima, v.13, n.3, p.91-96, 2015.

GARCEZ, S. et al. Analyses of pressure ulcer point prevalence at the first skin assessment in a Portuguese hospital. J. Tissue Viability, v.25, n.2, p.75-82, 2016.

GOMES, F.S.L. et al. Fatores associados à úlcera por pressão em pacientes internados nos centros de Terapia Intensiva de adultos. Rev. Esc. Enferm. USP, v.44, n.4, p.1070-6, 2010.

GONSKA, M.E. et al. The incidence and determinants of decubitus ulcers in hospital care. Deutsches Ärzteblatt International, v.110, n.33-34, p. 550-6, 2013.

GRAY, M. et al. Moisture-associated skin damage: overview and pathology. J. Wound Ostomy Continence Nurs., v.38, n.3, p. 233-241, 2011.

GRAY, M. Preventing and managing perineal dermatitis: a shared goal for wound and continence care. J. Wound Ostomy Continence Nurs., v.31, n.1, p.S2-S9, 2004.

GRAY, M. et al. Incontinence-associated dermatitis: A comprehensive review and update. J. Wound Ostomy Continence Nurs., v.39, n.1, p. 61-74, 2012.

GRAY, M. et al. Incontinence-associated dermatitis. J. Wound Ostomy Continence Nurs., v.34, n.1, p.45-54, 2007.

GRAY, M.; RATLIFF, C.; DONOVAN, A. Perineal skin care for the incontinent patient. Adv. Skin Wound Care, v.15, p.170-9, 2002.

GRUPO DE TRABALHO INTERNACIONAL SOBRE PÉ DIABÉTICO. Consenso Internacional sobre Pé Diabéticol publicado sob a direção de Hermelinda Cordeiro Pedrosa; tradução de Ana Claudia de Andrade, Hermelinda Cordeiro Pedrosa. Brasília: Secretaria de Estado de Saúde do Distrito Federal, 2001. 
GUNNINGBERG, L. et al. The first national pressure ulcer prevalence survey in county council and municipality settings in Sweden. J. Eval. Clin. Pract., v. 19, n. 5, p. 862-7, 2013.

HOLMES, R.F. et al. Skin tears care and management of the older adult at home. Home Healthc. Nurse, v.31, n.2, p.90-101, 2013.

HORAN, T.G. et al. CDC Definitions of nosocomial surgical site infection, 1992: a modification of CDC definitions of surgical wound infections. Infect. Control Hosp. Epidemiol., v.13, n.10, p.606-8, 1992.

IGARASHI, A. et al. Prevalence and incidence of pressure ulcers in Japanese long-term-care hospitals. Arch. Gerontol. Geriatr., v.56, n.1, p. 220-6, 2013.

IYUN, A.O. et al. Point prevalence of chronic wounds at a tertiary hospital in Nigeria. Wounds., v.28, n.2, p.57-62, 2016.

JIANG, Q. et al. The incidence, risk factors and characteristics of pressure ulcers in hospitalized patients in China. Int. J. Clin. Exp. Pathol., v.7, n.5, p. 2587-94, 2014.

JUNKIN, J.; SELEKOF, J.L. Prevalence of incontinence and associated skin injury in he acute care inpatient. J. Wound Ostomy Continence Nurs., v.34, n.3, p.260-9, 2008.

KAVITHA, K.V. et al. Choice of wound care in diabetic foot ulcer: A practical approach Mundo. J. Diabetes, v.5, n.4, p.546-556, 2014.

KHOR, H.M. et al. Determinants of mortality among older adults with pressure ulcers. Arch. Gerontol. Geriatr., v.59, p.536-41, 2014.

KOTTNER, J. et al. Associations between individual characteristics and incontinence-associateddermatitis: A secondary data analysis of a multicentre prevalence study. Int. J. Nurs Stud., v.51, n.10, p.1373-80, 2014.

KOYANO, Y. et al. Exploring the prevalence of skin tears and skin properties related to skin tears in elderly patients at a long-term medical facility in Japan. Int. Wound J., v.13, n.2, p.189-97, 2014.

KUO, L.C.; POLSON A.M.; KANG, T. Associations between periodontal diseases and systemic diseases: $A$ review of the inter-relationships and interactionS with diabetes, respiratory diseases, cardiovascular diseases and osteoporosis. Public Health, v.122, n.4, p.417-33, 2008. 
LADEIRA, P.R.S. et al. Úlceras nos membros inferiores de pacientes diabéticos: mecanismos moleculares e celulares. Rev. Med., v.90, n.3, p.122-7, 2011.

LEBLANC, K.; BARANOSKI, S. Skin tears: best practices for care and prevention. Nursing., v.44, n.5, p.36-46, 2014.

LEBLANC, K.; BARANOSKI, S.; Skin Tear Consensus Panel Members. Skin tears: state of the science: consensus statements for the prevention, prediction, assessment, and treatment of skin tears. Adv. Skin Wound Care, v.24, n.9 Suppl, p.2-15, 2011.

LEBLANC, $\mathrm{K}$. et al. Prevalence of skin tears in a long term care faciliy. $\mathbf{J}$. Wound Ostomy Continence Nurs., v.40, n.6, p.580-4, 2013.

LEIJON, S.; BERGH, I.; TERSTAPPEN, K. Pressure ulcer prevalence, use of preventive measures, and mortality risk in an acute care population: a quality improvement project. J. Wound Ostomy Continence Nurs., v.40, n.5, p.469-74, 2013.

LICHTENFELS, E. et al. Morbidity and mortality associated with arterial surgery site infections by resistant microorganisms. J. Vasc. Bras., v.13, n.3, p.175-181, 2014.

LITVOVÁ, S. et al. A point prevalence survey of healthcare-associated infections in the Slovak Republic. Epidemiol Mikrobiol Imunol., v.63, n.2, p.107-12, 2014.

MAIA, A.M.S. Risco das infecções cirúrgicas segundo o potencial de contaminação das feridas operatórias. [Dissertação]. Minas Gerais (MG): Faculdade de Medicina, Universidade Federal de Minas Gerais, 2006.

MANGLANO, J.D. et al. Pressure ulcers in patients hospitalized in Internal Medicine: associated factors and mortality. Rev. Clin. Esp., v.216, n.9, p.461-7, 2016.

MARCHI, M. et al. The Italian national surgical site infection surveillance programme and its positive impact, 2009 to 2011. Euro Surveill., v.19, n.21, p.pii:20815, 2014.

MARTIN, I.S. et al. Causas referidas para desenvolvimento de úlceras em pés de pessoas com diabetes mellitus. Acta Paul. Enferm., v. 25, n.2, p.218-24, 2012. 
MARTINEZ, I.L.G. et al. Point prevalence of pressure ulcers in three second level hospitals in Mexico. Int. Wound J., v.11, n.6, p.605-10, 2014.

MEHTA, C. et al. Pressure ulcer and patient characteristics - A point prevalence study in a tertiary hospital of India based on the European Pressure Ulcer Advisory Panel minimum data set. J. Tissue Viability, v.24, n.3, p.123-30, 2015.

MELO, E.M.V.B. et al. Infecção cirúrgica em colecistectomia videolaparoscópica usando ácido peracético como esterilizante dos instrumentais. Rev. Col. Bras. Cir., v.40, n.3, p.208-14, 2013.

MONGE, J.V. et al. Excess length of stay attributable to surgical site infection following hip replacement: a nested case-control study. Infect. Control Hosp. Epidemiol., v.27, n.12, p.1299-303, 2006.

MOORE, Z. et al. Pressure ulcer prevalence and prevention practices: a cross-sectional comparative survey in Norway and Ireland. J. Wound Care, v.24, n.8, p.333-9, 2015.

NATIONAL PRESSURE ULCER ADVISORY PANEL, European Pressure Ulcer Advisory Panel and Pan Pacific Pressure Injury Alliance. Prevention and treatment of pressure ulcers: quick reference guide. Emily Haesler (Ed.). Osborne Park, Australia: Cambridge Media; 2014.

NATIONAL PRESSURE ULCER ADVISORY PANEL. Terms and definitions related to support surfaces [Internet]. Disponível em: http://www.npuap.org. Acesso em: 11/07/2016.

NEHRING, P. et al. Diabetic foot risk factors in type 2 diabetes patients: a cross-sectional case control study. J. Diabetes Metab. Disord., v.13, p. 79, 2014.

NUNES, M.A.P. et al. Fatores predisponentes para amputação de membro inferior em pacientes diabéticos internados com pés ulcerados no estado de Sergipe. J. Vasc. Bras., v.5, n.2, p.123-30, 2006.

OLIVEIRA, A.C. et al. Colonization by resistant micro-organism and infection related to health care. Acta Paul. Enferm., v.25, n.2, p.183-9, 2012.

OLIVEIRA, J.C. et al. Pé diabético e amputações em pessoas internadas em hospital público: estudo transversal. ABCS Health Sci., v.41, n.1, p.34-9, 2016. 
PAGGIARO, A.O.; NETO, N.T.; FERREIRA, M.C. Princípios gerais do tratamento de feridas. Rev. Med. (São Paulo), v.89, n.3/4, p.132-6, 2010.

PARANHOS, W.Y.; SANTOS, V.L.C.G. Avaliação de risco para úlceras de pressão por meio da Escala de Braden, na língua portuguesa. Rev. Esc. Enferm. USP, v.33, n. especial, p.191-206, 1999.

PAYNE, R.; MARTIN, M.L. The epidemiology and management of skin tears in the older adults. Ostomy Wound Manage., v.26, p. 26-37, 1990.

PAYNE, R.L.; MARTIN, M.L. Defining and classifying skin tears: need for a common language. Ostomy Wound Manage., v.39, n.5, p.16-20, 22-4, 1993.

PEDRAS, S.; CARVALHO, R.; PEREIRA, M.G. Sociodemographic and clinical characteristics of patients with diabetic foot ulcer. Rev. Assoc. Med. Bras., v. 62, n.2, p.171-8, 2014.

PEREIRA, A.S. et al. Características, conhecimento e autocuidado de idosos portadores de Diabetes Melittus com úlcera de pé. Rev. Pesq. Saúde, v.11, n.2, p.20-5, 2010.

PERES, G.R.P. Prevalência e fatores associados às lesões por fricção em idosos de instituições de longa permanência. [Dissertação]. São Paulo: Universidade de São Paulo; 2014.

PIRES, A.M.; SEGRETO, R.A.; SEGRETO, H.R. RTOG criteria to evaluate acute skin reaction and its risk factors in patients with breast cancer submitted to radiotherapy. Rev. Lat. Am. Enfermagem, v.16, n.5, p.844-9; 2008.

PORTILLO-GALLO, J.H. et al. Surgical site infection rates in four Mexican cities: Findings of the International Nosocomial Infection Control Consortium (INICC). J. Infect. Public Health, v.7, n.6, p.465-71, 2014.

QUEIROZ, A.C.C.M. et al. Úlceras por pressão em pacientes em cuidados paliativos domiciliares: prevalência e características. Rev. Esc. Enferm. USP, v.48, n.2, p.264-271, 2014.

RAYNER, R.; et al. A review of patient and skin characteristics associated with skin tears. J. Wound Care, v.24, n.9, p.406-14, 2015.

REIS, R.B. et al. Incontinência urinária no idoso. Acta Cir. Bras., v.18, n. Supl.5, p.47-51, 2003. 
RIBEIRO, J.C. et al. Ocorrência e fatores de risco para infecção de sítio cirúrgico em cirurgias ortopédicas. Acta Paul. Enferm. v.26, n.4, p.353-9, 2013.

ROGENSKI, N.M.R.; SANTOS, V.L.C.G. Estudo sobre a prevalência de úlcera por pressão em um hospital universitário. Revista Estima, v.4, n.2, p.16-22, 2006.

ROHWER, K.; BLISS, M.N.D.Z.; SAVIK, K. Continence associated dermatitis in Community-Dwelling Individuals with fecal incontinence. J. Wound Ostomy Continence Nurs., v.40, n.2, p.181-4, 2013.

SALOMÉ, G.M. Ocorrência de úlcera por pressão em indivíduos internados em uma Unidade de Terapia Intensiva. Saúde Coletiva, v.7, n.42, p.183-8, 2010.

SANTOS, V.L. et al. Adaptação transcultural do Pressure Ulcer Scale for Healing (PUSH) para a língua portuguesa. Rev. Lat. Am. Enfermagem, v.13, n.3, p.305-313, 2005.

SANTOS, V.L.G.; SELLMER, D.; MASSULO, M.M. Confiabilidade Interobservadores do Pressure Scale for Healing (PUSH) em pacientes com úlcera crônicas de perna para a língua portuguesa. Rev. Latino Am. Enfermagem, v.15, n.3, p.391-6, 2007.

SARDO, P.M.G. et al. Analyses of pressure ulcer point prevalence at the first skin assessment in a Portuguese hospital. J. Tissue Viability, v.26, n.2, p.75-82, 2016.

SERPA, L.F. et al. Predictive validity of the Braden Scale for pressure ulcer development risk in critical care patients. Rev. Latino Am. Enfermagem, v.19, n.1, p.50-57, 2011.

SERPA, L.F. et al. Validity of the Braden and Waterlow subscales in predicting pressure ulcer risk in hospitalized patients. Appl. Nurs. Res., v.24, n.4, p.e23-8, 2011.

SERPA, L.F.; SANTOS, V.L. Validity of the Braden Nutrition Subscale in predicting pressure ulcer development. J. Wound Ostomy Continence Nurs., v.41, n.5, p.436-43, 2014.

SERPA, L.F.; SANTOS, V.L.; PARANHOS, W.Y. Escalas de avaliação de risco para o desenvolvimento de úlceras por pressão. In: BLANES L.; FERREIRA, L.M. (Org.). Prevenção e tratamento de úlcera por pressão. São Paulo. Atheneu, 2014. p.13-27. 
SILVA, Q.C.; BARBOSA, M.H. Risk factors for surgical site infection in cardiac surgery. Acta Paul. Enferm., v.25, n.2, p.89-95, 2012.

SIMÃO, C.M.F.; CALIRI, M.H.L.; SANTOS, C.B. Concordância entre enfermeiros quanto ao risco dos pacientes para úlcera por pressão. Acta Paul. Enferm., v.26, n.1, p.30-5, 2013.

SINHARAY, K. et al. Prevalence of diabetic foot ulcers in newly diagnosed diabetes mellitus patients. J. Indian Med. Assoc., v.110, n.9, p.608-11, 2012.

SKERRITT, L.; MOORE, Z. The prevalence, aetiology and management of wounds in a community care area in Ireland. Br. J. Community Nurs. Suppl., v.S11-7, 2014.

SOARES, G.M.T.; et al. Prevalência das principais complicações pósoperatórias em cirurgias cardíacas. Rev. Bras. Cardiol., v.24, n.3, p.139-46, 2011.

SOUZA, D.M. et al. Predictive validity of the Braden scale for pressure ulcer risk in elderly residents of long-term facilities. Geriatr. Nurs., v.31, n.2, p.95104, 2010.

STRACIERI, L.D.S. Cuidados e complicações pós-operatórias. Medicina (Ribeirão Preto), v.41, n.4, p.465-8, 2008.

STRAZZIERI-PULIDO, K.C. et al. Prevalência de lesão por fricção e fatores associados: revisão sistemática. Rev. Esc. Enferm. USP, v.49, n.4, p.67480, 2015.

STRAZZIERI-PULIDO, K.C.; SANTOS, V.L. Cultural adaptation and validation of STAR Skin Tear Classification System for Brazilians. Abstract. The Wound, Ostomy and Continence Nurses Society, 43rd Annual Conference, Lousiana, 2011.

STRAZZIERI-PULIDO, K.C.; SANTOS, V.L. O que precisamos saber acerca das lesões por fricção. Rev. Estima, v.8, n.3, p.34-41, 2010.

STRAZZIERI-PULIDO, K.C.; SANTOS, V.L.; CARVILLE, K. Cultural adaptation, content validity and inter-rater reliability of the 'STAR Skin Tear Classification System'. Rev. Lat. Am. Enfermagem, v. 23, n.1, p.155-61, 2015.

TILLOU, A. et al. Fascial dehiscence after trauma laparotomy: a sign of intraabdominal sepsis. Am. J. Surg., v.69, n.11, p.927-9, 2003. 
TUBAISHAT, A.; ALJEZAWI, M. The prevalence of pressure ulceration among Jordanian hospitalised patients. J. Wound Care, v.22, n.6, p.305-9, 2013.

VIEIRA, C.P.B. et al. Ações preventivas em úlceras por pressão realizadas por enfermeiros na atenção básica. J. Res. Fundam. Care, v.8, n.2, p.444759, 2016.

WAGNER, F.W.Jr. The dysvascular foot: A system for diagnosis and treatment. Foot Ankle, v.2, n.2, p.64-122, 1981.

WAIDMAN, M.A.P. et al. O cotidiano do Indivíduo com ferida crônica e sua saúde mental. Texto Contexto Enferm., v.20, n.4, p.691-9, 2011.

WERCKA, J. et al. Perfil epidemiológico, incidência e desfecho dos pacientes com fístula abdominal pós-operatória. Rev. Col. Bras. Cir., v.43, n.2, p.117-23, 2016.

WORLD HEALTH ORGANIZATION. BMI Classification. Global Database on Body Mass. Index: World Health Organization, 2013. Disponível em: http://www. who.int/en/2014. 
APENNDICES 


\section{APÊNDICE 1}

\section{INSTRUMENTO PARA COLETA DE DADOS}

\section{Dados sócio demográficos e clínicos}

\section{Data da coleta:}

Enfermaria:

\section{Data da internação do paciente:}

Instituição hospitalar:

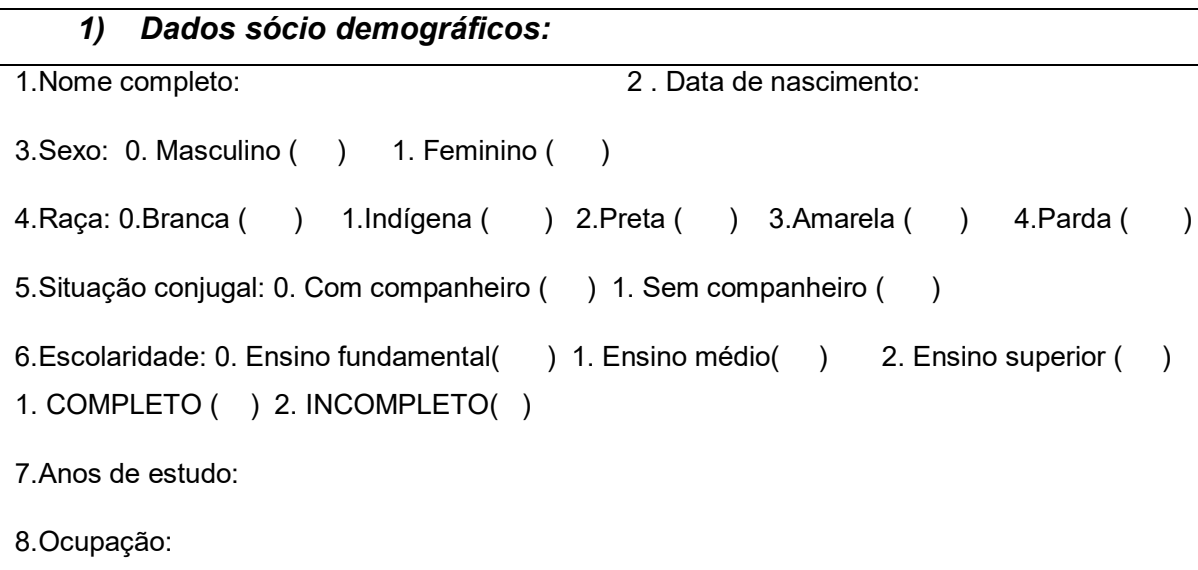

\subsection{Hábitos e comportamentos:}

1. Etilista :0. Não ( ) 1. Sim ( ) 2. Consumo de bebida ao dia: 3. Tempo de consumo (em meses)

2. Ex - etilista : 0. Não ( ) 1. Sim ( ）2.Tempo de consumo: ( ）; 3. Nunca bebeu: ( )

3. Tabagista: 0. Não ( ) 1. Sim ( ) 2. Consumo de cigarro ao dia: $(\quad$ );

4. Ex - tabagista : 0. Não ( ) 1. Sim ( ); 2. Tempo de consumo: ( ) ; 3. Nunca fumou: ( )

\subsection{Doenças Pré-existentes:}

1.Incontinência urinária: 0. Não ( ) 1. $\operatorname{Sim}(\quad)$

\section{INDICE DE INCONTINÊNCIA URINÁRIA:}

3.1.Com que freqüência você perde urina? (assinale uma resposta )

A. Nunca 0 ( )

B. Uma vez por semana ou menos 1 ( )

C. Duas ou três vezes por semana $2(\quad)$

D. Uma vez ao dia $3(\quad)$

E. Diversas vezes ao dia $4(\quad)$

F.O tempo todo 5 ( ) 
3.2.Gostaríamos de saber a quantidade de urina que você pensa que perde?

(assinale uma resposta)

A.Nenhuma 0 ( )

B.Uma pequena quantidade $2(\quad)$

C.Uma moderada quantidade $4(\quad)$

D.Uma grande quantidade $6(\quad)$

3.Em geral quanto que perder urina interfere em sua vida diária?

Por favor, DIGA um número entre 0 (não interfere) e 10 (interfere muito)

012345678910

Não interfere

Interfere muito

3.3.Incontinência anal: 0. Não（） 1. Sim( ）

3.4 ÍNDICE DE INCONTINÊNCIA ANAL:

Índice de Incontinência Anal (IIA) de Jorge e Wexner.

\begin{tabular}{|c|c|c|c|c|c|}
\hline $\begin{array}{l}\text { 2.ÍNDICE DE } \\
\text { INCONTINÊNCIA } \\
\text { ANAL: }\end{array}$ & $\begin{array}{l}\text { 2.ÍNDICE DE } \\
\text { INCONTINÊNCIA } \\
\text { ANAL: }\end{array}$ & $\begin{array}{l}\text { 2.ÍNDICE DE } \\
\text { INCONTINÊNCIA } \\
\text { ANAL: }\end{array}$ & $\begin{array}{l}\text { 2.ÍNDICE DE } \\
\text { INCONTINÊNCIA } \\
\text { ANAL: }\end{array}$ & $\begin{array}{l}\text { 2.ÍNDICE DE } \\
\text { INCONTINÊNCIA } \\
\text { ANAL: }\end{array}$ & $\begin{array}{l}\text { 2.ÍNDICE DE } \\
\text { INCONTINÊNCIA } \\
\text { ANAL: }\end{array}$ \\
\hline $\begin{array}{l}\text { Índice de } \\
\text { Incontinência Anal } \\
\text { (IIA) de Jorge e } \\
\text { Wexner. }\end{array}$ & $\begin{array}{l}\text { Índice de } \\
\text { Incontinência Anal } \\
\text { (IIA) de Jorge e } \\
\text { Wexner. }\end{array}$ & $\begin{array}{l}\text { Índice de } \\
\text { Incontinência Anal } \\
\text { (IIA) de Jorge e } \\
\text { Wexner. }\end{array}$ & $\begin{array}{l}\text { Índice de } \\
\text { Incontinência Anal } \\
\text { (IIA) de Jorge e } \\
\text { Wexner. }\end{array}$ & $\begin{array}{l}\text { Índice de } \\
\text { Incontinência Anal } \\
\text { (IIA) de Jorge e } \\
\text { Wexner. }\end{array}$ & $\begin{array}{l}\text { Índice de } \\
\text { Incontinência Anal } \\
\text { (IIA) de Jorge e } \\
\text { Wexner. }\end{array}$ \\
\hline $\begin{array}{l}\text { 2.ÍNDICE DE } \\
\text { INCONTINÊNCIA } \\
\text { ANAL: }\end{array}$ & $\begin{array}{l}\text { 2.ÍNDICE DE } \\
\text { INCONTINÊNCIA } \\
\text { ANAL: }\end{array}$ & $\begin{array}{l}\text { 2.ÍNDICE DE } \\
\text { INCONTINÊNCIA } \\
\text { ANAL: }\end{array}$ & $\begin{array}{l}\text { 2.ÍNDICE DE } \\
\text { INCONTINÊNCIA } \\
\text { ANAL: }\end{array}$ & $\begin{array}{l}\text { 2.ÍNDICE DE } \\
\text { INCONTINÊNCIA } \\
\text { ANAL: }\end{array}$ & $\begin{array}{l}\text { 2.ÍNDICE DE } \\
\text { INCONTINÊNCIA } \\
\text { ANAL: }\end{array}$ \\
\hline $\begin{array}{l}\text { Índice de } \\
\text { Incontinência Anal } \\
\text { (IIA) de Jorge e } \\
\text { Wexner. }\end{array}$ & $\begin{array}{l}\text { Índice de } \\
\text { Incontinência Anal } \\
\text { (IIA) de Jorge e } \\
\text { Wexner. }\end{array}$ & $\begin{array}{l}\text { Índice de } \\
\text { Incontinência Anal } \\
\text { (IIA) de Jorge e } \\
\text { Wexner. }\end{array}$ & $\begin{array}{l}\text { Índice de } \\
\text { Incontinência Anal } \\
\text { (IIA) de Jorge e } \\
\text { Wexner. }\end{array}$ & $\begin{array}{l}\text { Índice de } \\
\text { Incontinência Anal } \\
\text { (IIA) de Jorge e } \\
\text { Wexner. }\end{array}$ & $\begin{array}{l}\text { Índice de } \\
\text { Incontinência Anal } \\
\text { (IIA) de Jorge e } \\
\text { Wexner. }\end{array}$ \\
\hline $\begin{array}{l}\text { 2.ÍNDICE DE } \\
\text { INCONTINÊNCIA } \\
\text { ANAL: }\end{array}$ & $\begin{array}{l}\text { 2.ÍNDICE DE } \\
\text { INCONTINÊNCIA } \\
\text { ANAL: }\end{array}$ & $\begin{array}{l}\text { 2.ÍNDICE DE } \\
\text { INCONTINÊNCIA } \\
\text { ANAL: }\end{array}$ & $\begin{array}{l}\text { 2.ÍNDICE DE } \\
\text { INCONTINÊNCIA } \\
\text { ANAL: }\end{array}$ & $\begin{array}{l}\text { 2.ÍNDICE DE } \\
\text { INCONTINÊNCIA } \\
\text { ANAL: }\end{array}$ & $\begin{array}{l}\text { 2.ÍNDICE DE } \\
\text { INCONTINÊNCIA } \\
\text { ANAL: }\end{array}$ \\
\hline $\begin{array}{l}\text { Índice de } \\
\text { Incontinência Anal } \\
\text { (IIA) de Jorge e } \\
\text { Wexner. }\end{array}$ & $\begin{array}{l}\text { Índice de } \\
\text { Incontinência Anal } \\
\text { (IIA) de Jorge e } \\
\text { Wexner. }\end{array}$ & $\begin{array}{l}\text { Índice de } \\
\text { Incontinência Anal } \\
\text { (IIA) de Jorge e } \\
\text { Wexner. }\end{array}$ & $\begin{array}{l}\text { Índice de } \\
\text { Incontinência Anal } \\
\text { (IIA) de Jorge e } \\
\text { Wexner. }\end{array}$ & $\begin{array}{l}\text { Índice de } \\
\text { Incontinência Anal } \\
\text { (IIA) de Jorge e } \\
\text { Wexner. }\end{array}$ & $\begin{array}{l}\text { Índice de } \\
\text { Incontinência Anal } \\
\text { (IIA) de Jorge e } \\
\text { Wexner. }\end{array}$ \\
\hline
\end{tabular}

Escore Total:

4.Perfusão tissular alterada: 0.Não ( ） 1. $\operatorname{Sim}(\quad)$

5.Insuficiência venosa: 0.Não（） 1. Sim( )

6.Insuficiência arterial: 0.Não( ) 1. Sim( )

7.Doença Vascular Periférica: 0.Não（） 1. Sim( )

8.Hipertensão arterial sistêmica: 0. Não ( ) 1. Sim( )

9.Acidente vascular cerebral: 0.Não（） 1. Sim( )

10.Infarto Agudo do miocárdio: 0.Não ( ) 1. Sim( )

11.Distúrbio da tireóide: 0.Não（） 1. Sim( )

12.Doença Pulmonar crônica: 0.Não（） 1. Sim( )

13.Diabetes Mellitus tipo I: 0.Não（） 1. $\operatorname{Sim}(）$

14.Diabetes Mellitus tipo II: 0.Não（） 1. Sim( )

15.Exames laboratoriais:

1.Nível de glicemia em jejum: a. Normal ( ) b. Alterada ( ） c. Valor:

d. Ausente: ( ) 


\section{PELE}

1.Equimoses: a. Ausente ( ) b.Presente: ( )

2. Hematomas: a. Ausente ( ) b. Presente: ( )

3.Fitas e curativos adesivos na pele: a.Não ( ) b.Sim ( ) c.Local:

\section{Edema nos MMSS:}

0. ( ) $0 / 4+$ (sem edema); 1. ( ) 1+/4+ (leve cacifo, até $2 \mathrm{~mm}$; 2. ( ) 2+/4+ (cacifo $<5 \mathrm{~mm}$, mas com pé e perna com contornos definidos); 3. ( ) 3+/4+ cacifo entre 5 e $10 \mathrm{~mm}$, acompanhado por pé e perna; 4 . ( ) 4+/4+ cacifo >

$1 \mathrm{~cm}$ acompanhado por edema severo da perna e pé;

\section{Edema nos MMII:}

0. ( ) $0 / 4+$ (sem edema) ;1. ( ) 1+/4+ (leve cacifo, até $2 \mathrm{~mm}$ ); 2.( ) 2+/4+ (cacifo $<5 \mathrm{~mm}$, mas com pé e perna com contornos definidos); 3. ( )3+/4+ (cacifo entre 5 e $10 \mathrm{~mm}$, acompanhado por pé e perna); 4 . ( )4+/4+ (cacifo $>1 \mathrm{~cm}$ acompanhado por edema severo da perna e pé).

18. Estomia: 0.Não ( ) 1.Sim ( )

1.Tipo: 0. Colostomia ( ) 1. Ileostomia ( ) 2. Traqueostomia ( ) 3. Gastrostomia ( ) 4. Derivação urinária ( ).

\section{Quanto a cirurgia:}

1.CIRURGIA: 0. Não（）1. Sim（）

2. Classificação: 0.Eletiva ( ) 1. Urgência ( ) 2. Emergência ( )

\section{Quanto à locomoção:}

20.1.Rigidez MMSS: 0. Ausente ( ) 1.Presente: ( )

20.2.Rigidez MMII: 0. Ausente ( ) 1. Presente: ( )

20.33.Espasticidade MMSS: 0. Ausente ( ) 1. Presente: ( )

20.44.Espasticidade MMII: 0. Ausente ( ) 1. Presente: ( )

\section{ESTADO NUTRICIONAL}

1.Peso: $0 . \quad \mathrm{Kg} ; \quad$ 1. Altura: $\mathrm{m}$;

2. Valor do IMC: 0

\section{Dispositivos em uso:}

1.Uso de calçado ortopédico: 0.Não usa ( ) 1.Usa ( )

2.Presença de cateter vesical de demora: 0.Não usa ( ) 1.Usa ( )

3. Presença de drenos de Kehr: 0. Não usa ( ) 1. Usa ( )

4. Presença de drenos de Penrose: 0 . Não usa ( ) 1. Usa ( )

5. Presença de drenos PortoVac: 0. Não usa ( ) 1. Usa ( )

\section{Higiene}

1.Uso de sabonete liquido: 0. Não usa $($ ) 1. Usa ( )

2.Uso de sabão em barra: 0.Não usa ( ) 1.Usa ( )

3.Uso de sabonete em barra: 0.Não usa ( ) 1.Usa ( )

4.Uso de emoliente para a pele: 0.Não usa ( ) 1.Usa ( )

5.Uso de fralda descartável: 0.Não usa ( ) 1. Usa ( )

\section{Dor}

1.Existência de dor no local da lesão: 0. Não ( ) 1. Sim( ）

2. Classificação de intensidade da dor: 012345678910

1.( ) 0 ( Ausência de dor);

2. ( ) 1 a 3 (dor de baixa intensidade):

3. ( ) A 6 (dor de moderada intensidade com demanda relativa de analgésico);

4. ( ) 7 a 9 (dor de forte intensidade com demanda de analgésico):

5. ( ) 10 (dor de intensidade insuportável com demanda de analgésico em horários específicos). 


\section{Escala de Braden}

\begin{tabular}{|c|c|c|c|c|}
\hline 1.Percepção Sensorial & $\begin{array}{l}\text { 1. Totalmente } \\
\text { limitado }\end{array}$ & 2. Muito limitado & $\begin{array}{l}\text { 3. Levemente } \\
\text { limitado }\end{array}$ & 4. Nenhuma limitação \\
\hline 2.Umidade & $\begin{array}{l}\text { 1. Completamente } \\
\text { molhada }\end{array}$ & 2. Muito molhada & $\begin{array}{l}\text { 3. Ocasionalmente } \\
\text { molhada }\end{array}$ & $\begin{array}{l}\text { 4. Raramente } \\
\text { molhada }\end{array}$ \\
\hline 3.Atividade & 1. Acamado & $\begin{array}{l}\text { 2. Confinado a } \\
\text { cadeira }\end{array}$ & $\begin{array}{l}\text { 3. Anda } \\
\text { ocasionalmente }\end{array}$ & $\begin{array}{l}\text { 4. Anda } \\
\text { frequentemente }\end{array}$ \\
\hline 4.Mobilidade & 1. Totalmente Imóvel & 2. Bastante limitado & $\begin{array}{l}\text { 3. Levemente } \\
\text { limitado }\end{array}$ & $\begin{array}{l}\text { 4. Não apresenta } \\
\text { limitações }\end{array}$ \\
\hline 5.Nutrição & 1. Muito pobre & $\begin{array}{l}\text { 2. Provavelmente } \\
\text { Inadequado }\end{array}$ & 3. Adequada & 4. Excelente \\
\hline 6.Fricção/cisalhamento & 1. Problema & $\begin{array}{l}\text { 2. Problema em } \\
\text { potencial }\end{array}$ & 3. Nenhum problema & \\
\hline Total: & $\begin{array}{c}\text { Risco } \\
15 \text { a } 18(\quad)\end{array}$ & $\begin{array}{c}\text { Risco moderado } \\
13 \text { a } 14()\end{array}$ & $\begin{array}{l}\text { Alto risco } \\
10 \text { a } 12()\end{array}$ & $\begin{array}{c}\text { Risco muito alto } \\
\leq 9\end{array}$ \\
\hline
\end{tabular}

\section{Dados específicos por lesão:}

\begin{tabular}{|c|c|c|c|c|c|}
\hline Localização & Classificação & $\begin{array}{l}\text { Tipo de } \\
\text { tecido }\end{array}$ & $\begin{array}{c}\text { Quantidade } \\
\text { de } \\
\text { Exsudato }\end{array}$ & $\begin{array}{l}\text { Comp x } \\
\text { Larg x } \\
\text { Profund }\end{array}$ & Localização \\
\hline $\begin{array}{l}\text { 1.Região } \\
\text { occipital } \\
\text { 2.Escápula E } \\
\text { 3.Escápula D } \\
\text { 4.Tórax } \\
\text { 5. Abdômen } \\
\text { 6.Lombar } \\
\text { 7.Cotovelo E } \\
\text { 8.Cotovelo D } \\
\text { 9.Genitais } \\
\text { 10.Região } \\
\text { Sacra } \\
\text { 11.Trocânter } \\
\text { E } \\
\text { 12. Trocânter } \\
\text { D } \\
\text { 13.Região } \\
\text { glútea E } \\
\text { 14.Região } \\
\text { glútea D } \\
\text { 15.Ísquio E } \\
\text { 16.Ísquio D } \\
\text { 17. Calcâneo } \\
\text { E } \\
\text { 18. Calcâneo } \\
\text { D } \\
\text { 19. Maléolo } \\
\text { E } \\
\text { 20. Maléolo } \\
\text { D } \\
\text { 21. outra } \\
\text { (especificar): } \\
\text { 22. outra } \\
\text { (especificar): }\end{array}$ & $\begin{array}{l}\text { 1.Categoria I - hiperemia } \\
\text { em pele íntegra. } \\
\text { 2.Categoria II - } \\
\text { epiderme/derme rompida. } \\
\text { 3.Categoria III - } \\
\text { subcutâneo/fáscia } \\
\text { muscular. c/ou s/ necrose. } \\
\text { 4.Categoria IV - } \\
\text { músculo/osso, c/ ou s/ } \\
\text { necrose infecção. } \\
\text { 5.suspeita de lesão tissular } \\
\text { profunda - } \\
\text { 6. Estágio indeterminado }\end{array}$ & $\begin{array}{l}\text { 0.Fechada } \\
\text { 1.Epitelial } \\
\text { 2. Granulação } \\
\text { 3. Esfacelo } \\
\text { 4. Necrótico }\end{array}$ & $\begin{array}{l}\text { 0.Ausente } \\
\text { 1. Pequena } \\
\text { 2. Moderada } \\
\text { 3. Grande }\end{array}$ & $\begin{array}{l}\text { 0. } 0 \mathrm{~cm}^{2} \\
\text { 1. }<0,3 \mathrm{~cm}^{2} \\
\text { 2. } 0,3- \\
0,6 \mathrm{~cm}^{2} \\
\text { 3. } 0,7-1,0 \mathrm{~cm}^{2} \\
\text { 4. } 1,1-2,0 \mathrm{~cm}^{2} \\
\text { 5. } 2,1-3,0 \mathrm{~cm}^{2} \\
\text { 6. } 3,1-4,0 \mathrm{~cm}^{2} \\
\text { 7. } 4,1-8,0 \mathrm{~cm}^{2} \\
\text { 8. } 8,1- \\
\begin{array}{l}12,0 \mathrm{~cm}^{2} \\
\text { 9. } 12,1-\end{array} \\
\begin{array}{l}24,0 \mathrm{~cm}^{2} \\
\text { 10. } \\
\text { 2 } 24,0 \mathrm{~cm}\end{array}\end{array}$ & $\begin{array}{l}\text { 1.Região } \\
\text { occipital } \\
\text { 2.Escápula E } \\
\text { 3. Escápula D } \\
\text { 4.Tórax } \\
\text { 5. Abdômen } \\
\text { 6.Lombar } \\
\text { 7.Cotovelo E } \\
\text { 8.Cotovelo D } \\
\text { 9.Genitais } \\
\text { 10.Região } \\
\text { Sacra } \\
\text { 11.Trocânter } \\
\text { E } \\
\text { 12. Trocânter } \\
\text { D } \\
\text { 13.Região } \\
\text { glútea E } \\
\text { 14.Região } \\
\text { glútea D } \\
\text { 15.Ísquio E } \\
\text { 16.Ísquio D } \\
\text { 17. Calcâneo } \\
\text { E } \\
\text { 18. Calcâneo } \\
\text { D } \\
\text { 19. Maléolo } \\
\text { E } \\
\text { 20. Maléolo } \\
\text { D } \\
\text { 21. outra } \\
\text { (especificar): } \\
\text { 22. outra } \\
\text { (especificar): }\end{array}$ \\
\hline
\end{tabular}




\begin{tabular}{|c|c|c|c|c|c|}
\hline 4.LP & \multirow[t]{2}{*}{ 0. Localização } & \multirow[t]{2}{*}{ 1.Classificação } & \multirow[t]{2}{*}{$\begin{array}{l}\text { 2.Tipo de } \\
\text { tecido }\end{array}$} & \multirow[t]{2}{*}{$\begin{array}{l}\text { 3. Quantidade } \\
\text { de Exsudato }\end{array}$} & \multirow[t]{2}{*}{ 4.Medidas } \\
\hline $\mathbf{N}^{\circ}$ & & & & & \\
\hline 1. & & & & & \\
\hline 2. & & & & & \\
\hline \multicolumn{6}{|l|}{5.} \\
\hline Localização & Classificação & Tipo de tecido & $\begin{array}{l}\text { Quantidade de } \\
\text { Exsudato }\end{array}$ & $\begin{array}{c}\text { Comp } x \text { Larg } \mathrm{x} \\
\text { Profund }\end{array}$ & Localização \\
\hline $\begin{array}{l}\text { 1. Dorso do pé } \\
\text { E } \\
\text { 2. Dorso do pé } \\
\text { D } \\
\text { 3. Planta do } \\
\text { pé } E \\
\text { 4. Planta do } \\
\text { pé D } \\
\text { 5. Hálux E } \\
\text { 6. Halux } D \\
\text { 7. Segundo } \\
\text { pododáctilo } \\
\text { 8. Terceiro } \\
\text { pododáctilo } \\
\text { 9. Quarto } \\
\text { pododáctilo } \\
\text { 10. Quinto } \\
\text { pododáctilo } \\
\text { 11. Calcâneo } \\
\text { E } \\
\text { 12. Calcâneo } \\
D \\
\text { 13. Maléolo } \\
\text { E } \\
\text { 14. Maléolo } \\
\text { D. } \\
\text { 15. outra } \\
\text { (especificar): }\end{array}$ & $\begin{array}{l}\text { 1.Grau: } 0 \text { (pé em risco) } \\
\text { 2.Grau 1: (úlcera } \\
\text { superficial) } \\
\text { 3.Grau 2: } \\
\text { (subcutâneo/tendão/ligam.); } \\
\text { 4.Grau 3: } \\
\text { (infecção/abscesso) } \\
\text { 5.Grau 4: (pequena } \\
\text { Gangrena: dedos, } \\
\text { calcâneo, plantar } \\
\text { anterior/posterior) } \\
\text { 6.Grau 5: (grande } \\
\text { gangrena). }\end{array}$ & $\begin{array}{l}\text { 0.Fechada } \\
\text { 1.Epitelial } \\
\text { 2. Granulação } \\
\text { 3. Esfacelo } \\
\text { 4. Necrótico }\end{array}$ & $\begin{array}{l}\text { 0.Ausente } \\
\text { 1. Pequena } \\
\text { 2. Moderada } \\
\text { 3. Grande }\end{array}$ & $\begin{array}{l}\text { 0. } 0 \mathrm{~cm}^{2} \\
\text { 1. }<0,3 \mathrm{~cm}^{2} \\
\text { 2. } 0,3- \\
0,6 \mathrm{~cm}^{2} \\
\text { 3. } 0,7-1,0 \mathrm{~cm}^{2} \\
\text { 4. } 1,1-2,0 \mathrm{~cm}^{2} \\
\text { 5. } 2,1-3,0 \mathrm{~cm}^{2} \\
\text { 6. } 3,1-4,0 \mathrm{~cm}^{2} \\
\text { 7. } 4,1-8,0 \mathrm{~cm}^{2} \\
\text { 8. } 8,1- \\
12,0 \mathrm{~cm}^{2} \\
\text { 9. } 12,1- \\
24,0 \mathrm{~cm}^{2} \\
\text { 10. }>24,0 \mathrm{~cm} \\
2\end{array}$ & $\begin{array}{l}\text { 1. Dorso do pé } \\
\text { E } \\
\text { 2. Dorso do pé } \\
\text { D } \\
\text { 3. Planta do pé } \\
\text { E } \\
\text { 4. Planta do pé } \\
\text { D } \\
\text { 5. Hálux E } \\
\text { 6. Halux D } \\
\text { 7. Segundo } \\
\text { pododáctilo } \\
\text { 8. Terceiro } \\
\text { pododáctilo } \\
\text { 9. Quarto } \\
\text { pododáctilo } \\
\text { 10. Quinto } \\
\text { pododáctilo } \\
\text { 11. Calcâneo } \\
\text { E } \\
\text { 12. Calcâneo } \\
\text { D } \\
\text { 13. Maléolo } \\
\text { E } \\
\text { 14. Maléolo } \\
\text { D. } \\
\text { 15. outra } \\
\text { (especificar): }\end{array}$ \\
\hline 5.UD & 0. Localização & 1.Classificação & $\begin{array}{l}\text { 2.Tipo de } \\
\text { tecido }\end{array}$ & $\begin{array}{c}\text { 3. Quantidade } \\
\text { de }\end{array}$ & 4.Medidas \\
\hline $\mathbf{N}^{\circ}$ & & & & Exsudato & \\
\hline \multicolumn{6}{|l|}{1.} \\
\hline \multicolumn{6}{|l|}{2.} \\
\hline Localização & Classificação & $\begin{array}{l}\text { Tipo de } \\
\text { tecido }\end{array}$ & $\begin{array}{c}\text { Quantidade } \\
\text { de } \\
\text { Exsudato }\end{array}$ & $\begin{array}{l}\text { Comp x } \\
\text { Larg x } \\
\text { Profund }\end{array}$ & Localização \\
\hline $\begin{array}{l}\text { 1. Dorso da } \\
\text { mão D } \\
\text { 2. Dorso da } \\
\text { mão E } \\
\text { 2. Braço D } \\
\text { 3. Braço E } \\
\text { 4. Antebraço } \\
\text { D } \\
\text { 5. Antebraço } \\
\text { E } \\
\text { 4. Cotovelo }\end{array}$ & $\begin{array}{l}\text { STAR } \\
1.1 \mathrm{a} \\
2.1 \mathrm{~b} \\
3.2 \mathrm{a} \\
4.2 \mathrm{~b} \\
5.3\end{array}$ & $\begin{array}{l}\text { 0.Fechada } \\
\text { 1.Epitelial } \\
\text { 2. Granulação } \\
\text { 3. Esfacelo } \\
\text { 4. Necrótico }\end{array}$ & $\begin{array}{l}\text { 0. Ausente } \\
\text { 1. Pequena } \\
\text { 2. Moderada } \\
\text { 3. Grande }\end{array}$ & $\begin{array}{l}\text { 0. } 0 \mathrm{~cm}^{2} \\
\text { 1. }<0,3 \mathrm{~cm}^{2} \\
\text { 2. } 0,3-0,6 \mathrm{~cm}^{2} \\
\text { 3. } 0,7-1,0 \mathrm{~cm}^{2} \\
\text { 4. } 1,1-2,0 \mathrm{~cm}^{2} \\
\text { 5. } 2,1-3,0 \mathrm{~cm}^{2} \\
\text { 6. } 3,1-4,0 \mathrm{~cm}^{2} \\
\text { 7. } 4,1-8,0 \mathrm{~cm}^{2} \\
\text { 8. } 8,1- \\
12,0 \mathrm{~cm}^{2} \\
\text { 9. } 12,1-\end{array}$ & $\begin{array}{l}\text { 1. Dorso da } \\
\text { mão D } \\
\text { 2. Dorso da } \\
\text { mão E } \\
\text { 2. Braço D } \\
\text { 3. Braço E } \\
\text { 4. Antebraço } \\
\text { D } \\
\text { 5. Antebraço } \\
\text { E } \\
\text { 4. Cotovelo }\end{array}$ \\
\hline
\end{tabular}




\begin{tabular}{|c|c|c|c|c|c|}
\hline $\begin{array}{l}\text { D } \\
\text { 5. Cotovelo E } \\
\text { 6. Abdômen } \\
\text { 7. Perna D } \\
\text { 8. Perna E } \\
\text { 9. outra } \\
\text { (especificar): }\end{array}$ & & & & $\begin{array}{c}24,0 \mathrm{~cm}^{2} \\
\text { 10. }>24,0 \mathrm{~cm}^{2}\end{array}$ & $\begin{array}{l}\text { D } \\
\text { 5.Cotovelo E } \\
\text { 6. Abdômen } \\
\text { 7. Perna D } \\
\text { 8. Perna E } \\
\text { 9. outra } \\
\text { (especificar): }\end{array}$ \\
\hline 6.LF & 0. Localização & 1.Classificação & $\begin{array}{l}\text { 2.Tipo de } \\
\text { tecido }\end{array}$ & $\begin{array}{c}\text { 3. Quantidade } \\
\text { de } \\
\text { Exsudato }\end{array}$ & 4.Medidas \\
\hline \multicolumn{6}{|l|}{1.} \\
\hline \multicolumn{6}{|l|}{2.} \\
\hline Localização & Classificação & $\begin{array}{l}\text { Tipo de } \\
\text { tecido }\end{array}$ & $\begin{array}{c}\text { Quantidade } \\
\text { de } \\
\text { Exsudato }\end{array}$ & $\begin{array}{c}\text { Comp x } \\
\text { Larg } x \\
\text { Profund }\end{array}$ & Localização \\
\hline $\begin{array}{l}\text { 1. Abdômen } \\
\text { inferior / } \\
\text { suprapúbica } \\
\text { 2. Púbis } \\
\text { 3. Grandes } \\
\text { lábios } \\
\text { 4. Escroto } \\
\text { 5. Região } \\
\text { glútea E } \\
\text { 6. Região } \\
\text { glútea D } \\
\text { 7. Região } \\
\text { perianal } \\
\text { 8. Região } \\
\text { convexa das } \\
\text { nádegas } \\
\text { 9. Porção } \\
\text { superior das } \\
\text { coxas. } \\
\text { 10. outra } \\
\text { (especificar): }\end{array}$ & $\begin{array}{l}\text { 1. HIGH-RISK } \\
\text { 2.EARLY IAD } \\
\text { 3.MODERATE IAD } \\
\text { 4.SEVERE IAD } \\
\text { 5.FUNGAL - APPEARING } \\
\text { RASH. }\end{array}$ & $\begin{array}{l}\text { 0.Fechada } \\
\text { 1.Epitelial } \\
\text { 2. Granulação } \\
\text { 3. Esfacelo } \\
\text { 4. Necrótico }\end{array}$ & $\begin{array}{l}\text { 0.Ausente } \\
\text { 1. Pequena } \\
\text { 2. Moderada } \\
\text { 3. Grande }\end{array}$ & $\begin{array}{ll}0 . & 0 \mathrm{~cm}^{2} \\
1 . & <0,3 \mathrm{~cm}^{2} \\
2 . & 0,3- \\
& 0,6 \mathrm{~cm}^{2} \\
3 . & 0,7- \\
& 1,0 \mathrm{~cm}^{2} \\
4 . & 1,1- \\
& 2,0 \mathrm{~cm}^{2} \\
\text { 5. } & 2,1- \\
& 3,0 \mathrm{~cm}^{2} \\
6 . & 3,1- \\
& 4,0 \mathrm{~cm}^{2} \\
\text { 7. } & 4,1- \\
& 8,0 \mathrm{~cm}^{2} \\
8 . & 8,1- \\
& 12,0 \mathrm{~cm}^{2} \\
9 . & 12,1- \\
& 24,0 \mathrm{~cm}^{2} \\
\text { 10. } & >24,0 \mathrm{~cm}^{2} \\
& 2\end{array}$ & $\begin{array}{l}\text { 1. Abdômen } \\
\text { inferior / } \\
\text { suprapúbica } \\
\text { 2. Púbis } \\
\text { 3. Grandes } \\
\text { lábios } \\
\text { 4. Escroto } \\
\text { 5. Região } \\
\text { glútea E } \\
\text { 6. Região } \\
\text { glútea D } \\
\text { 7. Região } \\
\text { perianal } \\
\text { 8. Região } \\
\text { convexa das } \\
\text { nádegas } \\
\text { 9. Porção } \\
\text { superior das } \\
\text { coxas. } \\
\text { 10. outra } \\
\text { (especificar): }\end{array}$ \\
\hline 7.DAI & 0. Localização & 1.Classificação & $\begin{array}{l}\text { 2.Tipo de } \\
\text { tecido }\end{array}$ & $\begin{array}{c}\text { 3.Quantidade } \\
\text { de } \\
\text { Exsudato }\end{array}$ & 4.Medidas \\
\hline \multicolumn{6}{|l|}{1.} \\
\hline \multicolumn{6}{|l|}{2.} \\
\hline Localização & Classificação & $\begin{array}{l}\text { Tipo de } \\
\text { tecido }\end{array}$ & $\begin{array}{c}\text { Quantidade } \\
\text { de } \\
\text { Exsudato }\end{array}$ & $\begin{array}{l}\text { Comp x } \\
\text { Larg x } \\
\text { Profund }\end{array}$ & Localização \\
\hline $\begin{array}{l}\text { 1. Região } \\
\text { occipital } \\
\text { 2.Tórax } \\
\text { 3. Abdômen } \\
\text { 4. Lombar } \\
\text { 5. Genitais } \\
\text { 6. Região } \\
\text { Sacra } \\
\text { 7. Trocânter } \\
\text { E } \\
\text { 8. Trocânter } \\
\text { D }\end{array}$ & $\begin{array}{l}\text { 1. Hemorragia } \\
\text { 2.Fistula } \\
\text { 3. INFECÇÃO }\end{array}$ & $\begin{array}{l}\text { 0.Fechada } \\
\text { 1. Epitelial } \\
\text { 2. Granulação } \\
\text { 3. Esfacelo } \\
\text { 4. Necrótico }\end{array}$ & $\begin{array}{l}\text { 0. Ausente } \\
\text { 1. Pequena } \\
\text { 2. Moderada } \\
\text { 3. Grande }\end{array}$ & $\begin{array}{ll}\text { 0. } 0 \mathrm{~cm}^{2} \\
\text { 1. }<0,3 \mathrm{~cm}^{2} \\
\text { 2. } 0,3- \\
\text { 0,6- } \\
\text { 3. } 0,7-1,0 \mathrm{~cm}^{2} \\
\text { 4. } 1,1-2,0 \mathrm{~cm}^{2} \\
\text { 5. } 2,1-3,0 \mathrm{~cm}^{2} \\
\text { 6. } 3,1-4,0 \mathrm{~cm}^{2} \\
\text { 7. } 4,1-8,0 \mathrm{~cm}^{2} \\
\text { 8. } 8,1- \\
\text { 9. } 12,0 \mathrm{~cm}^{2} \\
\text { 9. } 12,1-\end{array}$ & $\begin{array}{l}\text { 1. Região } \\
\text { occipital } \\
\text { 2.Tórax } \\
\text { 3. Abdômen } \\
\text { 4. Lombar } \\
\text { 5. Genitais } \\
\text { 6. Região } \\
\text { Sacra } \\
\text { 7. Trocânter } \\
\text { E } \\
\text { 8. Trocânter } \\
\text { D }\end{array}$ \\
\hline
\end{tabular}




\begin{tabular}{|l|l|l|l|l|l|}
\hline $\begin{array}{l}\text { 9. Região } \\
\text { glútea E } \\
\text { 10. Região } \\
\text { glútea D } \\
\text { 11. Ísquio E } \\
\text { 12. Ísquio D } \\
\text { 13. outra } \\
\text { (especificar): }\end{array}$ & & & & $\begin{array}{l}24,0 \mathrm{~cm}^{2} \\
\text { 10. } 24,0 \mathrm{~cm} \\
2\end{array}$ & $\begin{array}{l}\text { 9. Região } \\
\text { glútea } \mathrm{E} \\
\text { 10. Região } \\
\text { glútea D } \\
\text { 11. Ísquio E } \\
\text { 12. Ísquio D } \\
\text { 13. outra } \\
\text { (especificar): }\end{array}$ \\
\hline $\mathbf{8 . F O C}$ & 0. Localização & 1.Classificação & $\begin{array}{l}\text { 2.Tipo de } \\
\text { tecido }\end{array}$ & $\begin{array}{l}\text { 3.Quantidade } \\
\text { de } \\
\text { Exsudato }\end{array}$ & 4.Medidas \\
\hline $\mathbf{N}^{\circ}$ & & & & & \\
\hline $\mathbf{1 .}$ & & & & & \\
\hline $\mathbf{2 .}$ & & & & & \\
\hline
\end{tabular}


ANEXOS 


\section{ANEXO 1}

\section{$(2)^{2}$ \\ vies \\ GOVERNO DO ESTADO DO AMAZONAS}

OFÍCIO $496 / 2014$ - DG/HPSAPBA

Manaus, 04 de novembro de 2014

AO SENHOR,

PREZADO SENHOR.

WAGNER WILLIAM DE SOUZA

SECRETÁRIO EXECUTIVO ADJUNTO DA CAPITAL-SUSAM

AV. ANDRÉ ARAÚJO, N701-ALEIXO.

Prezada Senhora,

Em reposta ao Memo. n004/2014-GUE/SEA, informo deferimento do projeto de pesquisa intitulado "Prevalência e Fatores Assoviados de Feridas Crônicas em Pacientes Públicos em Manaus-AM".

Solicito a vinda da aluna Nariani Souza Galvão à Educação Permanente da unidade para prosseguimento do processo.

Atenciosamente,

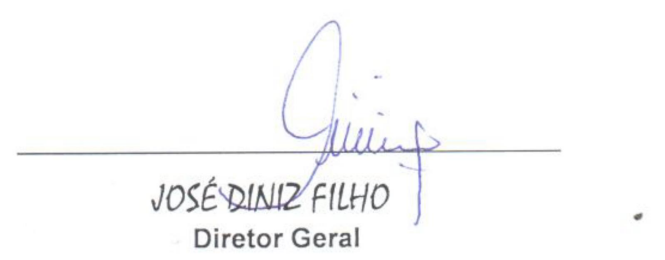

Avenida Autaz Mirim s/n - Jorge Teixeira 


\section{ANEXO 2}

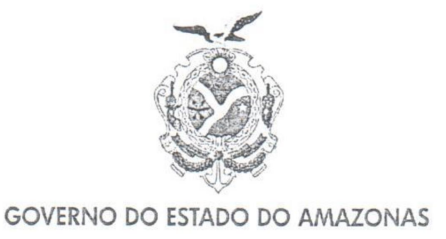

Oficio. 1140 / 2014 - DG - HPS

AO SENHOR,

PREZADO SENHOR,

WAGNER WILLIAM DE SOUZA

SECRETÁRIO EXECUTIVO ADJUNTO DA CAPITAL-SUSAMI

AV. ANDRÉ ARAÚJO, N701-ALEIXO

Prezada Senhora,

Em resposta ao Memo $n^{\circ} 004 / 2014-G U E / S E A$, informo deferimento do projeto de pesquisa intitulado "Prevalência e fatores associados de feridas crônicas em pacientes públicos em Manaus-Am".

Solicito a vinda da aluna Nariani Souza Galvão á Educação Permanente da unidade para prosseguimento do processo de pesquisa.

Atenciosamente,

FELIZARDO FRANCISCO DE ALMEIDA MONTEIRO

Diretor Geral em Exercício 


\section{ANEXO 3}

\section{AUTORIZAÇÃO PARA REALIZAÇÃO DE PESQUISA CARTA DE ANUÊNCIA}

Declaramos para os devidos fins que autorizamos a realização do estudo "Prevalência de feridas crônicas e fatores associados em pacientes de hospitais públicos em Manaus- AM." sob responsabilidade do pesquisador Nariani Souza Galvão e Vera Lúcia Conceição de Gouveia Santos.

Trata-se de um estudo cujo objetivo geral é "Identificar e analisar a prevalência e fatores demográficos e clínicos associados de algumas feridas crônicas como úlcera por pressâo (UP), ulcera diabética (UD), dermatite associada a Incontinência (DAI), lesão por fricção (LF) e ferida operatória complicada, entre pacientes hospitalizados" Os objetivos específicos são: 1-Descrever as características das feridas crônicas encontradas quanto a: classificação, número, localização, medida e etapa de cicatrização; 2 comparar a prevalência e os fatores associados dessas lesões crônicas entre pacientes indígenas e não indígenas hospitalizados.

O referido protocolo de pesquisa foi apreciado pelo Comitê Científico da Fundação CECON e obteve aprovação.

Lembramos que só poderá ter suas atividades iniciadas após a aprovação de um Comitê de ética em Pesquisa em Seres Humanos e a apresentação do parecer de aprovação do mesmo junto a Diretoria de Ensino e Pesquisa da Fundação CECON.

Manaus, 06 de Outubro de 2014.

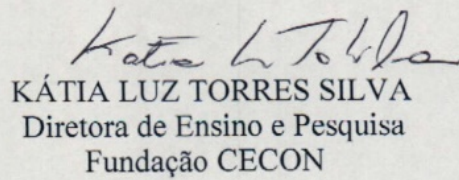


ANEXO 4

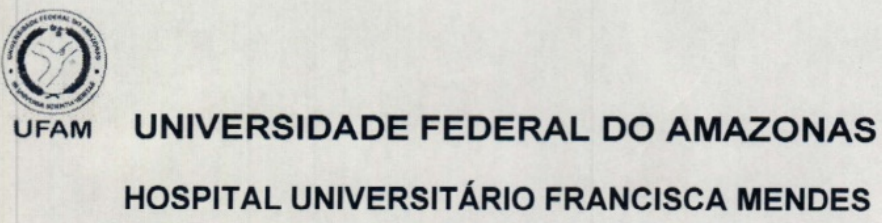

TERMO DE ANUÊNCIA

Ao Diretor do Hospital Universitário Francisca Mendes

Manaus, 01 de outubro de 2014

Senhor Diretor,

Servimo-nos da presente para solicitar o consentimento de V.Sa. para que a Nariani Souza Galvão (Enfermeira e Profa. da Escola de Enfermagem (UFAM)), realize a pesquisa intitulada: Prevalência de Feridas Crônicas e Fatores Associados em Pacientes de Hospitais Públicos em ManausAm, sob a orientaçăo da Prof. (a). $\operatorname{Dr}(a)$. Vera Lúcia Conceiçăo de Gouveia Santos, que tem por objetivo: Identificar e analisar a prevalência e fatores demográficos e clinicos associados à ocorrência de algumas feridas crônicas como Úlcera por Pressåo (UP), Úlcera Diabética (UD), Dermatite Associada à Incontinência (DAI), Lesăo por Fricção (LF) e Ferida Operatória Complicada em pacientes hospitalizados.

Trata-se de trabalho de doutorado Dinter/UFAM, cuja coleta de dados está prevista para o período de fevereiro/ 2015, após aprovaçăo do projeto pelo Comitê de Ética em Pesquisa da UFAM para a qual contamos com vossa aquiescência nos devidos encaminhamentos para a realização da pesquisa. Assim, coloco-me a disposiçăo de V.Sa, para quaisquer esclarecimentos nos telefones de contato ou endereço eletrônico da autora da pesquisa.

\section{Atenciosamente.}

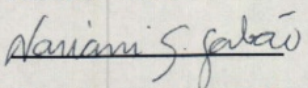

Pesquisadora: Nariani Souza Galvão

Telefone: 91324088

Email: profnane@hotmail.com

Na qualidade de Diretor do Hospital Universitário Francisca Mendes, autorizo a coleta de dados pertinentes a pesquisa acima referida.

Data:

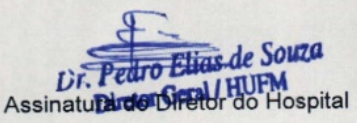




\section{ANEXO 5}

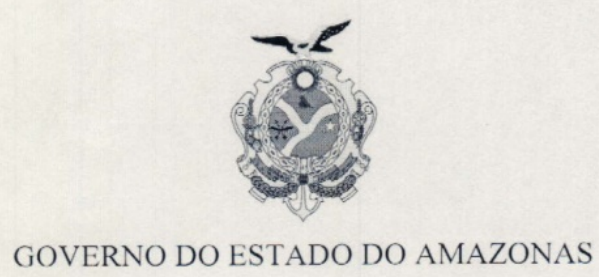

CARTA DE ANUÊNCIA

Utilizo-me desta para informar que o projeto de pesquisa intitulado "PREVALÊNCIA E FATORES ASSOCIADOS DE FERIDAS CRONICAS EM PACIENTES DE HOSPITAIS PÚBLICOS EM MANAUS - AM", tendo como Pesquisadora Responsável a Nariani Souza Galvão, a mesma tem autorização para realizar coleta de dados nesta Fundação mediante Parecer Consubstanciado do Comitê de Ética em Pesquisa ao qual o mesmo foi submetido, que ficará responsável pela avaliação do projeto.

Informamos ainda que a referida pesquisa só deverá ser iniciada após parecer de aprovação emitido pelo CEP ao qual foi submetido e a cópia do Parecer Consubstanciado deverá ser encaminhada ao Comitê de Ética em Pesquisa desta Fundação para apreciação e outras providências.

A Fundação Hospital Adriano Jorge não será responsável pelos custos da pesquisa e todos os procedimentos referentes à mesma serão de responsabilidade da Pesquisadora.

O Pesquisador Responsável também se compromete a, mediante esta autorização, enviar ao Comitê de Ética em Pesquisa desta Fundação os resultados finais referentes à pesquisa realizada e, sempre que necessário, deverá responder quaisquer questionamentos sobre a mesma.

Manaus, 16 de setembro de 2014 .

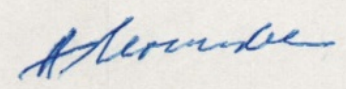

DR. ALEXANDRE BICHARA DA CUNHA

Diretor Presidente

Fundação Hospital Adriano Jorge 
ANEXO 6

UNIVERSIDADE FEDERAL DO AMAZONAS

HOSPITAL UNIVERSITÁRIO GETÚLIO VARGAS

GERÊNCIA DE ENSINO E PESQUISA

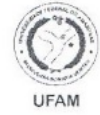

TERMO DE ANUÊNCIA

Declaramos para os devidos fins que estamos de acordo com a execução do Projeto de Pesquisa intitulado "Prevalência e fatores associados de feridas crônicas em pacientes de hospitais públicos em Manaus-AM" que tem por Pesquisadora Nariani Souza Galvão.

Manaus, 08 de agosto de 2014

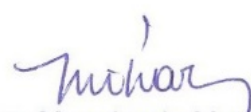

Dra. Miharu Maguinoria Matsuura Matos

Gerente de Ensino e Pesquisa do HUGV 
ANEXO 7

Aguardando emissão de $2^{a}$ via da anuência do Hospital e Pronto Socorro 28 de Agosto pela SUSAM (Secretaria de Estado de Saúde) (extraviado). 
ANEXO 8

\section{ESCOLA DE ENFERMAGEM DA
UNIVERSIDADE DE SÃO
PNFERMAGEM}

\section{PARECER CONSUBSTANCIADO DO CEP}

\section{DADOS DO PROJETO DE PESQUISA}

Título da Pesquisa: PREVALENCIA DE FERIDAS CRONICAS E FATORES ASSOCIADOS EM PACIENTES DE HOSPITAIS PÚBLICOS EM MANAUS-AM.

Pesquisador: NARIANI SOUZA GALVÃO

Área Temática:

Versão: 2

CAAE: 38329114.6 .0000 .5392

Instituição Proponente: Escola de Enfermagem da Universidade de São Paulo - EEUSP

Patrocinador Principal: Financiamento Próprio

DADOS DO PARECER

Número do Parecer: 912.522

Data da Relatoria: 08/12/2014

\section{Apresentação do Projeto:}

Este estudo epidemiológico, transversal, exploratório, descritivo e correlacional tem como finalidade a Tese

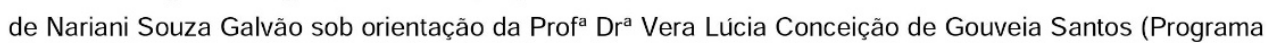
de Pós-Graduação em Enfermagem na Saúde do Adulto / Curso de Doutorado Interinstitucional Universidade de São Paulo e Universidade Federal do Amazonas/DINTER). Propõe-se a sua realização nas seguintes instituiçōes hospitalares da cidade de Manaus: Hospital e Pronto Socorro 28 de Agosto; Hospital e Pronto Socorro Dr. João Lúcio Pereira Machado; Hospital e Pronto Socorro Dr. Platão Araújo; Hospital Francisca Mendes (HFM); Hospital Universitário Getúlio Vargas (HUGV); Fundação Centro de Controle de Oncologia do Estado do Amazonas (FCECON) e Fundação Hospital Adriano Jorge. A amostra será constituída de todos os pacientes internados nesses Hospitais (inclusive os de etnia indígena), sendo excluídas as unidades de maternidade, com idade maior ou igual a 18 anos e que aceitarem participar da pesquisa. Para atender às Resoluçōes do Conselho Nacional de Saúde 466/2012 e 304/2000 o projeto foi aprovado (documentação comprobatória anexa na Plataforma Brasil), previamente, pelo Conselho Distrital Indígena (CDI) e Fundação Nacional do Índio (FUNAI). Os dados serão coletados por cinco enfermeiros especialistas no cuidado de lesões da pele ou que tenham experiência clínica comprovada nesse tipo de cuidado, após a doutoranda ministrar-Ihes um programa de

\footnotetext{
Endereço: Av. Dr Enéas de Carvalho Aguiar, 419

Bairro: Cerqueira Cesar CEP: $05.403-000$

UF: SP Município: SAO PAULO

Telefone: (11)3061-7548 Fax: (11)3061-7548 E-mail: edipesq@usp.br
} 


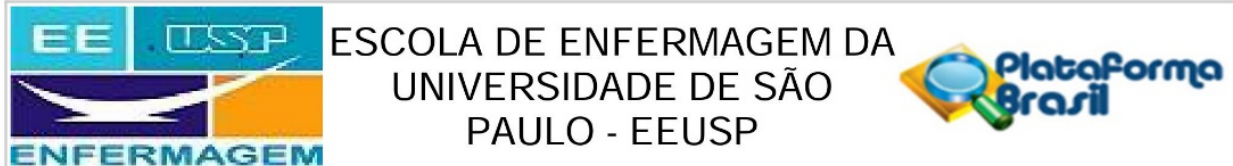

Continuaçâo do Parecer: 912.522

capacitação. Os participantes serão esclarecidos que somente as lesões Úlcera por Pressão (UP), Úlcera Diabética (UD), Dermatite Associada à Incontinência (DAI), Lesão por Fricção (LF) e Ferida Operatória Complicada (FOC) constituirão o objeto de estudo sendo, então, realizada a avaliação da pele e das características dessas feridas crônicas. Não ocorrerão intervenções, pois se trata de um estudo de observaçāo, e os cuidados de enfermagem empregados serāo os mesmos anteriores à participaçāo no estudo. Caso sejam detectadas novas lesōes durante a condução da pesquisa será comunicada à equipe de enfermagem da unidade para as devidas providências. Realizar-se-ão entrevistas para obtenção dos dados sociodemográficos e, caso o próprio paciente não consiga responder às perguntas, seu cuidador (formal ou informal) será solicitado a fazê-lo. Após a entrevista, os pacientes serão submetidos ao exame físico geral (para inspeção e palpação da pele) e dinâmico (para avaliação de rigidez, espasticidade, mobilidade física e marcha). As informações relacionadas às características clínicas serão obtidas nos prontuários dos pacientes como os medicamentos em uso; hábitos e comportamento; doenças préexistentes e exames ambulatoriais, onde serão utilizados os padrões de normalidade adotados pelos laboratórios dos hospitais. Ao exame físico geral o paciente será examinado obedecendo-se o sentido céfalo -caudal e ântero-posterior, sendo inspecionadas as regiões da cabeça, tórax (frontal e dorsal), abdome, genitais (glúteos), membros superiores e inferiores. Ao ser identificado a presença de feridas crônicas foco de estudo, essas serāo examinadas quanto a: classificaçāo, número, medida, localizaçāo e etapa de cicatrização. Além disso, solicitar-se-á permissão ao paciente e/ou responsável para fotografá-la utilizandose câmera digital fotográfica modelo cyber-shot-sony, 14.1 mega pixels, em ambiente de luminosidade clara, a $12 \mathrm{~cm}$ da lesão.

\section{Objetivo da Pesquisa:}

Objetivo primário:

- Identificar e analisar a prevalência, fatores demográficos e clínicos associados à ocorrência de algumas feridas crônicas como UP, UD, DAI, LF e FOC em pacientes hospitalizados.

Objetivos secundários:

- Descrever as características das feridas crônicas encontradas quanto a: classificaçāo, número, localização,medida e etapa de cicatrização;

- Comparar a prevalência e os fatores associados à ocorrência dessas lesões crônicas entre

Endereço: Av. Dr Enéas de Carvalho Aguiar, 419

Bairro: Cerqueira Cesa

CEP: $05.403-000$

UF: SP Município: SAO PAULO

Telefone: (11)3061-7548 Fax: (11)3061-7548_E-mail: edipesq@usp.br 


\section{EE TSSP ESCOLA DE ENFERMAGEM DA UNIVERSIDADE DE SÃO PAULO - EEUSP

Continuaçáo do Parecer: 912.52

pacientes indígenas e nāo indígenas hospitalizados

\section{Avaliação dos Riscos e Benefícios:}

Segundo as proponentes os riscos existentes referem-se à confidencialidade e privacidade de informações clínicas dos pacientes que serāo por elas respeitados. Quanto ao possível constrangimento ocasionado pela fotografia será explicado previamente sobre o anonimato e o uso exclusivo da imagem para fins científicos. Também para minimizar os riscos, não será utilizado nenhum dispositivo invasivo, que comprometa a integridade do participante, pois não haverá coleta orgânica e/ou de fluidos corporais durante a realização da coleta dos dados.

Os benefícios incluem bases para novas pesquisas na área da saúde e auxiliará os enfermeiros a ampliar os conhecimentos sobre feridas crônicas na regiāo.

\section{Comentários e Considerações sobre a Pesquisa:}

Concorda-se com as proponentes que o "conhecimento adquirido trará novas alternativas no cuidado das feridas" bem como "contribuirá cientificamente para o enriquecimento da literatura nacional" e para "o crescimento do profissional enfermeiro da região amazônica, uma vez que esse tipo de estudo é inédito na regiāo norte".

\section{Considerações sobre os Termos de apresentação obrigatória:}

O Termo de Consentimento Livre e Esclarecido (TCLE) reformulado é claro, conciso e objetivo tendo sido acatadas as modificaçōes solicitadas no Parecer Consubstanciado n 884.498 de 17/11/2014:

- Apresentou-se o conteúdo em parágrafos distintos a fim de favorecer a compreensão do paciente e/ou de seu responsável legal;

- Explicitou-se como se dará a participação daqueles que aceitarem integrar o estudo, bem como o tempo estimado para a realização da entrevista, do exame físico geral e dinâmico e das fotografias das lesōes.

\section{Recomendações:}

Atualizar o TCLE no arquivo do projeto de pesquisa

Conclusões ou Pendências e Lista de Inadequações:

Considera-se não haver óbices éticos que impeçam a aprovação do presente projeto de pesquisa.

Endereço: Av. Dr Enéas de Carvalho Aguiar, 419

Bairro: Cerqueira Cesar

UF: SP Município: SAOPAULO

Telefone: (11)3061-7548 Fax: (11)3061-7548 E-mail: edipesq@usp.br 


\section{EE DSCOLA DE ENFERMAGEM DA
UNIVERSIDADE DE SÃO
PAULO - EEUSP}

Continuaçăo do Parecer: 912.522

\section{Situação do Parecer:}

Aprovado

Necessita Apreciação da CONEP:

Não

Considerações Finais a critério do CEP:

A aprovação do Comitê de Ética em Pesquisa da EEUSP não substitui a autorização da instituição coparticipante para o início da pesquisa.

O CEP EEUSP informa que há necessidade de registro dos relatórios: parcial e final da pesquisa, na Plataforma Brasil.

SAO PAULO, 12 de Dezembro de 2014

Assinado por:

Ruth Natalia Teresa Turrini

(Coordenador)

Endereço: Av. Dr Enéas de Carvalho Aguiar, 419

Bairro: Cerqueira Cesa

CEP: $05.403-000$

UF: SP Município: SAOPAULO

Telefone: (11)3061-7548_Fax: (11)3061-7548_E-mail: edipesq@usp.br 


\section{ANEXO 9}

\section{TERMO DE CONSENTIMENTO LIVRE E ESCLARECIDO}

\section{Estudo: Prevalência e Fatores Associados de Feridas Crônicas em Pacientes de Hospitais Públicos em Manaus-Am.}

\section{Responsáveis pela pesquisa}

- Nome: Nariani Souza Galvão - investigador principal.

Cargo: Enfermeira. Aluna do Programa de Pós-Graduação em Enfermagem na Saúde do Adulto (PROESA)

Telefone: (92) 33055100/ (92) 991324088.

- $\quad$ Nome: Vera Lúcia Conceição de Gouveia Santos - orientadora do estudo.

Cargo: Enfermeira Estomaterapeuta (TISOBEST). Profa Associada do Departamento de Enfermagem Médico-Cirúrgica.

- Comitê de Ética em Pesquisa da Escola de Enfermagem da Universidade de São Paulo.

Endereço: Rua Enéas de Carvalho Aguiar, 419 - Cerqueira César - CEP: 05403-000 - São Paulo - SP - Telefone: 3061-7548 - E-mail: edipesq@usp.br.

\section{A. Registro dos esclarecimentos dos pesquisadores aos participantes da pesquisa ou} responsáveis legais.

Prezado (a) Senhor (a)

Nós, autoras do Projeto de Pesquisa apresentado ao Programa de Pós Graduação da Universidade de São Paulo e Escola de Enfermagem da Universidade Federal do Amazonas, convidamos você a participar de uma pesquisa intitulada "Prevalência e Fatores Associados de Feridas Crônicas em Pacientes de Hospitais Públicos em Manaus-Am".

A pesquisa tem por objetivo geral: Identificar e analisar a prevalência e fatores demográficos e clínicos associados de algumas feridas crônicas como Úlcera por Pressão (UP), Úlcera Diabética (UD), Dermatite Associada à Incontinência (DAI), Lesão por Fricção (LF) e Ferida Operatória Complicada, entre pacientes hospitalizados.

A coleta de dados ocorrerá por meio de uma entrevista com o(a) Senhor(a), exame físico geral e dinâmico mediante a avaliação da pele e das características das feridas crônicas e por fotografia dessas lesões, tendo como duração aproximadamente 10 minutos. O estudo não acarretará riscos ao(à) senhor(a). Pois não ocorrerão intervenções, uma vez que se trata de um estudo de observação, e os cuidados de enfermagem empregados serão os mesmos anteriores à participação no estudo. Certamente, caso alguma ferida seja encontrada, o pessoal da unidade será comunicado e seu tratamento será iniciado assim que possível por eles.

É importante ressaltar que sua participação é livre, portanto, não receberá qualquer pagamento por isso. Também, poderá ter acesso aos resultados, caso tenha interesse, inclusive para sanarmos quaisquer dúvidas ou fazermos esclarecimentos. Os resultados da pesquisa serão analisados e publicados, mas sua identidade não será divulgada, sendo guardada em sigilo.

Algumas perguntas podem causar certo constrangimento, porém nenhum dano e serão garantidos a confidencialidade, o sigilo e privacidade das informações.

Caso aceite participar, o(a) senhor(a) deverá assinar as duas vias deste termo de consentimento, sendo que uma ficará conosco e a outra será entregue ao(à) senhor(a).

Desde já agradecemos a sua atenção e ficamos à disposição para quaisquer esclarecimentos sobre a pesquisa.

\section{B. Autorização da participante ou responsáveis legais:}

Compreendo o objetivo desta pesquisa e concordo em participar de forma voluntária da mesma, entendendo que as informações serão confidenciais, que não haverá identificação nominal e que não sofrerei qualquer tipo de sanção ou prejuízo, caso desista de participar deste estudo.

Declaro que, após convenientemente esclarecido pelo pesquisador e ter entendido o que me foi explicado, consinto em participar do presente Projeto de Pesquisa.

\section{Dados do Participante}

Nome:

Sexo: RG:

Endereço:

Bairro: Data de nascimento: Telefone: CEP: 


\section{Dados do responsável legal}

Nome: RG:

Natureza (grau de parentesco, tutor, cuidador, etc):

Sexo: Data de nascimento:

Telefone:

Endereço:

Bairro: Cidade: CEP:

Assinatura do residente/representante legal e Data

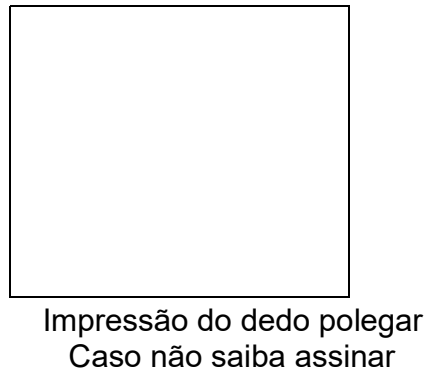

Declaro que obtive de forma apropriada e voluntária o Consentimento Livre e Esclarecido deste residente ou representante legal para a participação neste estudo.

Nariani Souza Galvão

Data 1

Assinatura da pesquisadora Responsável 


\section{Sistema de Classificação STAR - Lesão por Fricção}

\section{Diretrizes do Sistema de Classificação STAR - Lesão por Fricção}

1. Controlar o sangramento e limpar a ferida de acordo com o protocolo institucional.

2. Realinhar (se possível) qualquer segmento de pele ou retalho.

3. Avaliar o grau de perda tissular e a cor da pele ou do retalho utilizando o Sistema de Classificação STAR - Lesões por Fricção.

4. Avaliar as condições da pele adjacente à ferida quanto a fragilidade, edema, descoloração e arroxeamento (aspecto de equimose).

5. Avaliar a pessoa, a(s) ferida(s) e a cicatrização de acordo com o protocolo institucional. 6. Se a pele ou o retalho estiver pálido, opaco ou escurecido, reavaliar em 24-48 horas ou na primeira troca de curativo.

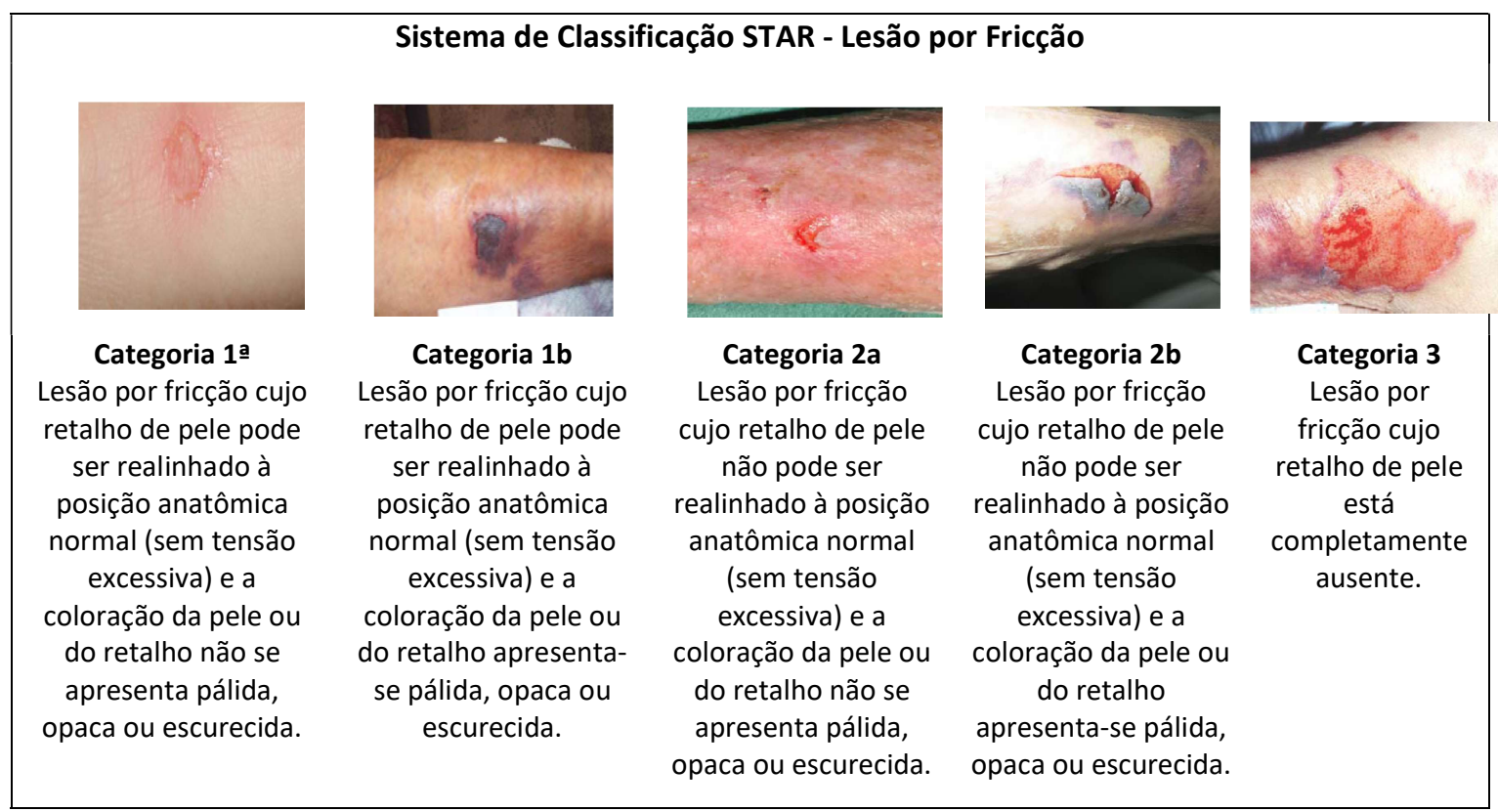

Copyright of original version: Skin Tear Audit Research (STAR). Silver Chain Nursing. Association and School of Nursing and Midwifery, Curtin University of Technology. Revised 4/2/2010.

Copyright of Brazilian's adapted and validated version of STAR: Strazzieri-Pulido e Santos 2010. 


\section{ANEXO 11}

Incontinence-Associated Dermatitis Intervention Tool (IADIT)

\begin{tabular}{|c|c|}
\hline \multicolumn{2}{|c|}{$\begin{array}{l}\text { Skin Care for Incontinent Persons } \\
\text { The \#1 priority is to address the cause of incontinence. Use this tool until incontinence is resolved. }\end{array}$} \\
\hline $\begin{array}{l}\text { 1. Cleanse incontinence ASAP and } \\
\text { apply barrier. }\end{array}$ & $\begin{array}{l}\text { 3. Notify primary care provider when skin injury occurs } \\
\text { and collaborate on the plan of care. }\end{array}$ \\
\hline $\begin{array}{l}\text { 2. Document condition of skin at least once every } \\
\text { shift in nurse's notes or per organization's } \\
\text { policy for documenting skin breakdown. }\end{array}$ & $\begin{array}{l}\text { 4. Consider use of external catheter or fecal collector. } \\
\text { 5. Consider short term use of urinary catheter only in } \\
\text { cases of IAD complicated by secondary infection. }\end{array}$ \\
\hline
\end{tabular}

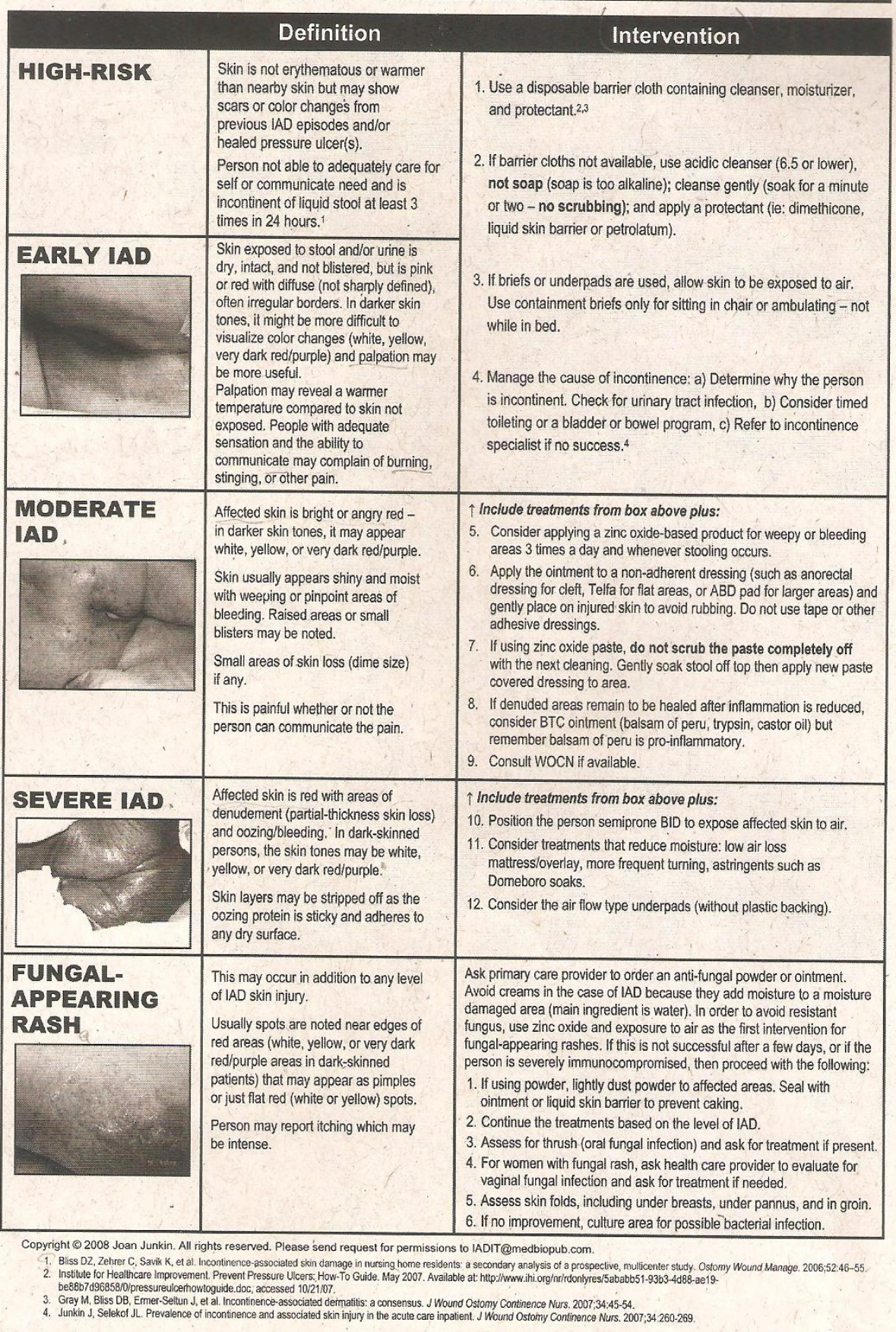

FIGURE 1. Incontinence-associated dermatitis intervention tool. 
ANEXO 12

\section{Pressure Ulcer Scale for Healing (PUSH - PERNA)}

Quadro 1 - Características e respectivos subescores

\begin{tabular}{|c|c|c|c|c|c|c|c|c|c|c|c|}
\hline $\begin{array}{c}\text { Comprimento } \\
\mathrm{X} \\
\text { Largura }\end{array}$ & $\begin{array}{c}0 \\
0 \mathrm{~cm}^{2}\end{array}$ & $<\begin{array}{c}1 \\
<0.3 \mathrm{~cm}^{2}\end{array}$ & $\begin{array}{c}2 \\
0.3-0.6 \mathrm{~cm}^{2}\end{array}$ & $\begin{array}{c}3 \\
0.7-1.0 \mathrm{~cm}^{2}\end{array}$ & $\begin{array}{c}4 \\
1.1-2.0 \mathrm{~cm}^{2}\end{array}$ & $\begin{array}{c}5 \\
2.1-3.0 \\
\mathrm{~cm}^{2}\end{array}$ & $\begin{array}{c}6 \\
3.1-4.0 \\
\mathrm{~cm}^{2}\end{array}$ & $\begin{array}{c}7 \\
4.1-8.0 \\
\mathrm{~cm}\end{array}$ & $\begin{array}{c}8 \\
8.1-12.0 \\
\mathrm{~cm}^{2}\end{array}$ & $\begin{array}{c}9 \\
12.1-24.0 \\
\mathrm{~cm}^{2}\end{array} \mid$ & $\begin{array}{l}10 \\
>24.0 \\
\mathrm{~cm}^{2}\end{array}$ \\
\hline $\begin{array}{l}\text { Quantidade } \\
\text { Exsudato }\end{array}$ & $\begin{array}{c}0 \\
\text { Ausente }\end{array}$ & $\begin{array}{c}1 \\
\text { Pequena }\end{array}$ & $\begin{array}{c}2 \\
\text { Moderada }\end{array}$ & $\begin{array}{c}3 \\
\text { Grande }\end{array}$ & & & & & & & \\
\hline $\begin{array}{l}\text { Tipo de } \\
\text { Tecido }\end{array}$ & $\begin{array}{c}0 \\
\text { Ferida } \\
\text { Fechada }\end{array}$ & $\begin{array}{c}1 \\
\text { Tecido } \\
\text { Epitelial }\end{array}$ & $\begin{array}{c}2 \\
\text { Tecido de } \\
\text { Granulação }\end{array}$ & $\begin{array}{c}3 \\
\text { Esfacelo }\end{array}$ & $\begin{array}{c}4 \\
\text { Tecido } \\
\text { Necrótico }\end{array}$ & & & & & & \\
\hline
\end{tabular}

TABELA DE CICATRIZAÇÃO DE ÚLCERA DE PERNA

- Nome do paciente:

- Data da avaliação inicial:

- Número da úlcera (até 4):

- Localização das úlceras:

\begin{tabular}{|c|c|c|c|}
\hline ÚLCERA n ${ }^{0} 1$ & ÚLCERA n $^{0} 2$ & ÚLCERA n ${ }^{0} 3$ & ÚLCERA n ${ }^{0} 4$ \\
\hline & & & \\
\hline
\end{tabular}

Avalie a úlcera em intervalos regulares, registrando a data, o número da úlcera, os sub-escore de cada

\begin{tabular}{|c|c|c|c|c|c|c|c|c|c|c|c|c|c|c|c|c|c|c|c|c|}
\hline \multicolumn{21}{|l|}{ DATA } \\
\hline ÚLCERA & 1 & 2 & 3 & 4 & 1 & 2 & 3 & 4 & 1 & 2 & 3 & 4 & 1 & 2 & 3 & 4 & 1 & 2 & 3 & 4 \\
\hline $\begin{array}{l}\text { Compr. } \\
\text { /Largura }\end{array}$ & & & & & & & & & & & & & & & & & & & & \\
\hline $\begin{array}{c}\text { Qtdade de } \\
\text { exsudato }\end{array}$ & & & & & & & & & & & & & & & & & & & & \\
\hline Tipo de tecido & & & & & & & & & & & & & & & & & & & & \\
\hline Escore Total & & & & & & & & & & & & & & & & & & & & \\
\hline
\end{tabular}

National Pressure Ulcer Advisory Panel

Versão adaptada por Santos, Sellmer, Massulo,

2007.

\section{Pressure Ulcer Scale for Healing (PUSH - UP)}

Quadro 1 - Características e respectivos subescores

\begin{tabular}{|c|c|c|c|c|c|c|c|c|c|c|c|}
\hline $\begin{array}{c}\text { Comprimento } \\
\mathrm{X} \\
\text { Largura }\end{array}$ & $\stackrel{0}{0} \mathrm{~cm}^{2}$ & $<\begin{array}{c}1 \\
<0.3 \mathrm{~cm}^{2}\end{array}$ & $\begin{array}{c}2 \\
0.3-0.6 \mathrm{~cm}^{2}\end{array}$ & $\begin{array}{c}3 \\
0.7-1.0 \mathrm{~cm}^{2}\end{array}$ & $\begin{array}{c}4 \\
1.1-2.0 \mathrm{~cm}^{2}\end{array}$ & $\begin{array}{c}5 \\
2.1-3.0 \\
\mathrm{~cm}^{2}\end{array}$ & $\begin{array}{c}6 \\
3.1-4.0 \\
\mathrm{~cm}^{2}\end{array}$ & $\begin{array}{c}7 \\
4.1-8.0 \\
\mathrm{~cm}\end{array}$ & $\begin{array}{c}\mathbf{8} \\
8.1-12.0 \\
\mathrm{~cm}^{2}\end{array}$ & $\begin{array}{c}9 \\
12.1-24.0 \\
\mathrm{~cm}^{2}\end{array}$ & $\begin{array}{c}10 \\
>24.0 \\
\mathrm{~cm}^{2}\end{array}$ \\
\hline $\begin{array}{l}\text { Quantidade } \\
\text { Exsudato }\end{array}$ & $\begin{array}{c}0 \\
\text { Ausente }\end{array}$ & $\begin{array}{c}1 \\
\text { Pequena }\end{array}$ & $\begin{array}{c}2 \\
\text { Moderada }\end{array}$ & $\begin{array}{c}3 \\
\text { Grande }\end{array}$ & & & & & & & \\
\hline $\begin{array}{l}\text { Tipo de } \\
\text { Tecido }\end{array}$ & $\begin{array}{c}\mathbf{0} \\
\text { Ferida } \\
\text { Fechada }\end{array}$ & $\begin{array}{c}1 \\
\text { Tecido } \\
\text { Epitelial }\end{array}$ & $\begin{array}{c}2 \\
\text { Tecido de } \\
\text { Granulação }\end{array}$ & $\begin{array}{c}3 \\
\text { Esfacelo }\end{array}$ & $\begin{array}{c}\mathbf{4} \\
\text { Tecido } \\
\text { Necrótico }\end{array}$ & & & & & & \\
\hline
\end{tabular}

TABELA DE CICATRIZAÇÃO DE ÚLCERA DE PRESSÃO

- Nome do paciente:

- Data da avaliação inicial:

- Número da úlcera (até 4):

- Localização e Estágio das UP: 


\begin{tabular}{|c|c|c|c|c|c|c|c|}
\hline \multicolumn{2}{|c|}{ UP $n^{0} 1$} & \multicolumn{2}{|c|}{ UP $n^{0} 2$} & \multicolumn{2}{|c|}{ UP $n^{0} 3$} & \multicolumn{2}{|c|}{ UP $n^{0} 4$} \\
\hline LOCALIZAÇÃO & ESTÁGIO & LOCALIZAÇÃO & ESTÁGIO & LOCALIZAÇÃO & ESTÁGIO & LOCALIZAÇÃO & ESTÁGIO \\
\hline$S(\quad)$ & I & $S(\quad)$ & I & $S(\quad)$ & I & S ( & I \\
\hline$M(\quad)$ & II & $M(\quad)$ & II & $M(\quad)$ & II & $M(\quad)$ & II \\
\hline$T(\quad)$ & III & $\mathrm{T}(\quad)$ & III & $\mathrm{T}(\quad)$ & III & $\mathrm{T}(\quad)$ & III \\
\hline$C(\quad)$ & IV & $C(\quad)$ & IV & $C(\quad)$ & IV & C ( & IV \\
\hline OUTRA: & & OUTRA: & & OUTRA: & & OUTRA: & \\
\hline
\end{tabular}

S: Sacra/ M: maleolar D/E ;T: trocantérica D/E; C: Calcânea D/E.

Avalie a UP em intervalos regulares, registrando a data, o número da UP, os subescores de cada característica e o escore total na tabela a seguir, para cada UP avaliada.

\begin{tabular}{|c|c|c|c|c|c|c|c|c|c|c|c|c|c|c|c|c|c|c|c|c|c|}
\hline Data & & & & & & & & & & & & & & & & & & & & & \\
\hline UP & 1 & 2 & 3 & 4 & 1 & 2 & 3 & 4 & 1 & 2 & 3 & 4 & 1 & 2 & 3 & 4 & 1 & 2 & 3 & 4 & $\ldots$ \\
\hline Compr. & & & & & & & & & & & & & & & & & & & & & \\
\hline $\begin{array}{l}\text { Qtdd de } \\
\text { exsudatc }\end{array}$ & & & & & & & & & & & & & & & & & & & & & \\
\hline $\begin{array}{l}\text { Tipo de } \\
\text { tecido }\end{array}$ & & & & & & & & & & & & & & & & & & & & & \\
\hline $\begin{array}{l}\text { Escore } \\
\text { Total }\end{array}$ & & & & & & & & & & & & & & & & & & & & & \\
\hline
\end{tabular}


ANEXO 13

\section{ESCALA DE BRADEN}

\section{Escala de Braden* (versảo adaptada e validada para 0 Brasil)"*}

\begin{tabular}{|c|c|c|c|c|}
\hline $\begin{array}{l}\text { Recepka ensoriat: } \\
\text { Capacidade \& reagir } \\
\text { ignificativamente a pressio } \\
\text { relacionada ao desconforto }\end{array}$ & 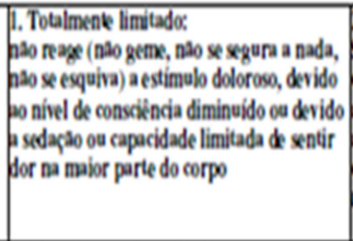 & 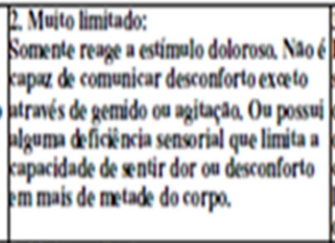 & 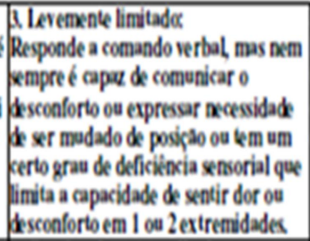 & $\begin{array}{l}\text { 1. Nenhuma limitaça. } \\
\text { Responde a comandos verbais nas } \\
\text { um dKficit sensorial que limitaria a } \\
\text { capacidade d entir ou verbalizar } \\
\text { dor ou desconforto }\end{array}$ \\
\hline $\begin{array}{l}\text { Imidade: } \\
\text { Nivel ao qual a pele céposta a } \\
\text { umidade }\end{array}$ & 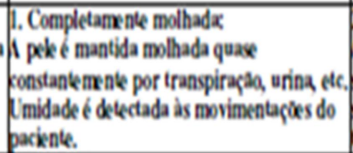 & $\begin{array}{l}\text { 2. Muito molhada: } \\
\text { i pekesta freqeencemente, mas nem } \\
\text { cempre molhada A roupa de cama deve } \\
\text { er trocada pelo menos uma vez por } \\
\text { eurno. }\end{array}$ & $\begin{array}{l}\text { O. Ocasionalmente molhadx: } \\
\text { A ple fica ocadionalmente molhada } \\
\text { requerendo uma troca extra de roupa } \\
\text { \& cama por dia }\end{array}$ & 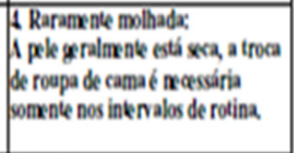 \\
\hline $\begin{array}{l}\text { Atwidade: } \\
\text { Crau de atividade fisca }\end{array}$ & $\begin{array}{l}\text { 1. A camado: } \\
\text { Confinado a camn } \\
\end{array}$ & 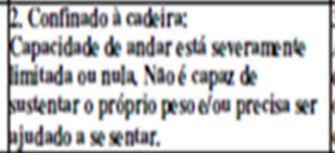 & $\begin{array}{l}\text { 3. Anda ocasionalmente: } \\
\text { inda ocasionalmente durante o dia } \\
\text { embora distincias mujto curtas com } \\
\text { ou sema ajuda. Passa a maior parte } \mathrm{e} \\
\text { cada turno na cama ou na cadeira. }\end{array}$ & $\begin{array}{l}\text { 4. Anda frequentemente: } \\
\text { inda fora do quarto pelo manos } 2 \\
\text { yezes por diae dentro do quarto } \\
\text { pelo uma vez a cada } 2 \text { boras durante } \\
\text { as horasem que está acordada }\end{array}$ \\
\hline $\begin{array}{l}\text { Mobilidade: } \\
\text { Capacidade } \alpha \text { mudare } \\
\text { controlar a posica do do corpo }\end{array}$ & $\begin{array}{l}\text { 1. Totalmene imbiel: } \\
\text { Nao fau nem mesmo pequenas mudanças na } \\
\text { posicto do corpo ou exitremidades sem } \\
\text { pjuda }\end{array}$ & 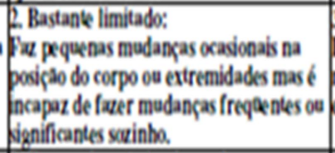 & $\begin{array}{l}\text { Levemente limitado } \\
\text { Faz frequentes embora pequenas } \\
\text { modancas na posicao do corpo ou } \\
\text { oxtremidades semajuda }\end{array}$ & $\begin{array}{l}\text { I Na apresenta limitaçes } \\
\text { Faz importantes e frequentes } \\
\text { mudancas sem auxilia. }\end{array}$ \\
\hline $\begin{array}{l}\text { Nutricho: } \\
\text { Padrato usual de consum } \\
\text { alimentar }\end{array}$ & 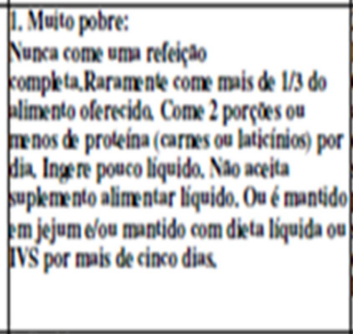 & 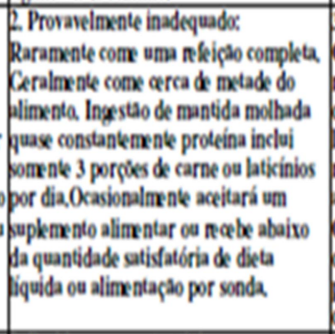 & 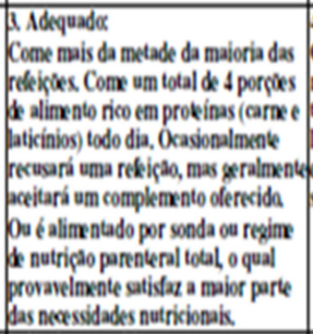 & 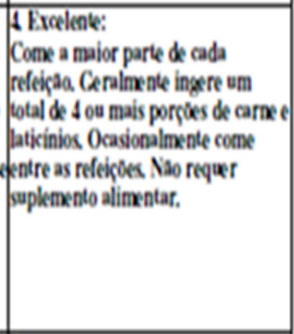 \\
\hline Friçato e cisallhamento & 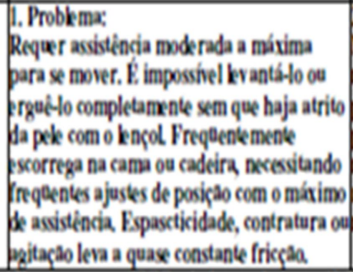 & $\begin{array}{l}\text { 2. Problema em potendial } \\
\text { Mowe-se mas sem vigor ou requer } \\
\text { minima assistincia Durante o movimento } \\
\text { provavelmente ocorne um erto atrito da } \\
\text { pele com o lencol, cadeira ou outrox. Na } \\
\text { maior parte do tempo mankim posicto } \\
\text { pelativamente boa na cama ou na cadeira } \\
\text { pas ocasionalmente escorrega }\end{array}$ & $\begin{array}{l}\text { 3. Nenhum problemx } \\
\text { Marese suinho na cama ou cadeina e } \\
\text { em suficknte forca muscular para } \\
\text { erguer-e comple tamente durante } 0 \\
\text { movimento.Sempre mantim boa } \\
\text { posipato na cama ou na cadeira }\end{array}$ & 1. \\
\hline
\end{tabular}

\footnotetext{
*Copynght (1) Braden, Bergstrom 1988. Adaptada e validada no Brasil por Paranhos, Santos 1999.
} 


\section{ANEXO 14}

Tabela 1. Classificação de Wagner para as lesões do pé diabético.

$\begin{array}{ll}\text { Grau } & \text { Características } \\ \text { Grau 0 } & \text { Pé em risco } \\ \text { Grau 1 } & \text { Úlcera superficial, sem infecção } \\ \text { Grau 2 } & \text { Profunda, com infecção sem osteomielite } \\ \text { Grau } 3 & \text { Profunda, abscesso com osteomielite } \\ \text { Grau } 4 & \begin{array}{l}\text { Necrose localizada em dedos, região } \\ \text { plantar ou calcanhar }\end{array} \\ \text { Grau 5 } & \begin{array}{l}\text { Necrose de quase todo o pé } \\ \hline\end{array}\end{array}$

Fonte: WAGNER, 1981. 